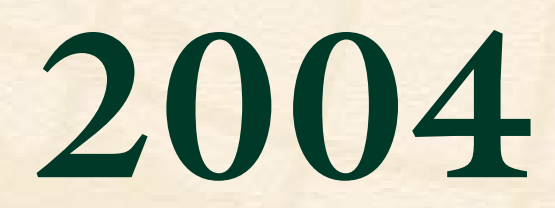

\title{
United States Animal Health Report
}

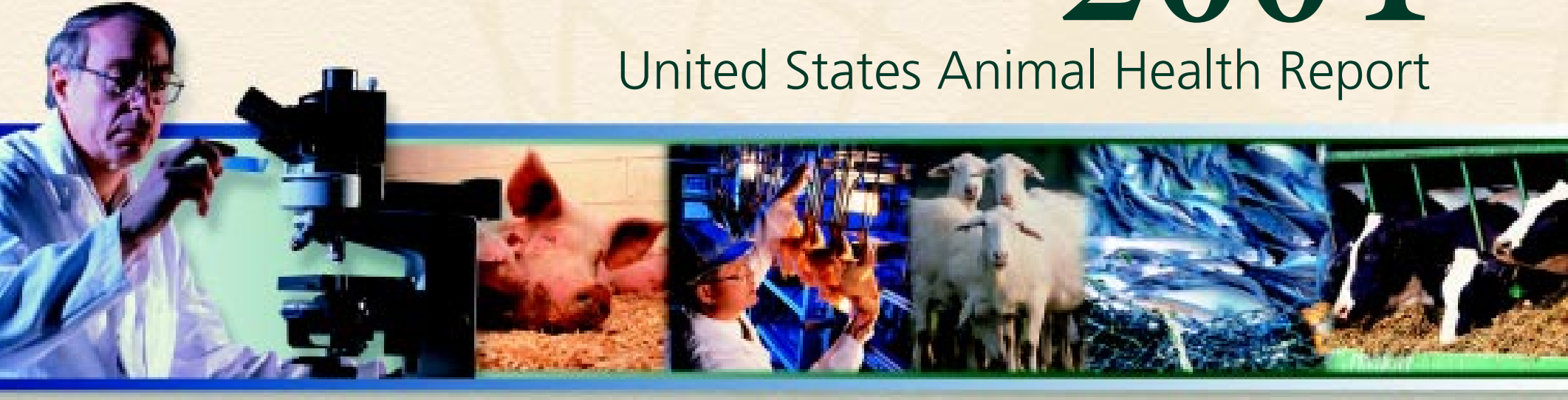

United States Department of Agriculture

Animal and Plant Health Inspection Service

Agriculture Information Bulletin No. 798 
The U.S. Department of Agriculture (USDA) prohibits discrimination in all its programs and activities on the basis of race, color, national origin, age, disability, and where applicable, sex, marital status, familial status, parental status, religion, sexual orientation, genetic information, political beliefs, reprisal, or because all or part of an individual's income is derived from any public assistance program. (Not all prohibited bases apply to all programs.) Persons with disabilities who require alternative means for communication of program information (Braille, large print, audiotape, etc.) should contact USDA's TARGET Center at (202) 720-2600 (voice and TDD). To file a complaint of discrimination, write to USDA, Director, Office of Civil Rights, 1400 Independence Avenue, S.W., Washington, D.C. 20250-9410, or call (800) 795-3272 (voice) or (202) 720-6382 (TDD). USDA is an equal opportunity provider and employer.

Mention of companies or commercial products does not imply recommendation or endorsement by the USDA over others not mentioned. USDA neither guarantees nor warrants the standard of any product mentioned. Product names are mentioned solely to report factually on available data and to provide specific information.

Issued August 2005

U.S. Department of Agriculture

Animal and Plant Health Inspection Service

Veterinary Services

Centers for Epidemiology and Animal Health

NRRC Building B, Mailstop 2E7

2150 Centre Avenue

Fort Collins, CO 80526-8117

(970) 494-7000

http://www.aphis.usda.gov/oa/pubs/bproglist.html 


\section{Foreword}

Welcome to the first report on the status of animal health in the United States. I believe you will find it both informative and useful. As an annual publication, the Animal Health Report will be updated and refined each year to ensure that it addresses issues of current importance to our stakeholders.

The United States has vast domestic and wildlife animal resources. Maintaining their health is of utmost importance. Historically, the United States has been blessed with an abundance of safe food and has prevented the establishment of many foreign animal diseases and eradicated several important domestic animal diseases. These successes, however, have brought new challenges to maintaining a healthy animal population, including increased global trade, larger and more concentrated animal populations, and the potential for complacency in assuming that our domestic and wild animal populations will always be healthy.

This report-a national overview of domestic animal health in the United States for 2004-is a direct result of an external review of the Nation's animal health safeguarding system. The Animal Health Safeguarding Review assessed the performance, processes, and procedures used to ensure the success of the mission of the U.S. Department of Agriculture (USDA)-Animal and Plant Health Inspection Service's (APHIS) Veterinary Services (VS) program: to protect and to improve the health, quality, and marketability of our Nation's animals, animal products, and veterinary biologics. The review, completed in October 2001, presented a number of specific recommendations:

- Develop an annual APHIS-VS animal health report.

- Create a national surveillance system.

Provide a framework for a national surveillance system.

Communicate surveillance findings to stakeholders.

Expand the role of the Centers for Epidemiology and Animal Health (CEAH) as the Nation's epidemiologic reference center.

Expand participation in international animal health discussions and activities.

In 2004 - in response to a Canadian case of bovine spongiform encephalopathy (BSE) in May 2003 and the December 2003 discovery of BSE in a Canadian cow in Washington State-APHIS, USDA's Food Safety and Inspection Service (FSIS), and the Food and Drug Administration (FDA) developed an enhanced national BSE surveillance plan. This one-time effort calls for the testing of as many animals as possible from the targeted high-risk populations during a 12 - to 18 -month period. This report highlights this and other initiatives and provides insight into the Nation's animal health surveillance activities. Within its eight chapters, the report addresses the many components of the U.S. animal health infrastructure, animal populations, new initiatives, and approaches to foreign animal disease (FAD) surveillance.

The U.S. animal health infrastructure is a multifaceted network of Federal, State, and private entities, working in concert to ensure the continued health and vitality of the Nation's livestock commodities and the wholesomeness and safety 
of its food. In addition, the network reaches beyond U.S. borders via APHIS' International Services (IS) unit. IS cooperates in surveillance, eradication, and control programs in foreign countries in which economically significant pests or diseases are found. IS also plays a major role in ensuring that U.S. agricultural exports are accessible to foreign countries.

To ascertain the geographic distribution of U.S. livestock, poultry, and aquaculture commodities, USDA's National Agricultural Statistics Service (NASS) conducts the Census of Agriculture every 5 years. Probability-based population surveys are conducted periodically (monthly, quarterly, semiannually, or annually) to provide the most up-to-date inventories and production estimates.

This report highlights new initiatives in the numerous U.S. animal disease and eradication programs and provides updates on some individual, long-standing ones. For example, VS is actively addressing the support of epidemiologic investigations with the implementation of the National Animal Identification System (NAIS). Goals for the system include coordinating the establishment of species-specific working groups, supporting the development of State premises systems, and developing a national allocation database for Premises Identification Numbers. In addition, to coordinate the development of the National Animal Health Surveillance System, VS created a National Surveillance Unit (NSU), which is located within CEAH.

I offer you this report as a valuable source of information on the state of U.S. livestock, poultry, and aquaculture commodities as well as the programs and strategies used to ensure their continued health.

—John R. Clifford

Deputy Administrator Veterinary Services USDA-APHIS Washington, DC 


\section{Contents}

Chapter 1-Animal Health Infrastructure in the United States

Introduction

1

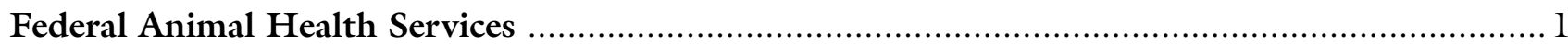

Animal and Plant Health Inspection Service (APHIS) ...................................................... 1

Other Federal Animal Health Services Agencies ............................................................. 5

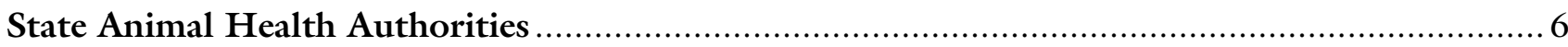

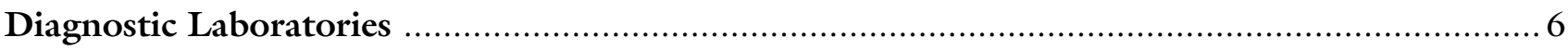

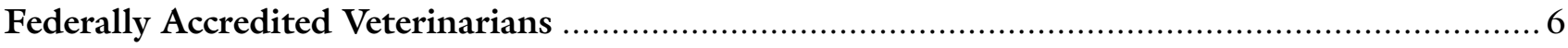

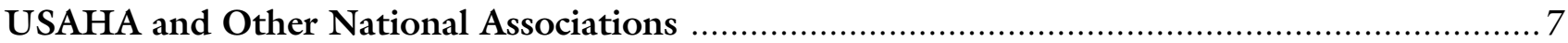

Working With Other Nations' Animal Health Infrastructures ...................................... 7

Chapter 2-Demographics of U.S. Livestock, Poultry, and Aquaculture Production in 2004

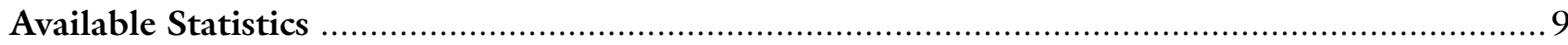

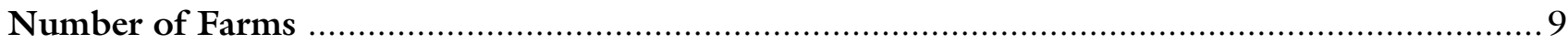

Relative Magnitude of Industries by Value of Production ............................................

Introduction to the Livestock, Poultry, and Aquaculture Industries ................................ 9

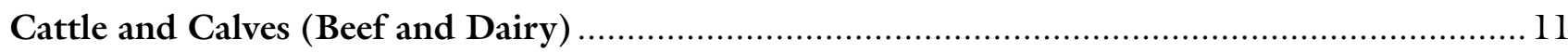

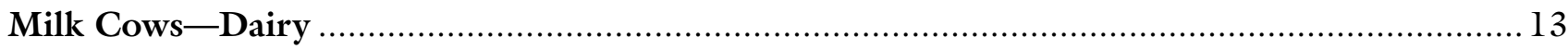

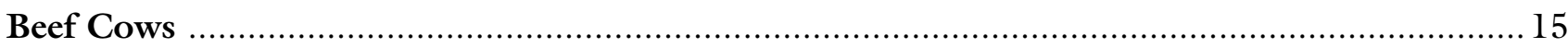

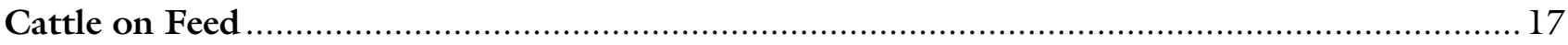

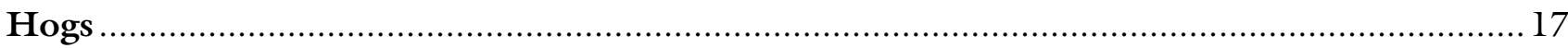

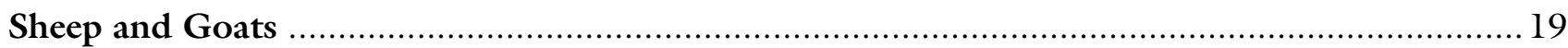

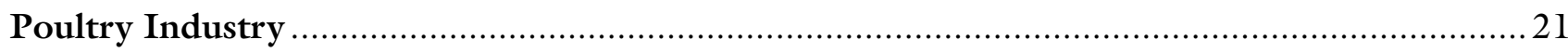

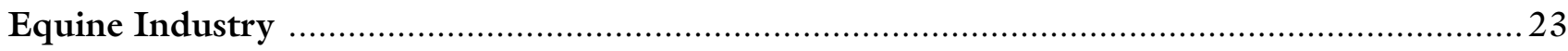




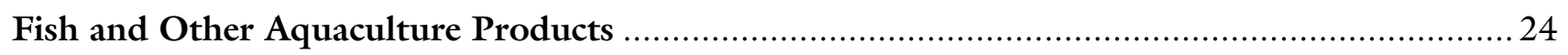

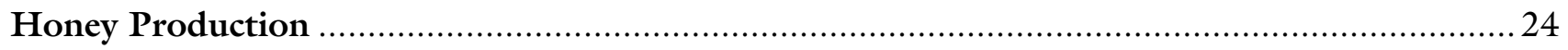

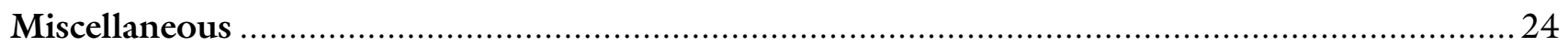

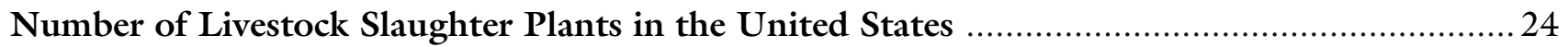

Chapter 3-Animal Disease Eradication and Control and Certification Programs

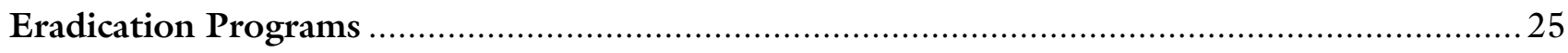

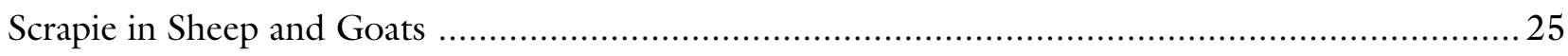

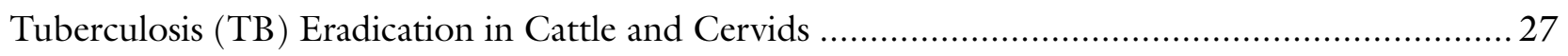

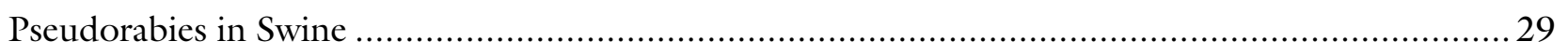

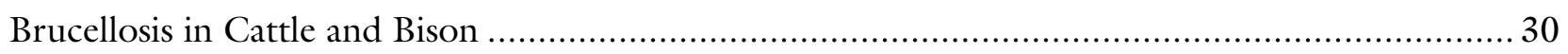

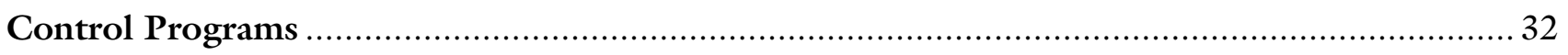

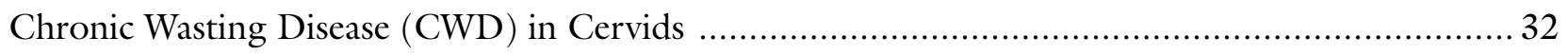

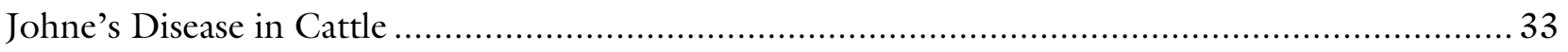

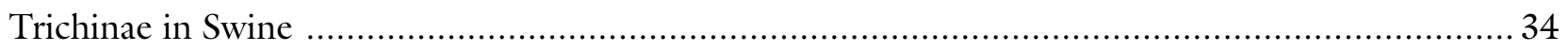

Swine Health Protection Inspection Program ……………....................................................... 35

\section{Chapter 4-Animal Health Initiatives}

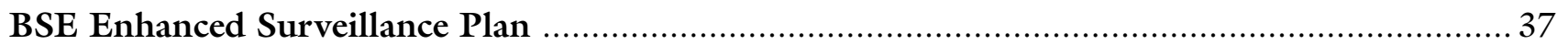

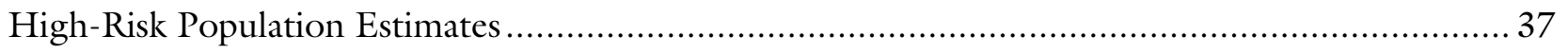

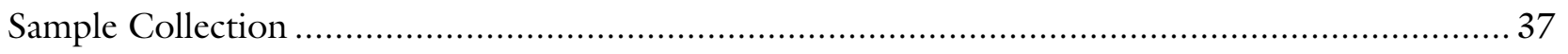

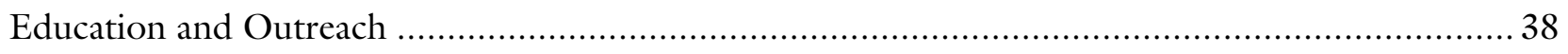

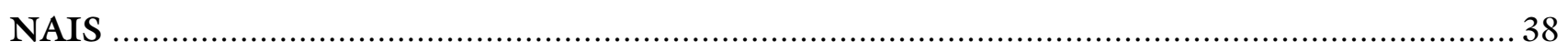

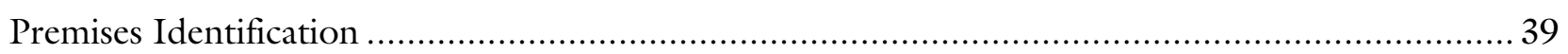

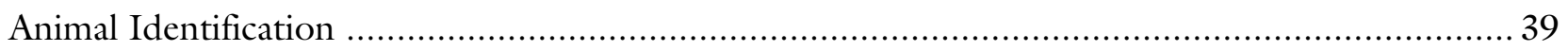

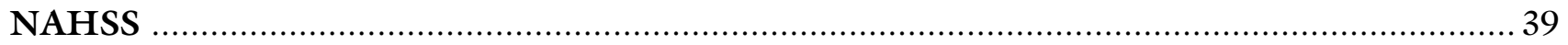

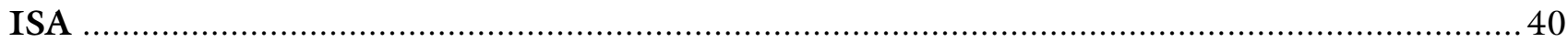

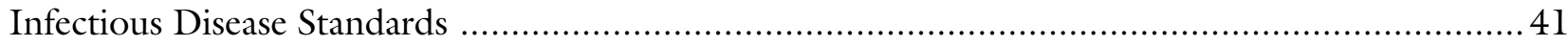

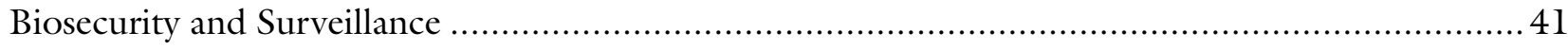

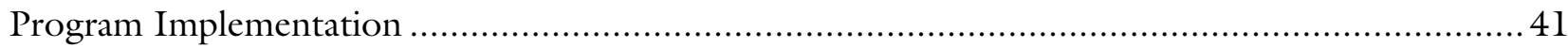

Reference

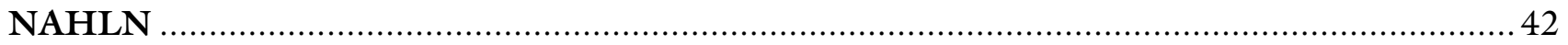


Chapter 5-Foreign Animal Disease (FAD) Prevention, Surveillance, and Emergency Response

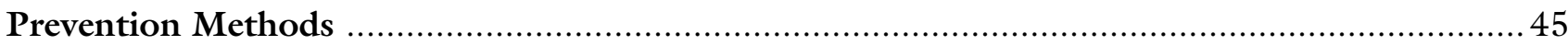

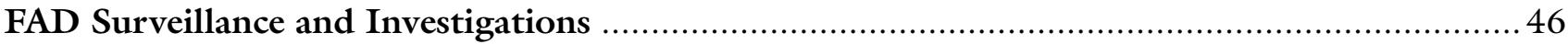

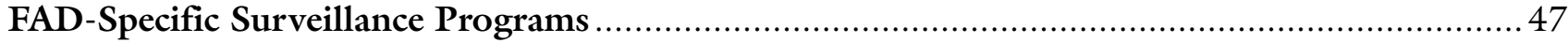

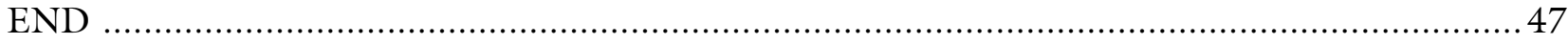

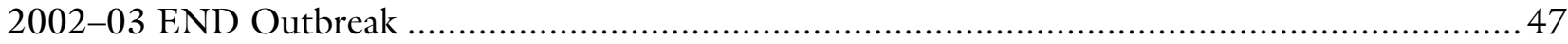

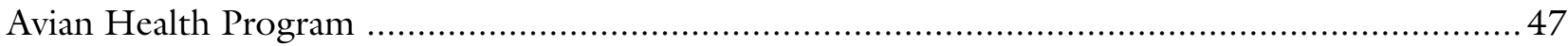

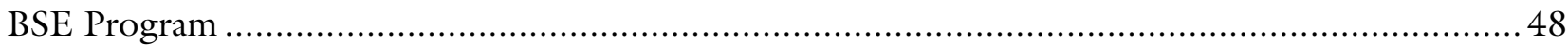

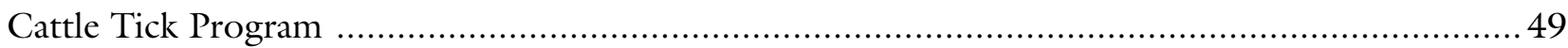

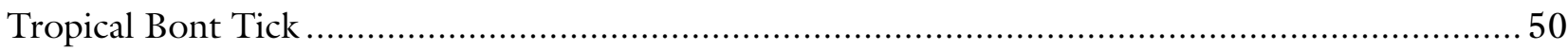

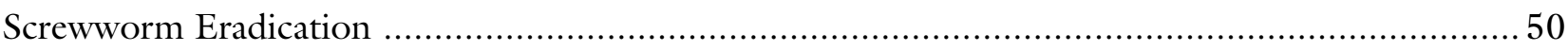

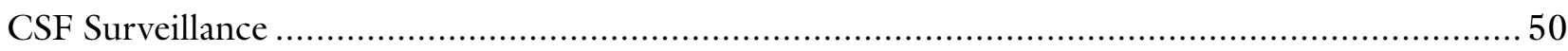

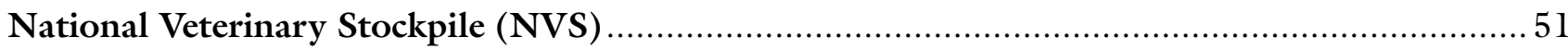

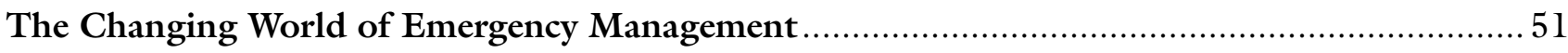

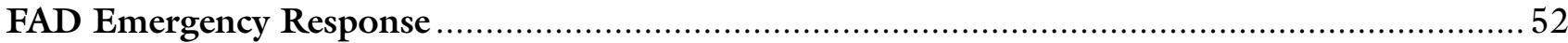

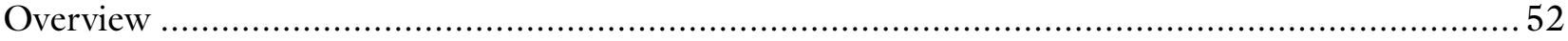

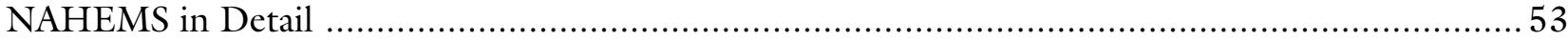

Chapter 6-Foreign Animal Disease (FAD) Status Evaluations:

Regionalization, Risk Assessment, and Rulemaking

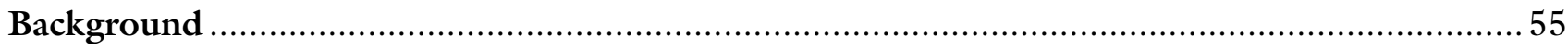

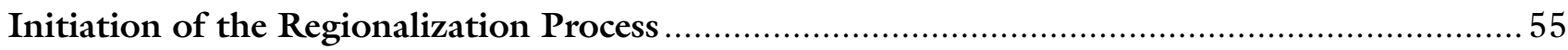

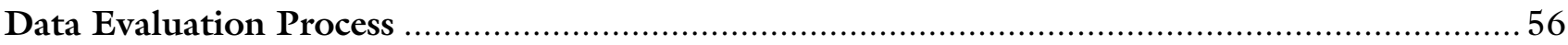

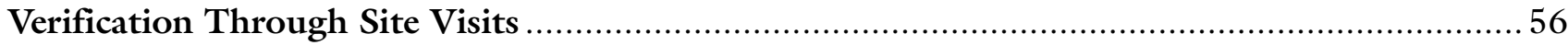

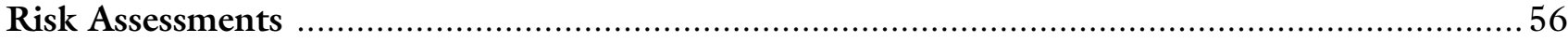

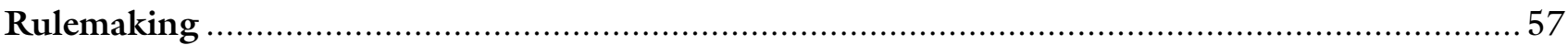

Chapter 7-U.S. Export Certification Procedures

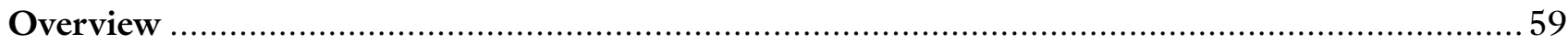

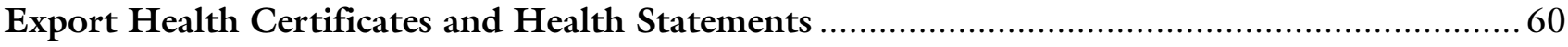


Chapter 8-Epidemiologic Events in 2004

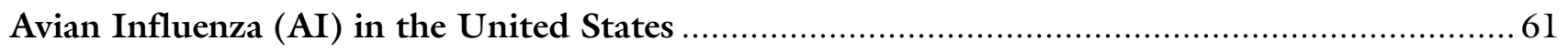

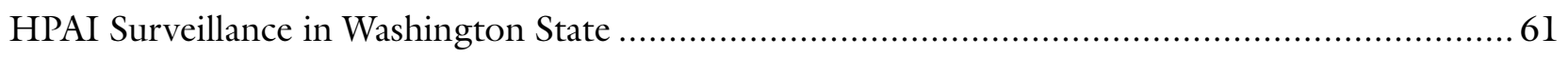

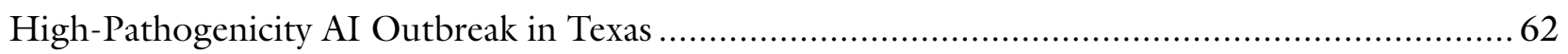

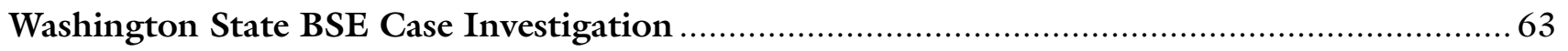

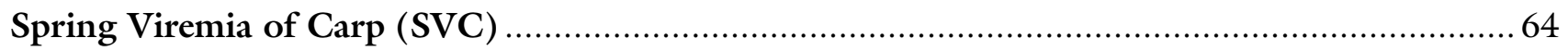

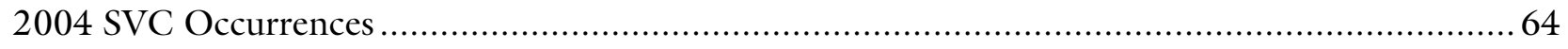

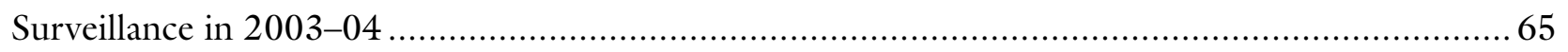

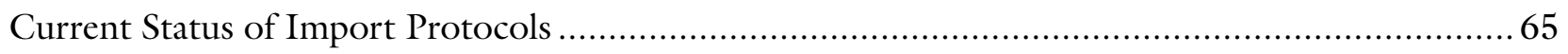

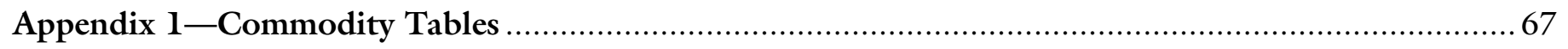

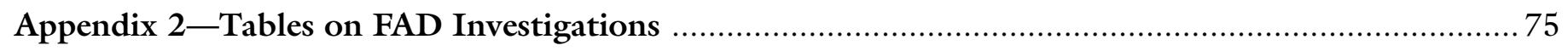

Appendix 3-Animal Health Contacts in the United States ............................................. 77

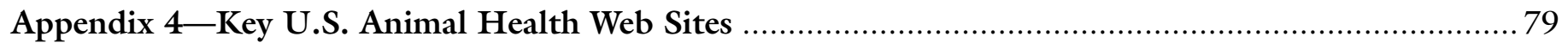

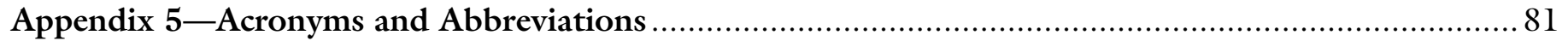




\section{CHAPTER 1 \\ Animal Health Infrastructure in the United States}

\section{Introduction}

The U.S. animal health infrastructure is a complex network of activities, programs, and people that includes but is not limited to

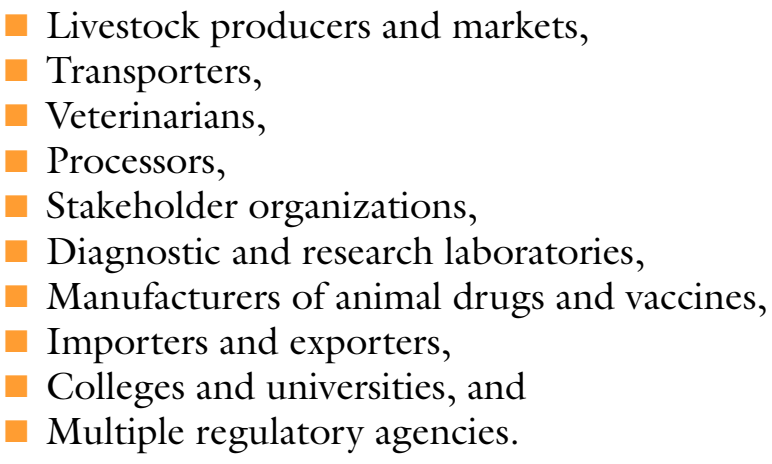

This network responds to animal health issues, scientific, economic, and political conditions pertinent to consumers, public-health issues, and trade interests as well as environmental, wildlife, food-safety, and animal-welfare concerns.

By implementing measures that mitigate risks and deter hazardous activities, the U.S. animal health infrastructure works to ensure healthy animal populations, wholesome and safe food supplies, rapid response to animal health emergencies, effective disease control programs, functional surveillance and reporting systems, and the expansion of export markets. Among the key components of the infrastructure are

Federal animal health services,

State animal health authorities,

Diagnostic laboratories,

Federally accredited veterinarians,

- The United States Animal Health Association (USAHA) and other animal health organizations, and

The global animal health infrastructure.

These organizations and facilities directly improve animal health, work toward eliminating disease risks, and limit transmission of diseases from animal to animal and from animals to people. Success requires cooperation across the network.

\section{Federal Animal Health Services}

Ensuring the health of U.S. livestock is the responsibility of many Federal agencies, most of which are part of the U.S. Department of Agriculture (USDA) (fig. 1). Each agency is charged with specific tasks and responsibilities, and all work to protect the health and vitality of U.S. agriculture through established rules and regulations.

Federal animal health and food-safety regulations are outlined in the U.S. Code of Federal Regulations (CFR). The CFR, which is revised annually, codifies regulations developed by Government agencies under laws passed by Congress and signed by the President. Animal health and food-safety regulations are detailed in Titles 9 and 21 of the code (9 CFR, 21 CFR). Before adoption, proposed regulations appear for public review and comment in the Federal Register, which is published each business day. All proposed rules that may impact U.S. trade in livestock and animal health products are also provided to the World Trade Organization (WTO) to allow for comment by foreign governments and overseas suppliers. Further, VS publishes Uniform Methods and Rules, which are minimum program standards for the implementation of specific animal health programs covered by regulations.

\section{Animal and Plant Health Inspection Service (APHIS)}

USDA-APHIS plays a lead role in animal health matters through its legal authorities, national perspectives, and role as the Nation's representative in international livestock issues. There are six program
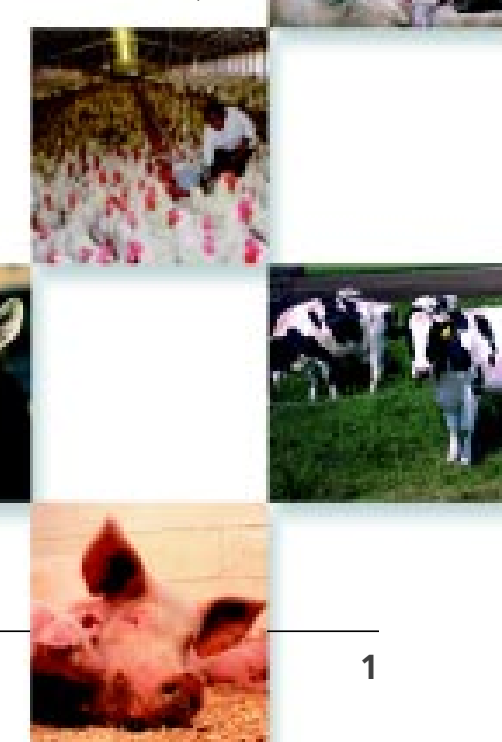


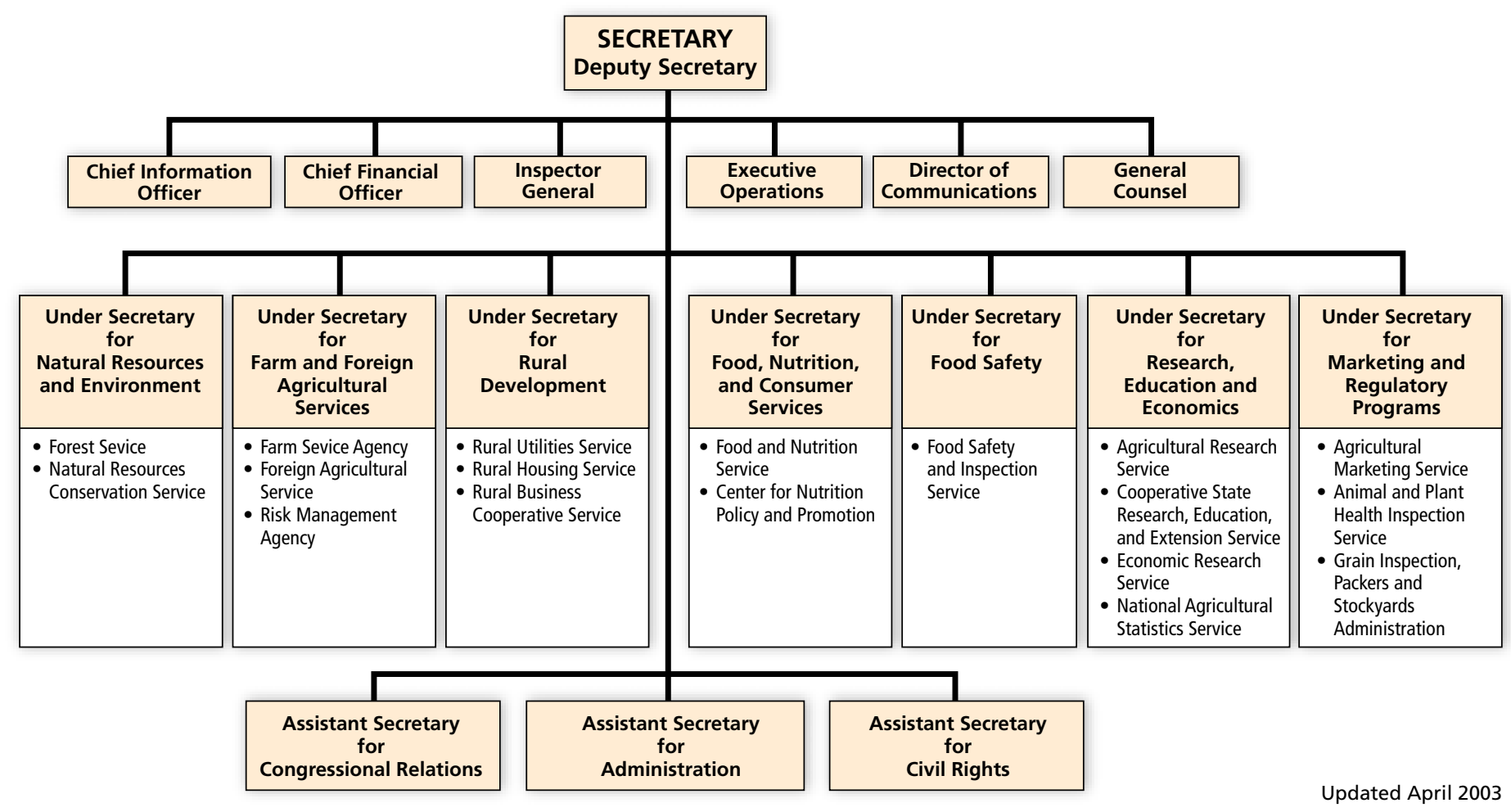

Figure 1-USDA organizational chart. APHIS falls under the Marketing and Regulatory Programs branch of the Department.

units within APHIS: Animal Care (AC), Biotechnology Regulatory Services (BRS), International Services (IS), Plant Protection and Quarantine (PPQ), Veterinary Services (VS), and Wildlife Services (WS).

AC is responsible for administering the Animal Welfare and the Horse Protection Acts and for providing leadership in establishing acceptable standards of humane animal care and handling.

BRS regulates the field testing (confined release of genetically engineered organisms into the environment), interstate movement, and importation of genetically engineered organisms through a permit and notification process. BRS assesses the agricultural and environmental safety of genetically engineered organisms and evaluates petitions to USDA to cease the regulation of specific engineered organisms.

IS provides animal and plant health experts overseas and in Washington, DC, who enhance USDA's capacity to safeguard American agricultural health and promote agricultural trade.
PPQ develops regulations, policies, and guidelines to safeguard agricultural and natural resources from the risks associated with the entry, establishment, or spread of plant pests and noxious weeds.

WS provides leadership for managing wildlife damage and resolving wildlife-related conflicts involving human activities, agricultural production, and natural resource protection.

VS plays a lead role in protecting and improving the health, quality, and marketability of U.S. livestock, animal products, and veterinary biologics by preventing, controlling, and eradicating animal diseases and monitoring and promoting animal health and productivity.

VS employs nearly 1,700 people with a wide range of scientific, technical, and administrative skills (table 1 ). The VS workforce includes veterinarians, animal health technicians, animal caretakers, budget analysts, biological technicians, computer specialists, economists, entomologists, epidemiologists, geographers, management analysts, microbiologists, pathologists, statisticians, spatial analysts, and other scientists, and administrative and animal-health support professionals. 
TABLE 1

\begin{tabular}{l|c|c}
\hline Veterinary Services Workforce, $\mathbf{2 0 0 4}$ & \\
\hline Occupation & Number & $\begin{array}{c}\text { Percent of } \\
\text { workforce }\end{array}$ \\
\hline Veterinarians & 518 & 30.5 \\
Animal health technicians & 328 & 19.3 \\
Other & 852 & 50.2 \\
\hline Total & 1,698 & 100.0 \\
\hline
\end{tabular}

VS maintains headquarters facilities in Riverdale, $\mathrm{MD}$, and Washington, DC, where much of the program policy and regulatory development for the organization are established (fig. 2). These offices also provide liaison with other Federal agencies, members of the Executive Branch, and congressional offices.

The VS field infrastructure is distributed nationally. VS maintains area offices in most of the 50 States and major ports-of-entry, although some area offices serve multiple States. VS also has personnel and offices in Puerto Rico and in U.S. territories. VS disease eradication and control activities, export certification, and surveillance actions take place primarily out of these field-office sites. Regional offices located in Raleigh, NC, and Fort Collins, CO, oversee these field offices.

The emergency management arm of VS is comprised of three groups: Emergency Programs (EP), the National Veterinary Services Laboratories (NVSL), and the Center for Veterinary Biologics (CVB).

EP is responsible for preventing, preparing for, and coordinating the response to animal health emergencies caused by foreign or emerging animal diseases and pests and natural disasters. In the event of an emergency, EP reacts immediately to minimize the adverse effects on the health of animal and human populations.

NVSL are divided into two campuses located in Ames, IA, and Plum Island, NY. The Ames campus houses the Diagnostic Bacteriology Laboratory, the Diagnostic Virology Laboratory, and the Pathobiology Laboratory. The Foreign Animal Disease Diagnostic Laboratory is located at the Plum Island campus.

\section{Veterinary Services Organizational Chart}

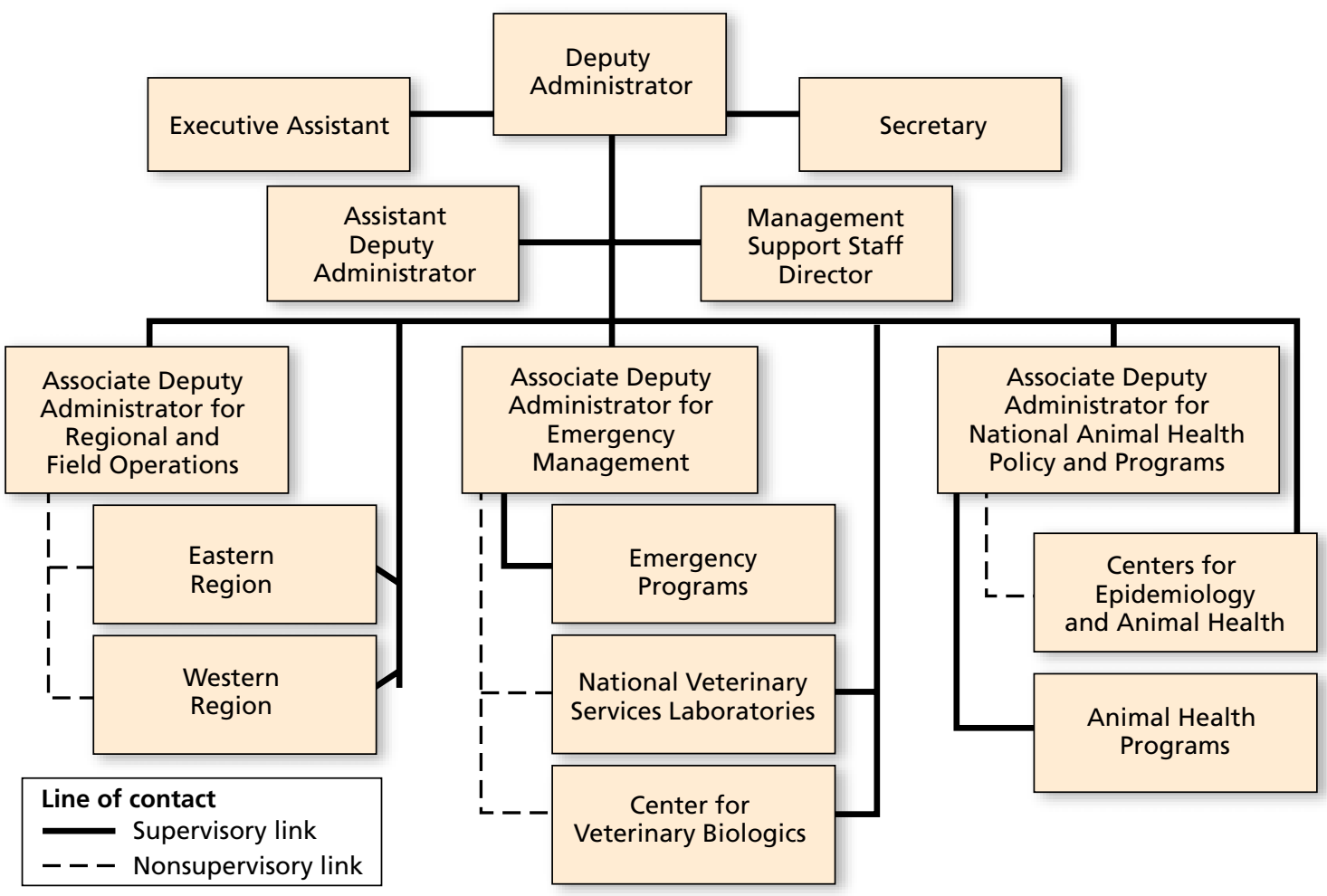

Figure 2-Organizational chart for APHIS-VS. 
NVSL's responsibilities include

- Diagnosing domestic and foreign animal diseases, Providing diagnostic support for disease control, disease eradication, and animal health monitoring programs,

- Testing samples from animals for import and export,

Training APHIS and other U.S. and international personnel,

Certifying laboratories in the United States to handle the testing for selected diseases, and

Acting as a comprehensive reference laboratory.

CVB regulates animal vaccines and other veterinary biologics used to prevent, treat, or diagnose animal diseases. CVB implements the Virus-Serum-Toxin Act to ensure the availability of safe and effective veterinary biologics.

\section{CVB's responsibilities include}

Reviewing biological product license applications and associated studies;

Issuing biological product licenses and permits;

- Testing biological products for purity and potency;

- Inspecting biological product manufacturing facilities;

- Regulating the release of biological products to the marketplace; and

- Conducting postmarketing surveillance of biological products.

Both NVSL and CVB are collaborating centers of the World Organisation of Animal Health for the diagnosis of animal disease and vaccine evaluation in the Americas.

Within VS, two groups-Animal Health Programs (AHP) and the Centers for Epidemiology and Animal Health (CEAH) - are associated with VS' National Animal Health Policy and Programs.

AHP initiates, leads, coordinates, and facilitates national certification and eradication programs that promote, protect, and improve U.S. animal health by preventing, minimizing, or eradicating animal diseases of economic and public health concern. AHP includes four subunits: the National Center for Import and Export (NCIE), National Center for Animal Health Programs (NCAHP), professional development staff, and information systems support staff. NCIE is discussed in detail in chapter 6.
The NCAHP includes three subunits: Ruminant Health Programs (RHP); Aquaculture, Swine, Equine, and Poultry Health Programs (ASEPHP); and Surveillance and Identification Programs (SIP).

RHP and ASEPHP are responsible for the following eradication campaigns:

Bovine brucellosis, Swine brucellosis,

Bovine tuberculosis,

Swine pseudorabies, and

Scrapie.

The RHP and ASEPHP also are responsible for the following programs:

Johne's disease,

- National Low-Pathogenicity Avian Influenza Program,

National Poultry Improvement Plan,

Exotic Newcastle disease surveillance,

Equine diseases,

Chronic wasting disease,

Aquaculture disease programs,

Classical swine fever surveillance, and

Slaughter Horse Transport Program.

SIP helps coordinate national surveillance, animal identification, veterinary accreditation, and livestock markets.

The CEAH includes three subunits: Center for Emerging Issues (CEI), Center for Animal Disease Information and Analysis (CADIA), and the National Center for Animal Health Surveillance (NCAHS).

The CEI is responsible for

Rapid assessment of the impacts of foreign and domestic disease outbreaks, economic events, and natural disasters;

Developing surveillance approaches for emerging diseases; and

Providing geographic information system support to VS activities.

The CADIA is responsible for

- Import and domestic risk analysis, and

- Program disease support via database development and maintenance. 
The NCAHS is responsible for

Coordinating national animal health surveillance, and

Providing baseline information on health, disease, and production through the National Animal Health Monitoring System.

CEAH is a collaborating center of the World Organisation for Animal Health (formerly called the International Office of Epizootics and still using "OIE" as its acronym) for animal-disease information systems and risk analysis. CEAH personnel also develop technology applications, maintain key databases, and conduct epidemiologic, economic, and spatial analyses.

The Web site for VS is <http://www.aphis.usda.gov/ vs $>$. The site provides updates on VS programs and electronic copies of various VS forms.

\section{Other Federal Agencies Providing Animal Health Services}

In addition to APHIS, several other Federal agencies exercise authority and responsibility for maintaining domestic animal health. These agencies include, but are not limited to, the Food and Drug Administration (FDA), the U.S. Department of Homeland Security's (DHS) Customs and Border Protection (CPB), the U.S. Department of Commerce's

National Marine Fisheries Service (NMFS), and three USDA agencies: the Agricultural Research Service (ARS), the Cooperative State Research, Education, and Extension Service (CSREES), and the Food Safety and Inspection Service (FSIS).

FDA oversees the manufacture, importation, and use of human and animal pharmaceuticals, including antimicrobial and anti-inflammatory drugs, and a variety of natural and synthetic compounds. FDA also regulates food labeling, food product safety (except meat, poultry, and certain egg products), livestock feed, and pet food.

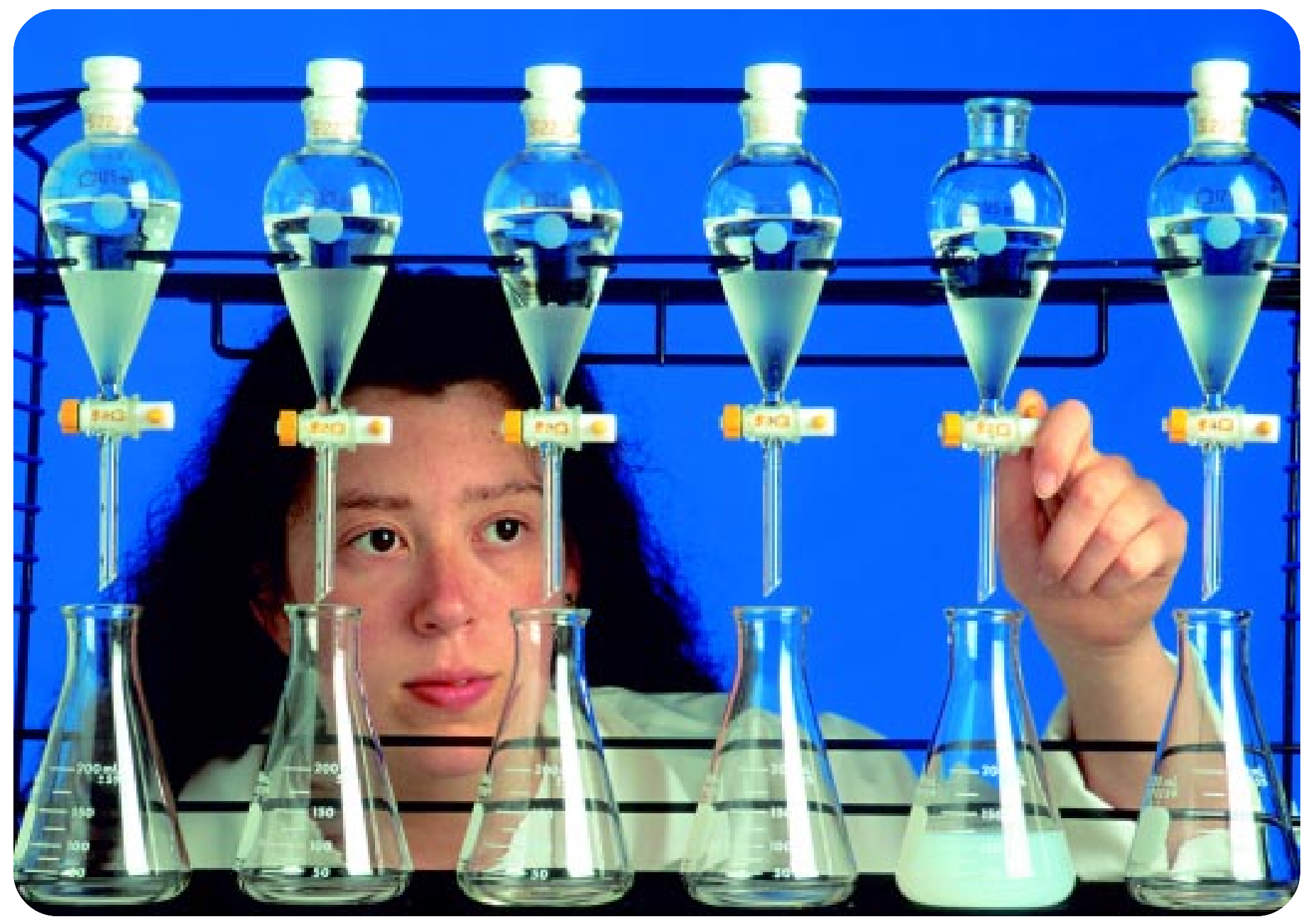


DHS has responsibility for emergencies related to animal diseases. CBP, an agency of DHS, has agricultural inspection responsibility at the Nation's borders and ports-of-entry to prevent the introduction of foreign animal and plant pests and diseases that could harm the country's agricultural resources.

NMFS provides a voluntary inspection service to fisheries and aquaculture industries.

ARS is the primary research agency within USDA for livestock and crop-related production issues, including animal health and food safety.

CSREES seeks to advance knowledge for agriculture, the environment, human health and well-being, and communities by supporting research, education, and extension programs in the Land-Grant University System and other partner organizations.

FSIS inspects all meat, poultry, and egg products sold in interstate commerce to ensure that they are safe, wholesome, and properly labeled, and reinspects imported products.

\section{State Animal Health Authorities}

Animal health authorities in each State are responsible for monitoring and controlling diseases in its domestic livestock. States control diseases through inspections, testing, vaccinations, treatments, quarantines, and other activities. States have authority to prohibit the entry of livestock, poultry, aquaculture species, and animal products from other States if those animals or products are considered health risks to local animal populations. Consequently, each State develops its own respective domestic commerce regulations. VS cooperates with States at markets where interstate movements may occur and, in conjunction with States, conducts disease surveillance programs at slaughter plants and livestock concentration points. States and VS also cooperate in national and State animal-disease control and education programs. In addition, States maintain veterinary diagnostic laboratories, provide animal disease information to veterinary practitioners, and encourage prompt reporting of specific conditions. Also, there is communication with departments of public health, colleges of veterinary medicine, and wildlife agencies within each State.
To participate in national programs, States must adhere to specific requirements. However, on the basis of individual States' needs, State-specific requirements can be developed. Generally, Statespecific requirements are more stringent than national program requirements.

In addition, States cooperate with Federal agencies to develop animal health emergency plans. States also implement producer education programs for disease management and control.

\section{Diagnostic Laboratories}

Diagnosing livestock and poultry diseases frequently requires laboratory tests. Diagnostic laboratories diagnose endemic and exotic diseases, support disease-control and reporting programs, and meet expectations of trading partners. OIE reference laboratories confirm FADs.

In the United States, the American Association of Veterinary Laboratory Diagnosticians (AAVLD) accredits laboratories. Accreditation is dependent on several criteria, including promoting excellence in diagnostic service, establishing internal quality control, hiring and retraining qualified staff and professional personnel, developing innovative techniques, and operating adequate facilities to conduct laboratory diagnostic services. Additionally, laboratories can become certified by VS to conduct specific tests to certify animals for movement or to participate in disease eradication programs.

Multiple APHIS-approved laboratories serve livestock and poultry producers (see <http:// www.aphis.usda.gov/vs/nvsl/Labs/ labcertification.htm >). To coordinate the capabilities of Federal, State, and university laboratories, a laboratory network has been created. See chapter 4 for more information on the APHIS laboratory network.

\section{Federally Accredited Veterinarians}

Private veterinary practitioners are an integral part of the U.S. veterinary infrastructure. Through their interactions with producers, practitioners function as a key resource for the enhancement of U.S. animal health. The National Veterinary Accreditation Program (NVAP) is a voluntary program that certifies private veterinary practitioners to work cooperatively with Federal veterinarians and State animal health 
officials. Since 1921, the United States has used these private practitioners, known as accredited veterinarians, as representatives of the Federal Government. Accredited veterinarians identify and inspect animals, collect specimens, vaccinate livestock, and prepare point-of-origin health certificates for interstate movement and export. VS grants national accreditation to private veterinary practitioners only after specific training and eligibility requirements are met.

In 2004, there were more than 60,000 accredited veterinarians in the NVAP database. This number represents more than 80 percent of all U.S. veterinarians. Accredited veterinarians enhance the capability of the United States to perform competent health certifications (including inspecting, testing, and certifying the health of animals) and to effectively maintain extensive disease surveillance, including timely monitoring and reporting of changes in animal health status.

\section{USAHA and Other National Associations}

The United States Animal Health Association (USAHA) provides a forum for communication and coordination among State and Federal governments, universities, industry, and other groups on issues of animal health and welfare, disease control, food safety, and public health. USAHA also serves as a clearinghouse for new information and methods. USAHA develops solutions to animal health issues based on science, new information and methods, and public policy risk-benefit analysis.

USAHA works to develop a consensus among varied groups for changing laws, regulations, policies, and programs. Committees are formed within USAHA dedicated to specific topics and issues. USAHA provides input to, and makes requests of, VS and other Federal agencies in the form of resolutions from the committees.

Other nationally oriented associations with important roles in U.S. animal health are

The National Institute for Animal Agriculture, which functions as a forum for building consensus and advancing solutions for animal agriculture and provides continuing education and communication linkages for animal agriculture professionals;
The American Veterinary Medical Association, which advances veterinary medicine and its role in public health, biological science, and agriculture and serves as an advocate for the veterinary profession by presenting views to government, academia, agriculture, and other concerned publics;

- The AAVLD, which works to establish uniform diagnostic techniques as well as to develop and improve them, to coordinate activities of diagnostic laboratories, and to disseminate animal disease diagnostic information;

The Animal Agriculture Coalition, which is an alliance of livestock, poultry, and aquaculture trade associations and the veterinary and scientific communities, all of which monitor and influence animal health, the environment, food safety, research, and education issues; and

- The National Association of State Departments of Agriculture, which represents the State and U.S. Territory departments of agriculture in the development, implementation, and communication of public policy and programs related to the agriculture industry.

\section{Working With Other Nations' Animal Health Infrastructures}

The United States is a signatory country of the WTO and is obligated to comply with the WTO's Agreement on the Application of Sanitary and Phytosanitary Standards (SPS Agreement). The SPS Agreement's main intent is to facilitate trade while recognizing the right of countries to protect the life and health of humans, animals, and plants. To prevent the use of SPS measures as unjustified trade barriers, the SPS Agreement dictates that all protective measures be scientifically based and not unnecessarily restrictive.

The WTO assigned standards-setting authority to the OIE for international trade-related animal health issues, to the International Plant Protection Convention (IPPC) for plant health issues, and to the Codex Alimentarius Commission for food safety.

For more than 25 years, VS has reported to OIE data from State officials, veterinary journals, diagnostic test results, and disease surveillance programs and, since 1998, data from the National Animal Health Reporting System (NAHRS). NAHRS is a joint effort of USAHA, AAVLD, and APHIS. NAHRS 
assimilates data, from chief State animal health officials, on the presence of confirmed OIE list A and B clinical diseases in specific commercial livestock, poultry, and aquaculture species in the United States. This information is used by the United States and OIE member countries to

Improve livestock and public health strategies,

- Prioritize animal health programs and research activities,

- Strengthen border security,

- Provide a basis for trade negotiations, and

- Certify point-of-origin health status of exported animals, poultry, and related products.

USDA agencies (including APHIS, the Foreign Agricultural Service, and FSIS) regularly send representatives to negotiate animal health issues in bilateral, regional (such as the North America Free
Trade Agreement), and multilateral forums, including the WTO. These representatives also work in dozens of specialized animal-health and food-safety committees under the OIE, IPPC, and Codex Alimentarius. Working together, U.S. specialists promote sound science, transparent rulemaking, and effective monitoring to reduce the risk of exposure to animal disease, while at the same time promoting fair and safe trade.

Animal health officials from Canada, Mexico, and the United States have created the North American Animal Health Committee, which meets regularly to discuss common animal health issues. Similarly, U.S. animal health officials meet regularly with their Australian, New Zealand, and Canadian counterparts in the Quadrilateral Animal Health Committee. 


\section{CHAPTER 2 \\ Overview of U.S. Livestock, Poultry, and Aquaculture Production in 2004}

\section{Available Statistics}

USDA's National Agricultural Statistics Service (NASS) collects and publishes official statistics for the U.S. livestock, poultry, and aquaculture populations. These statistics are based on the Census of Agriculture conducted every 5 years (e.g., 1997 and 2002) and surveys conducted monthly, quarterly, or annually, depending on the particular commodity.

Frequency of surveys and sample sizes by commodity are shown in appendix 1 at table Al.l.

The Census of Agriculture, which is a complete enumeration of the entire agricultural segment of the economy, is the only source of detailed, county-level data of all farms and ranches in all 50 States selling or intending to sell agricultural products worth $\$ 1,000$ or more in a year. The most recent Census data were collected for 2002 and published in spring 2004.

The U.S. maps presented in this chapter are based on the 2002 Census of Agriculture, which provides animal inventory levels as of December 31, 2002.

In NASS' ongoing sample survey and estimation programs, data are collected and estimates are published within the same month to provide users with the most up-to-date and timely information even in the years the Census is conducted. The Census requires a massive data collecting, editing, and summarizing effort, which results in a publication lag. Consequently, sample survey estimates and final Census reports rarely show exactly the same numbers.

\section{Number of Farms}

Estimates for the number of farms are based on the definition of a farm as "any establishment from which $\$ 1,000$ or more of agricultural products were sold or would be normally sold during the year." Map 1 illustrates the distribution of farms across the United States based on the 2002 Census of Agriculture. In general, there were fewer farms in the western half of the United States; however, western farms and ranches were generally larger than those in the eastern half of the United States. There were 2.11 million farms in 2004, compared with 2.13 million in
2003. Total land in farms was 936.6 million acres in 2004, which represents a decrease from 938.7 million acres in 2003.

\section{Relative Magnitude of Industries by Value of Production}

The value of production (primarily value of marketings) can be used as the standard for measuring the relative magnitude of the major livestock, poultry, and crop commodities produced in the United States. In recent years, the total value of production has been split nearly equally between crop and livestock (and poultry) production. In the 2002 Census of Agriculture, 52.6 percent of total value of production came from livestock and poultry. Table Al.2 in appendix 1 shows specific major livestock and poultry commodity values for 2004 (50.4 percent of the total). Map 2 shows the U.S. distribution of livestock and poultry by value of products sold.

\section{Introduction to the Livestock, Poultry, and Aquaculture Industries}

Almost one out of two farms in the United States has cattle and calves, for a total of 989,460 cattle operations. A cattle operation is any place having one or more head of cattle on hand at any time during the year. In 2004 , only a small proportion of these cattle operations were dairies for milk production $(81,440)$. The value of production for cattle and calves is roughly $\$ 34.9$ billion. The value of milk production is approximately $\$ 27.5$ billion. The poultry industry is the next largest commodity with a
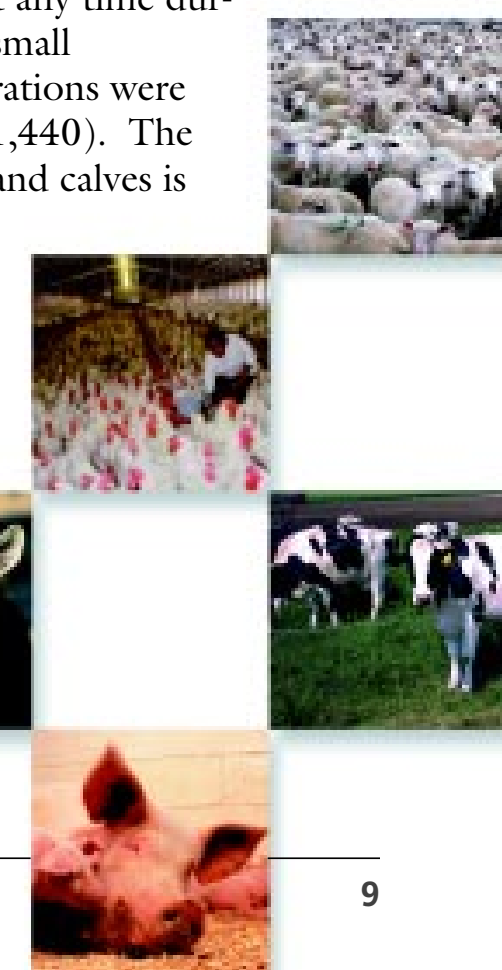
MAP 1

\section{Number of Farms: 2002}

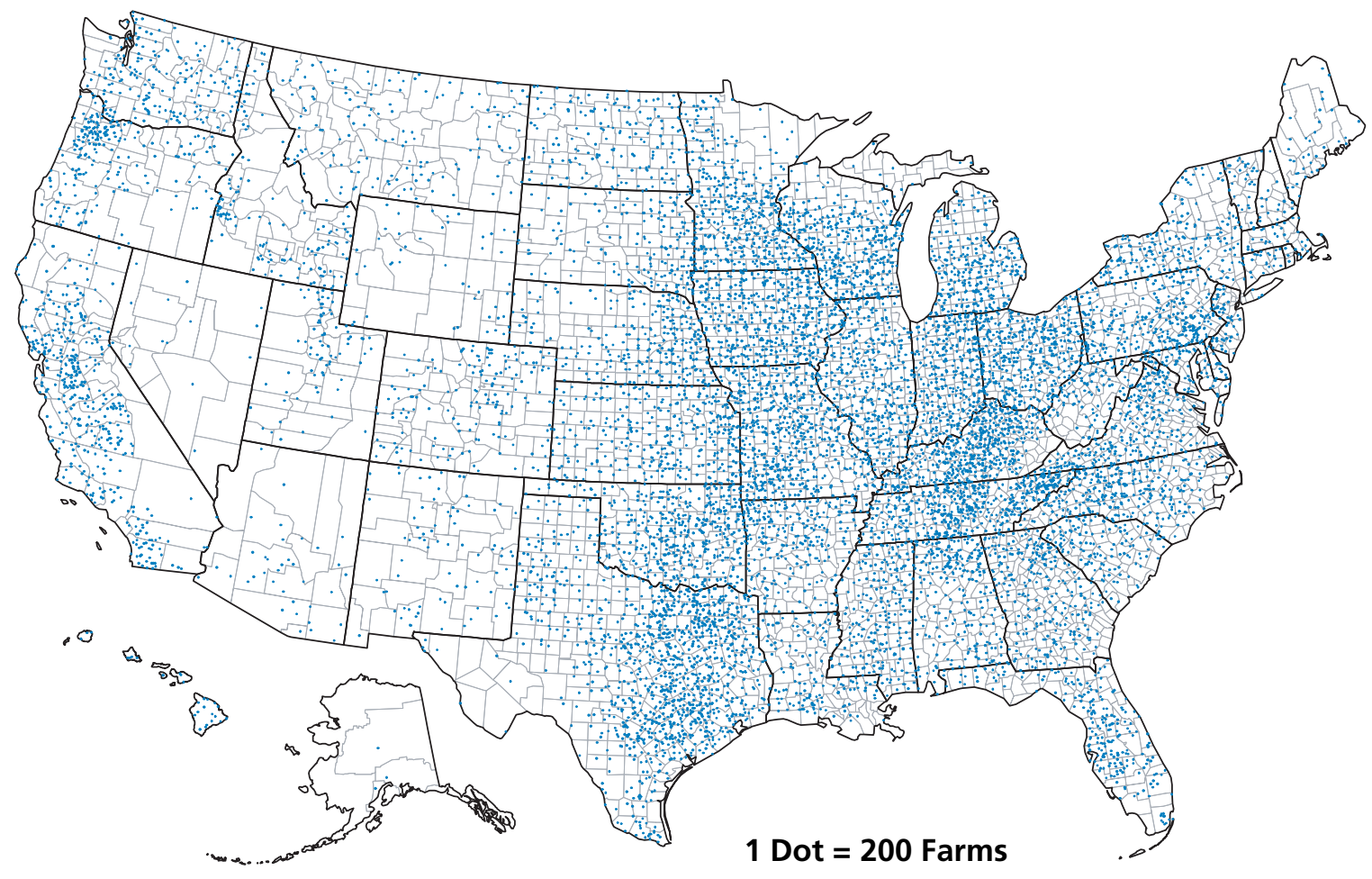

Source: 2002 Census of Agriculture

United States Total: 2,128,982

MAP 2

Value of Livestock, Poultry, and Their Products Sold: 2002

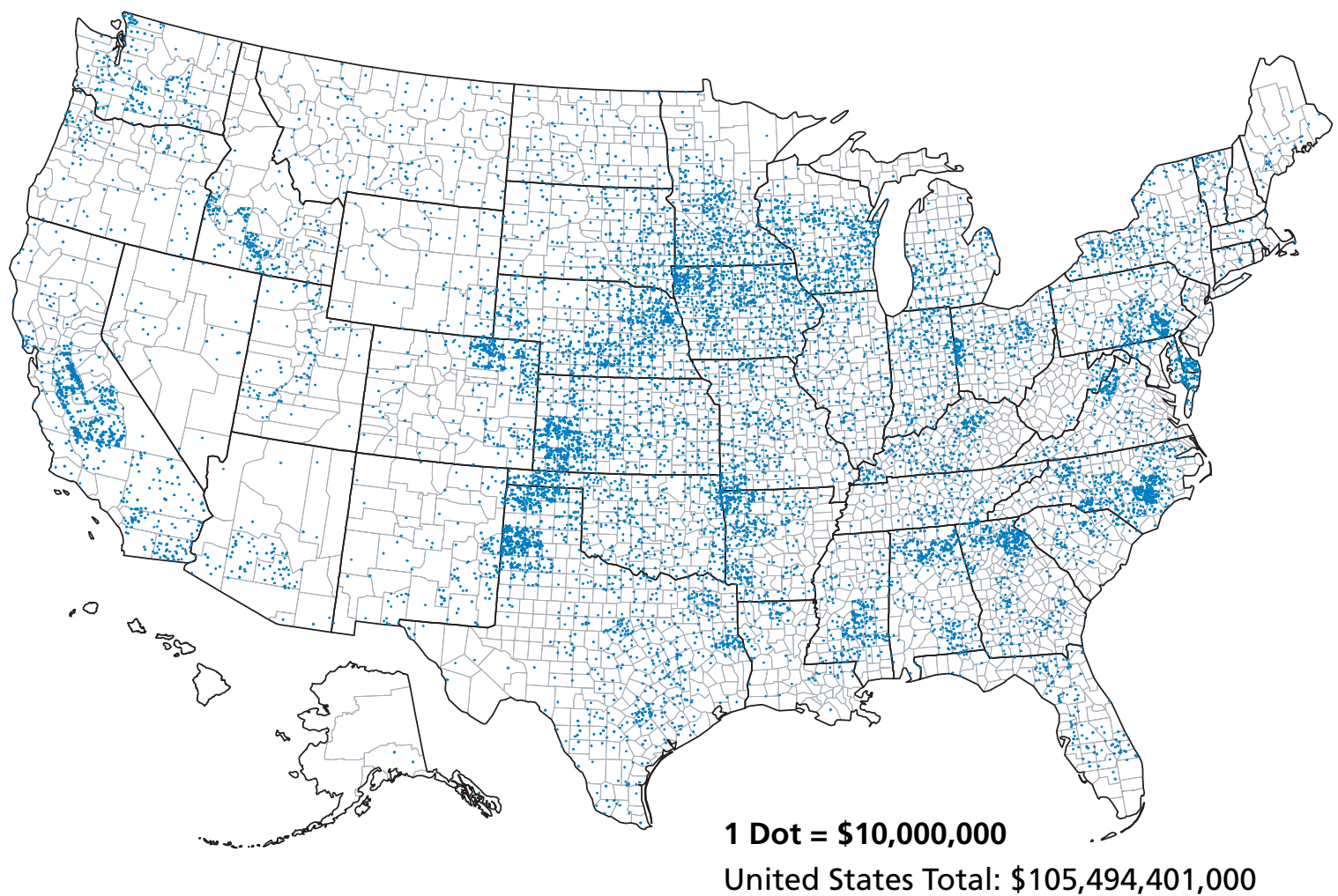


value of production of approximately $\$ 28.9$ billion. Numbers are very similar for the operations with hogs and those with sheep $(69,420$ and 67,160 , respectively), although the comparative values of production are dissimilar (table 2). Note: Detailed statistics for each commodity are provided in tables Al.2 through Al.14 in appendix 1.

\section{Cattle and Calves (Beef and Dairy)}

The Nation's nearly 100 million cattle and calves (beef and dairy) are dispersed widely across the country with a heavier concentration generally in the Central States (map 3).

TABLE 2

Livestock, poultry, and aquaculture statistics for 2004

\begin{tabular}{|c|c|c|c|c|}
\hline Commodity & $\begin{array}{c}\text { Inventory } \\
(1,000)\end{array}$ & Operations & $\begin{array}{c}\text { Value of } \\
\text { production } \\
(\$ 1,000)\end{array}$ & $\begin{array}{l}\text { Appendix } \\
\text { reference } \\
\text { for detail }\end{array}$ \\
\hline All cattle and calves & 195,848 & 989,460 & $34,887,821$ & A1.3 \\
\hline Milk cows & 19,005 & 81,440 & ${ }^{2} \mathrm{NA}$ & A1.4 \\
\hline Beef cows & 133,055 & 774,630 & NA & A1.5 \\
\hline Cattle on feed & 113,749 & 90,176 & NA & A1.6 \\
\hline Sheep and lambs (plus wool) & ${ }^{1} 6,135$ & 67,160 & 442,264 & A1.8 \\
\hline Poultry & NA & NA & $28,872,757$ & A1.9 \\
\hline Equine & 45,317 & NA & NA & A1.10 \\
\hline Catfish & NA & 1,158 & 480,175 & A1.11 \\
\hline Trout & NA & 601 & 68,716 & A1.11 \\
\hline
\end{tabular}

${ }^{1}$ Inventory as of January 1, 2005. ${ }^{3}$ Inventory as of December 1, 2004

${ }^{2}$ Not available. $\quad{ }^{4}$ Inventory as of January 1, 1999.

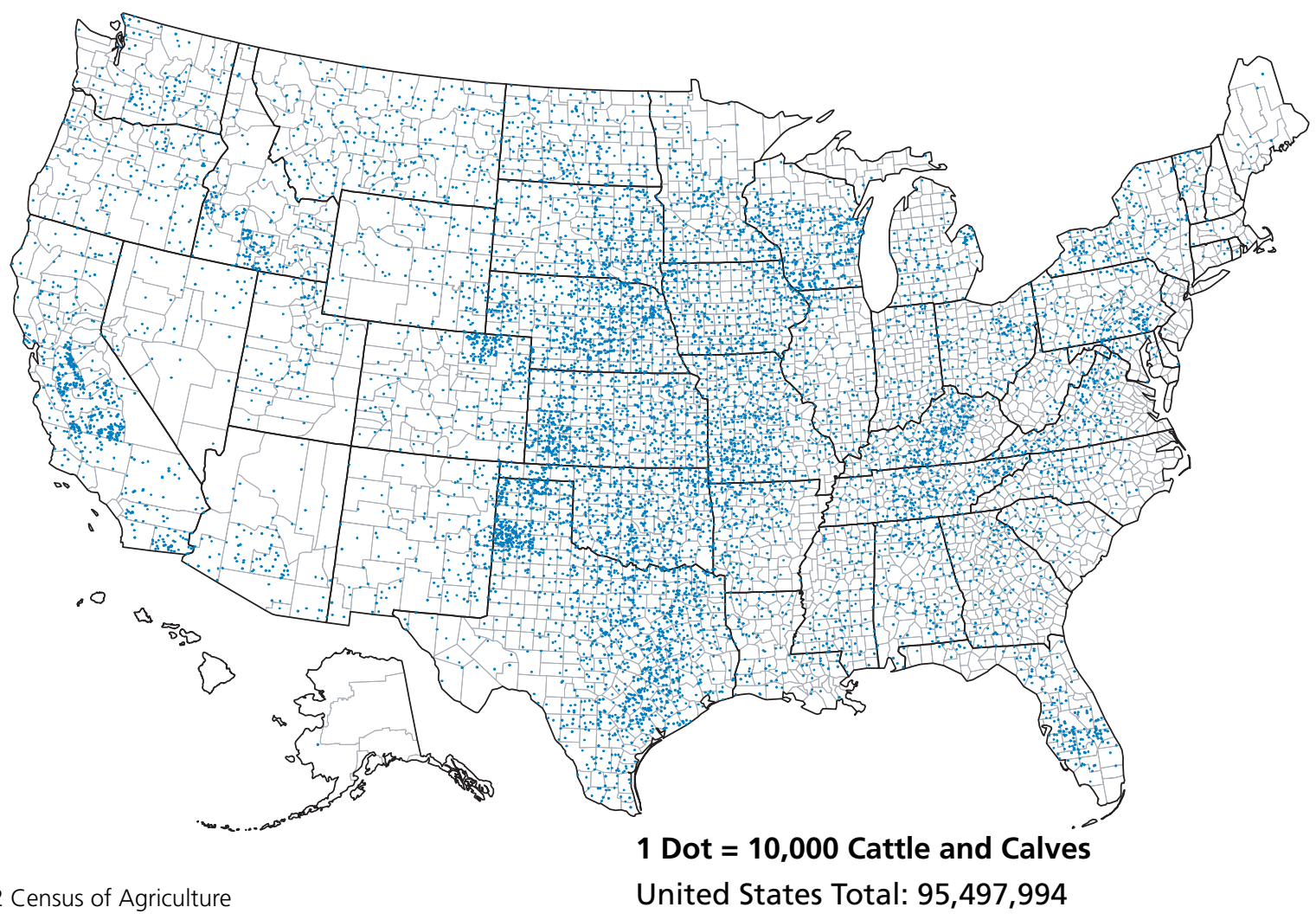


Overall, the number of cattle and calves in the United States declined during the past two decades despite a slight upturn in the mid-1990s. Historically, changes in the cattle cycle occur at approximately 10-year intervals. Presently, the Nation's inventory of cattle and calves shows a slight upward turn after 8 years of gradual decline (fig. 3).

Over the past decade, the decline in the number of cattle and calf operations occurred at a faster pace than the general decline in inventories (fig. 4). The decreasing trend in the number of cattle and calves operations is due primarily to the decline in the number of small operations.

In 2004, smaller operations accounted for 62.5 percent of all operations but only 11.3 percent of the total inventory of cattle and calves. Larger operations accounted for just 2.9 percent of all operations and contained 41.7 percent of the total inventory of cattle and calves (table Al.3 in appendix 1).
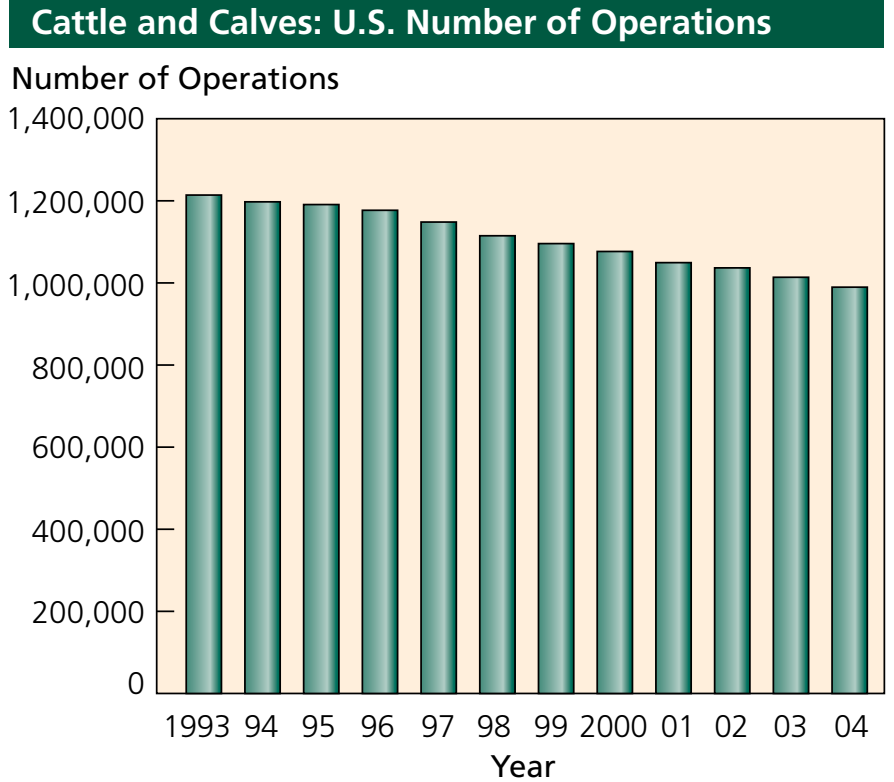

Source: USDA-NASS

Figure 4-Cattle and calf operations in the United States, 1993-2004.

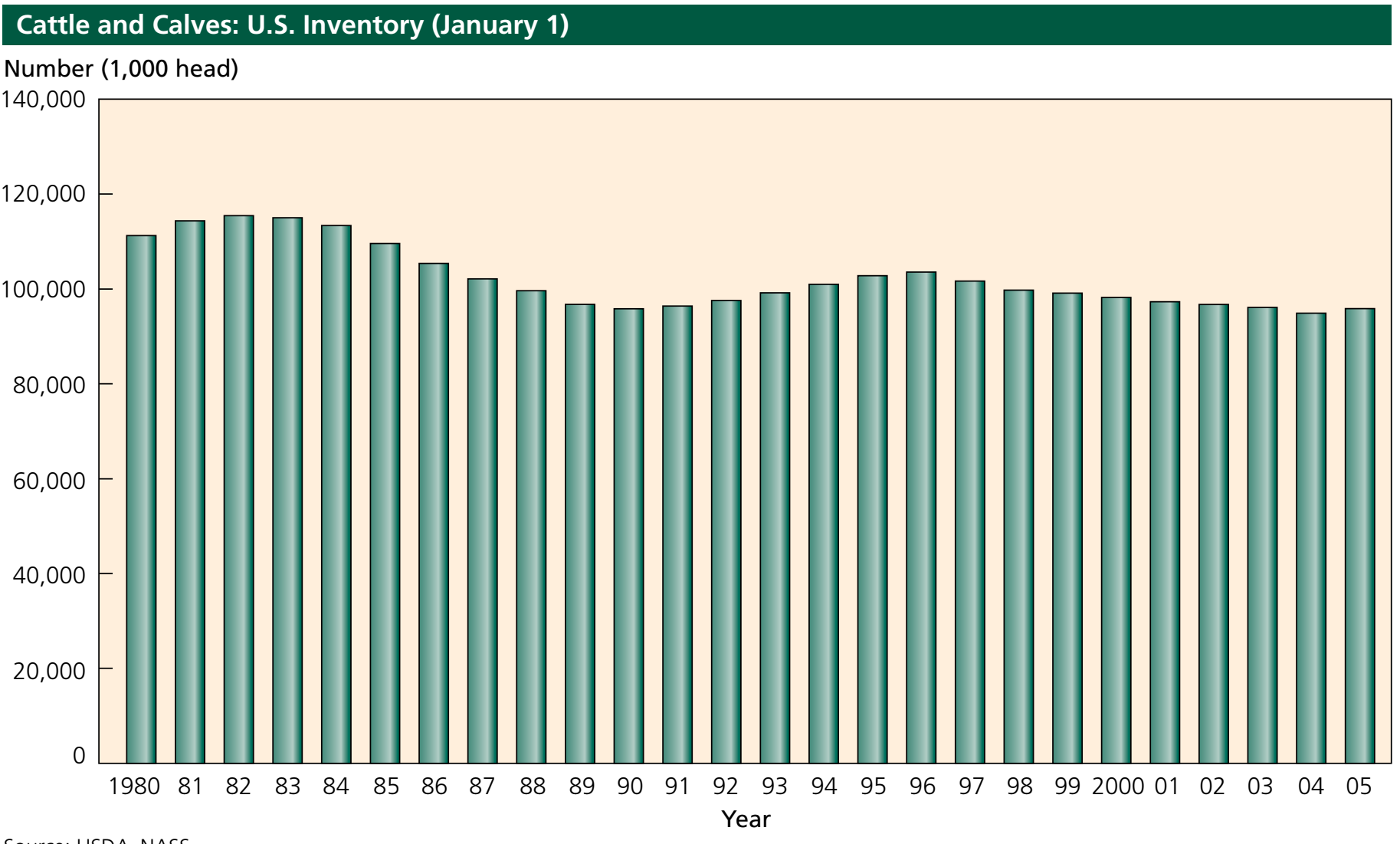

Source: USDA-NASS

Figure 3-The number of cattle and calves in the national herd, 1980-2005. 


\section{Milk Cows-Dairy}

The distribution of milk cows in the United States is characterized by a concentration of milk cows in California, Wisconsin, Minnesota, and the Northeastern States (map 4).

The U.S. milk cow population has remained relatively stable, with only a 5-percent decrease since 1995 (fig. $5)$. In contrast, the number of such operations with milk cows in 2004 is only 55 percent of the number of operations in 1994 (fig. 6). Annual milk production per cow increased from 16,179 pounds in 1994 to 18,957 pounds in 2004 (a 17-percent increase). Table Al.4 in appendix 1 documents dairy production for 2003 and 2004.

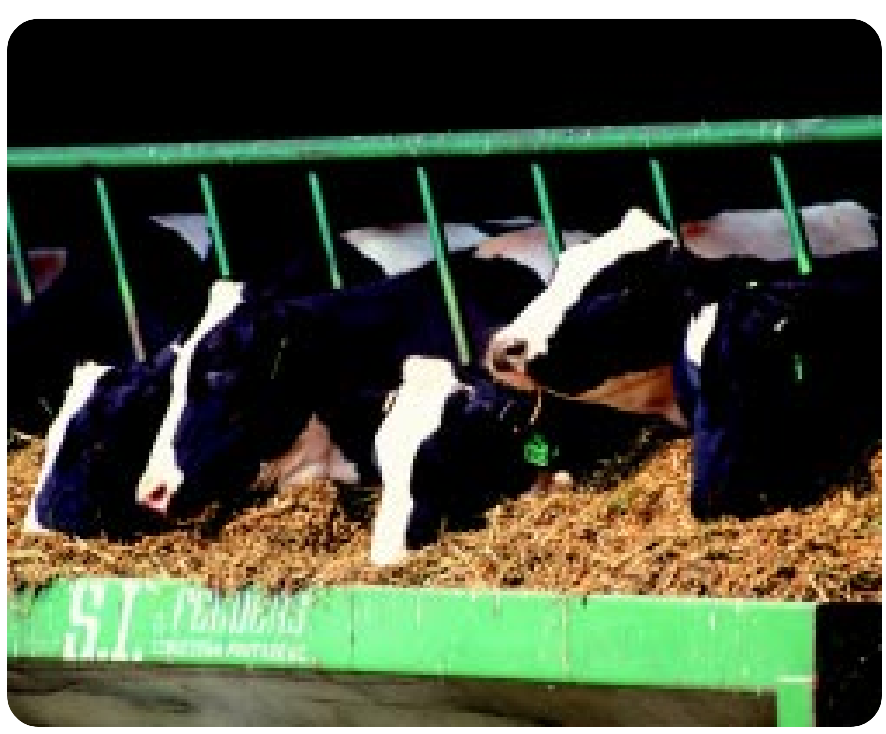

MAP 4

Milk Cows-Inventory: 2002

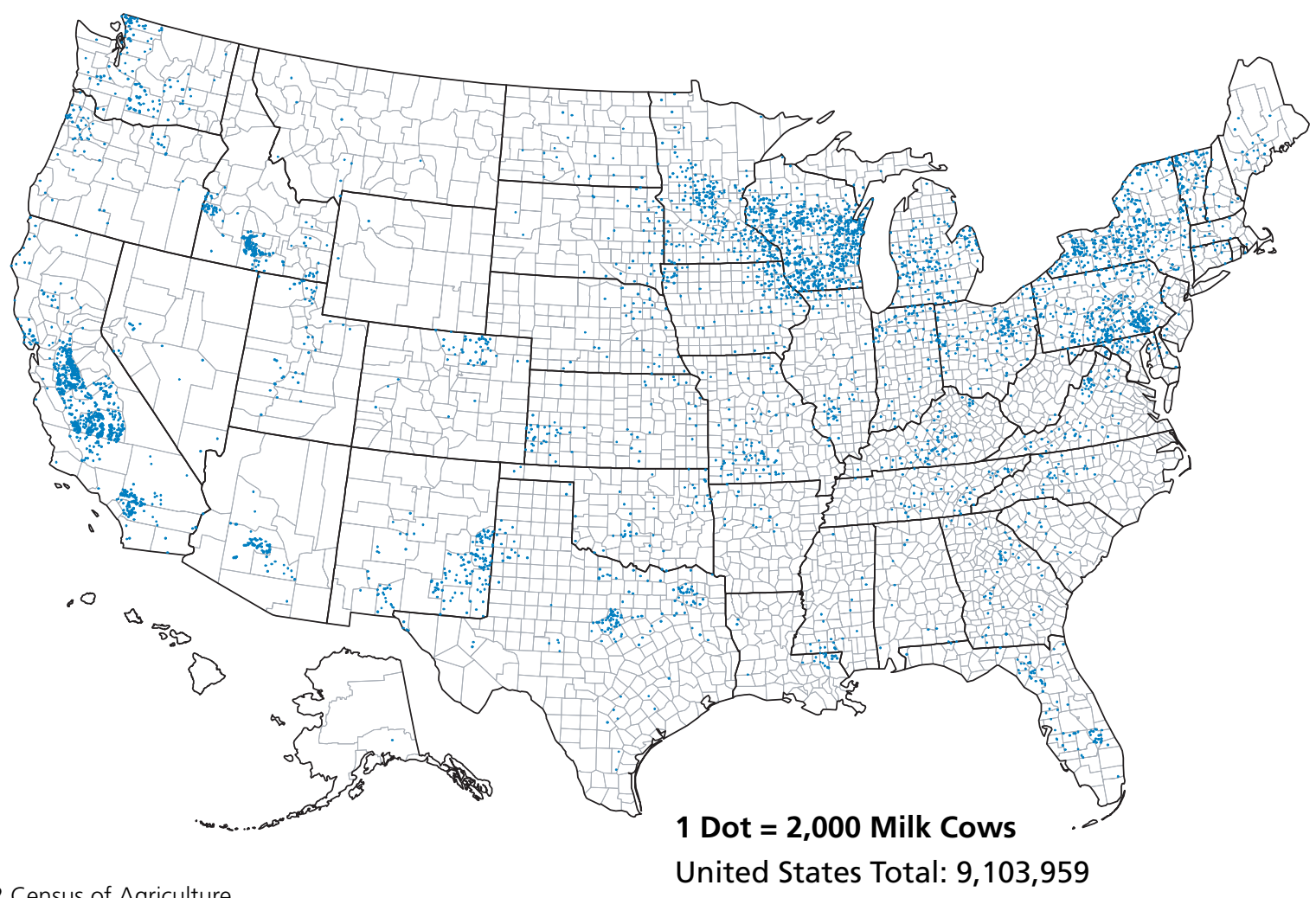

Source: 2002 Census of Agriculture 


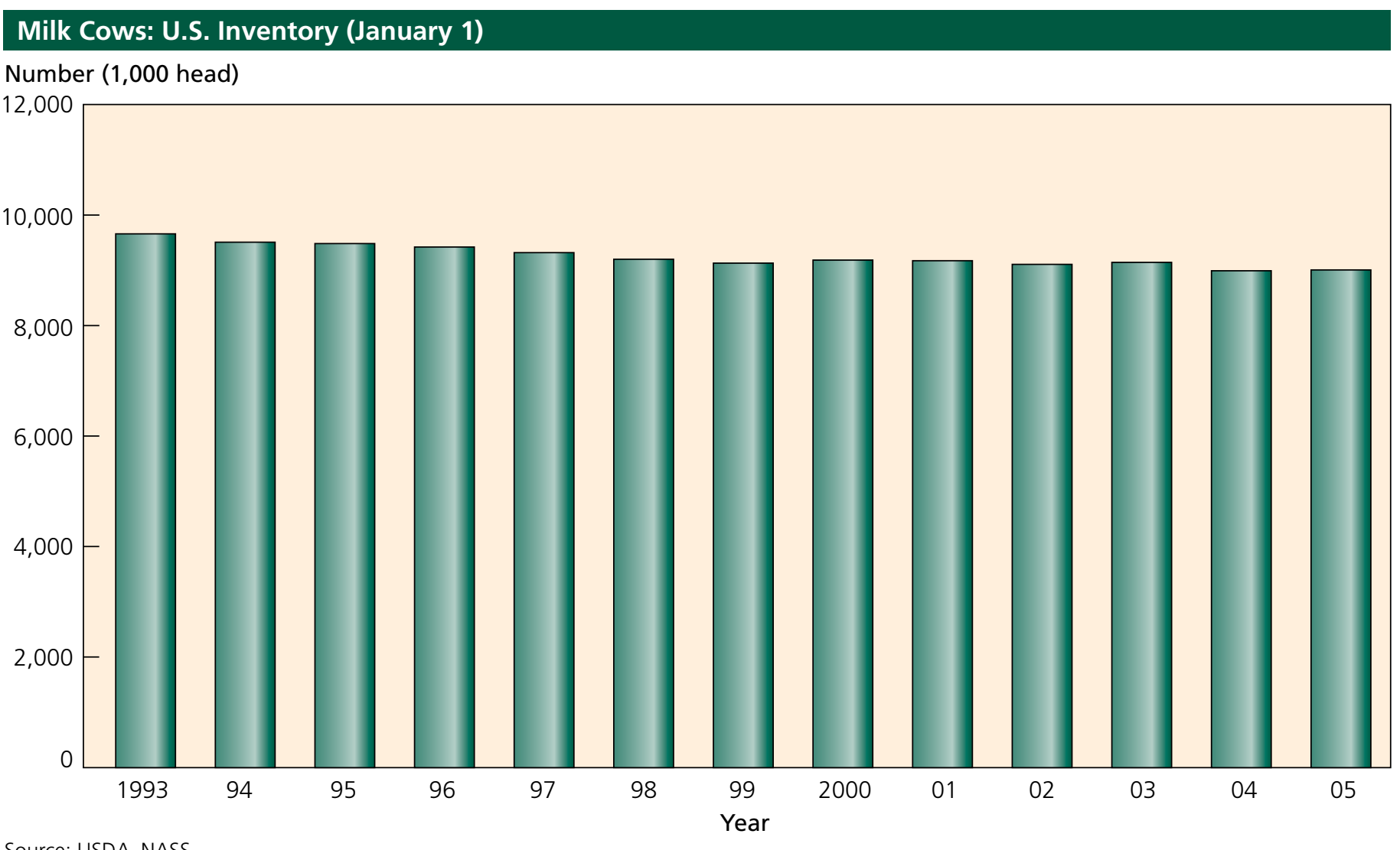

Source: USDA-NASS

Figure 5-Population of milk cows in the United States, 1993-2005.
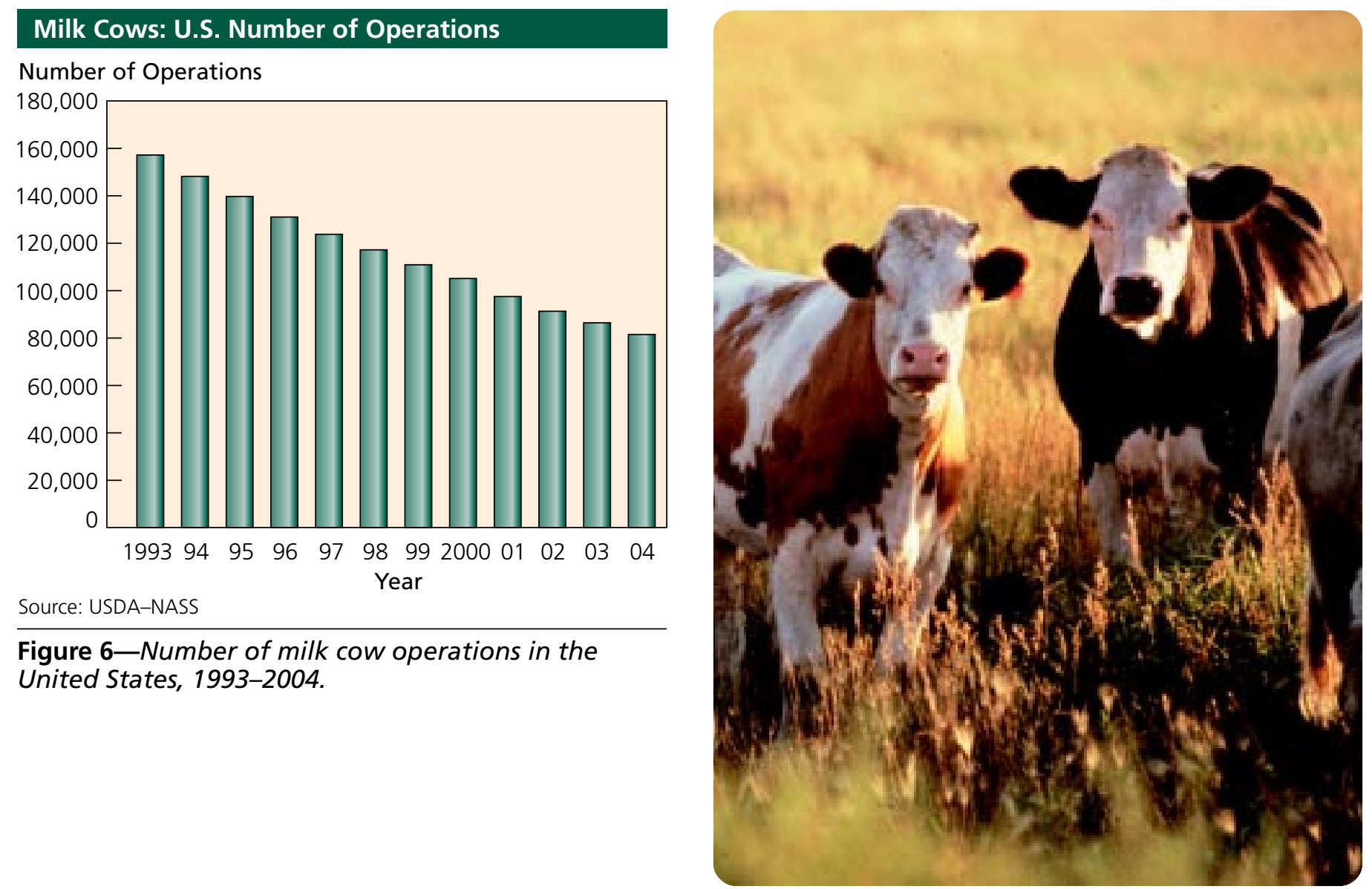

Figure 6-Number of milk cow operations in the United States, 1993-2004. 


\section{Beef Cows}

Beef cows are distributed widely across the United States, although heavier concentrations are generally found in the Central States (map 5).

The trend in the number of beef cows (fig. 7) over time follows that shown for the total inventory of cattle and calves (fig. 3). Beef cows accounted for 78.6 percent of the total cow inventory on January 1 , 2005 .

A relatively large number of operations $(774,630)$ in the United States have beef cows. However, the number of operations with beef cows has declined gradually since 1995 ( 1 to 2 percent per year, fig. 8). This decrease is most notable in small operations ( $1-49$ head). Following a common trend seen in other livestock commodities, the population of beef cows on larger operations (100+ head) increased from 51.9 percent of total U.S. inventory in 1994 to 52.8 percent of total U.S. inventory in 2004 (table Al.5 in appendix 1). These large operations account for only 10 percent of all beef cow operations in the United States but have more than half of the total beef cow inventory.

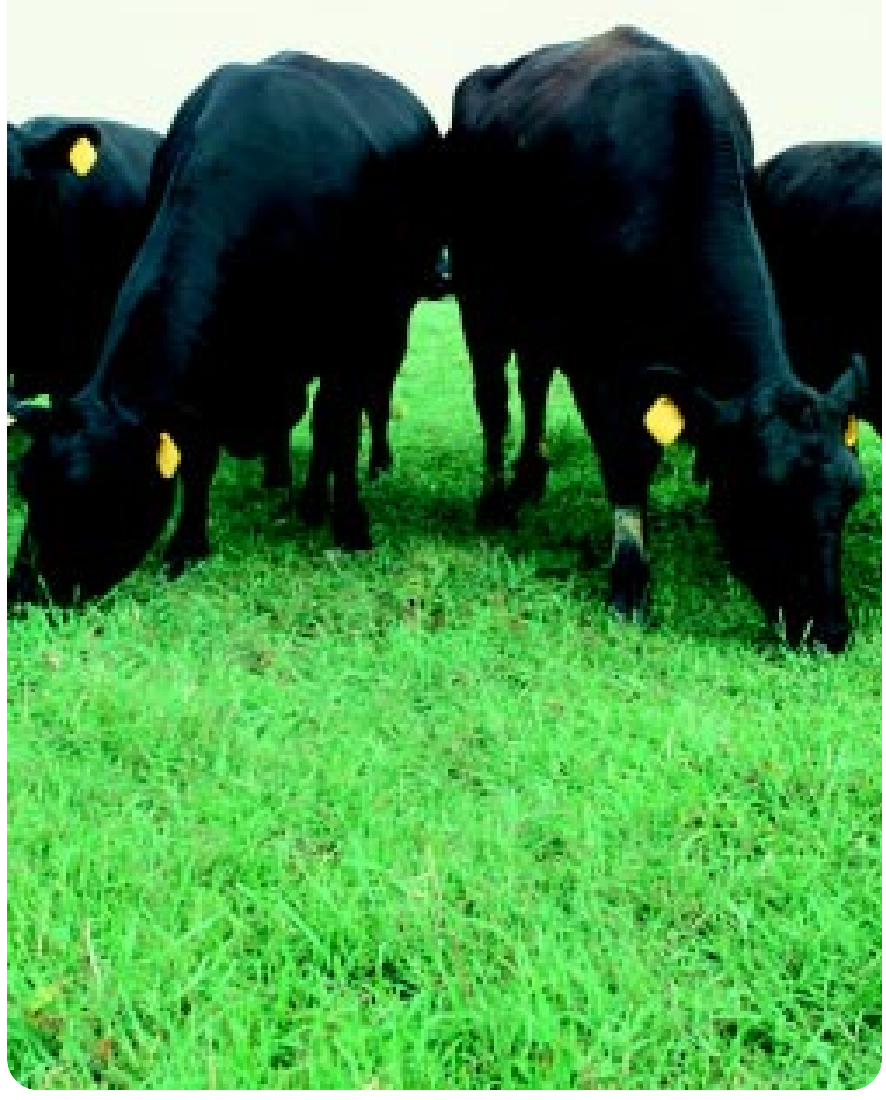

MAP 5

\section{Beef Cows-Inventory: 2002}

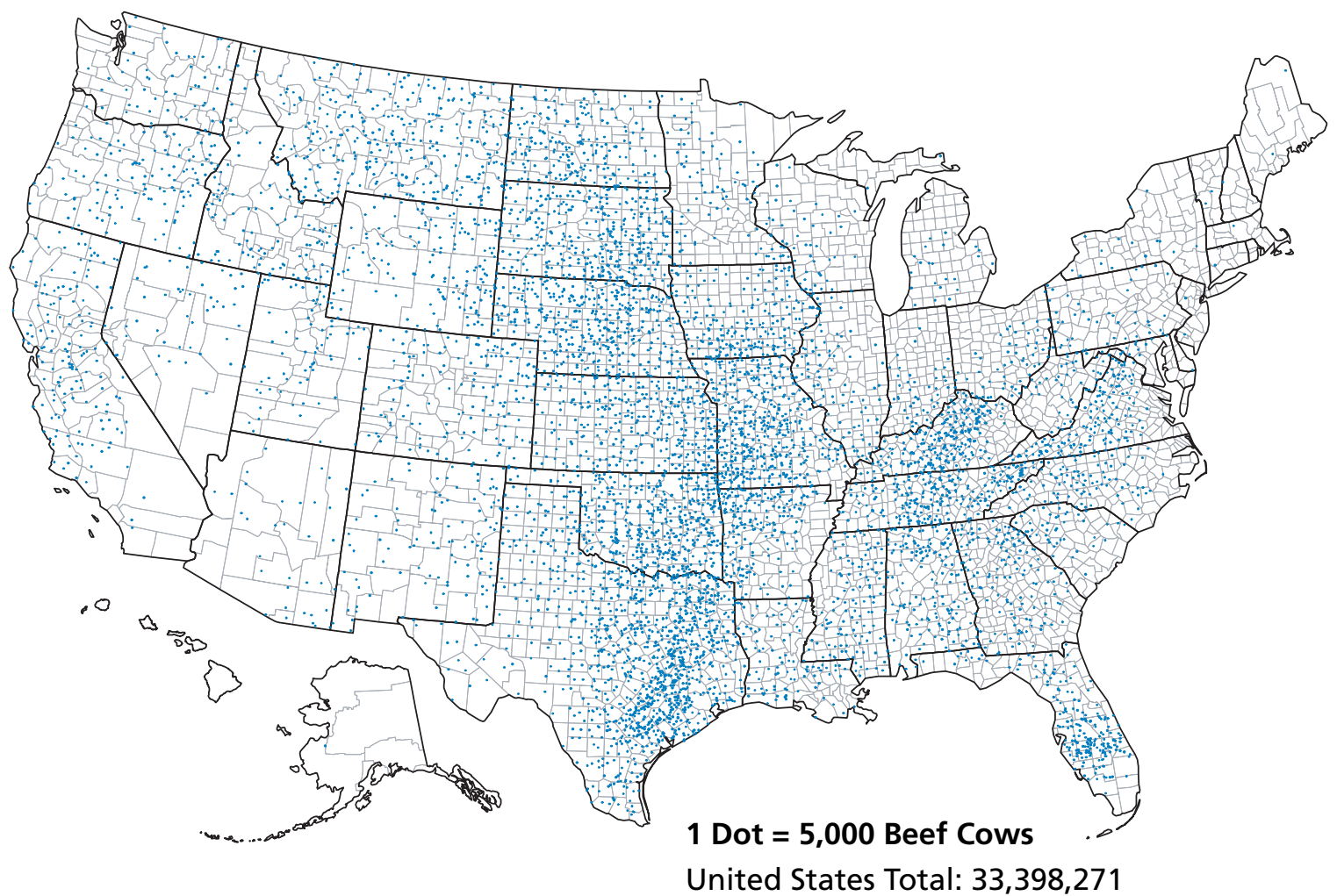




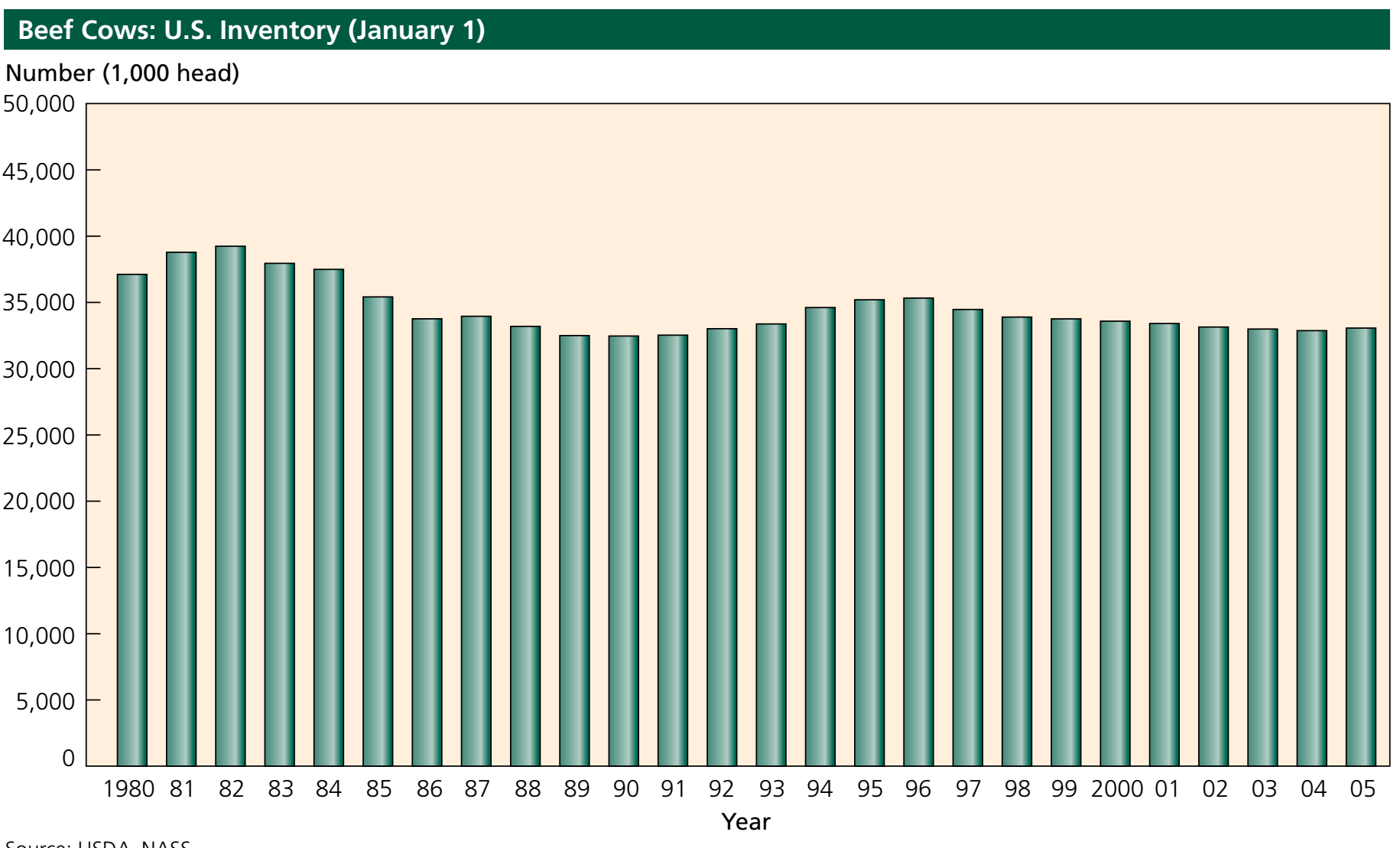

Source: USDA-NASS

Figure 7-Population of beef cows in the United States, 1980-2005.

\section{Beef Cows: U.S. Number of Operations}

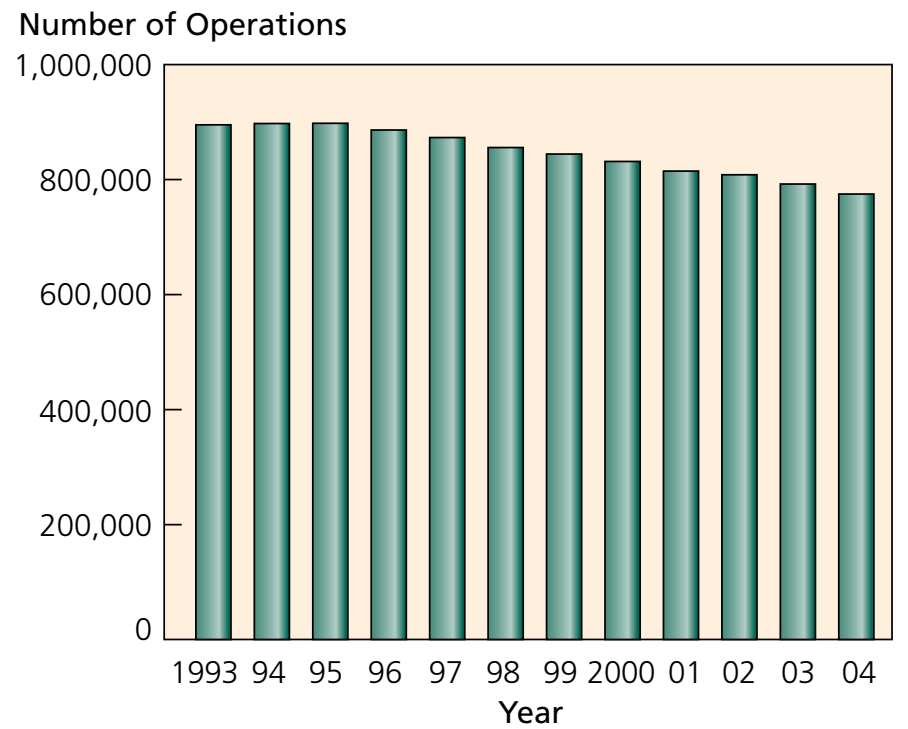

Source: USDA-NASS

Figure 8-Number of beef cow operations in the United States, 1993-2004. 


\section{Cattle on Feed}

Cattle and calves on feed are fed a ration of grain or other concentrate in preparation for slaughter, and the majority are in feedlots in States with large grain supplies.

On January 1, 2005, only 124 feedlots ( 0.1 percent of all feedlots) accounted for 39.4 percent of the total U.S. cattle-on-feed inventory (table Al.6 in appendix 1). Inventory numbers in feedlots typically reach high points in December, January, and February and low points in August and September because of the seasonal availability of grazing resources and the predominance of spring-born calves.

\section{Hogs}

Historically, hog production has been most common in the upper Midwest (map 6). Iowa is the largest hog-producing State and had 26.6 percent of the December 1, 2004, inventory. During the past two decades, North Carolina increased its production and is now the Nation's second-largest hog-producing State with 16.2 percent of the inventory. Recent

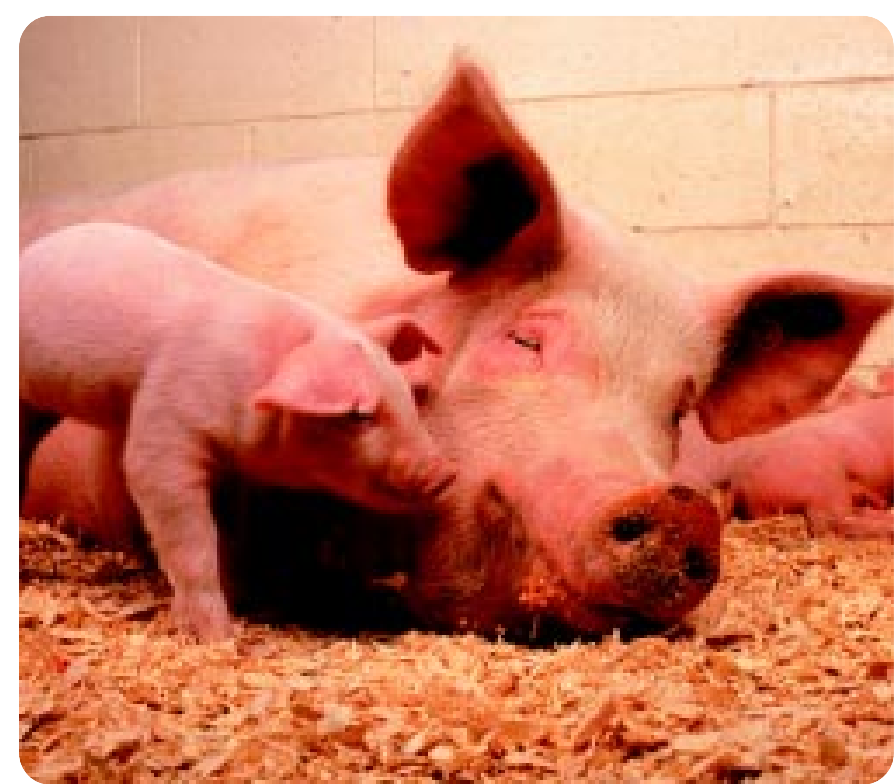

trends indicate that hog production is moving to nontraditional hog-producing States in the West, such as Colorado, Oklahoma, Texas, and Utah. In addition, the practice of shipping pigs from production areas (e.g., North Carolina) to grower/ finisher areas in the upper Midwest has increased considerably.

MAP 6

\section{Hogs and Pigs_-Inventory: 2002}

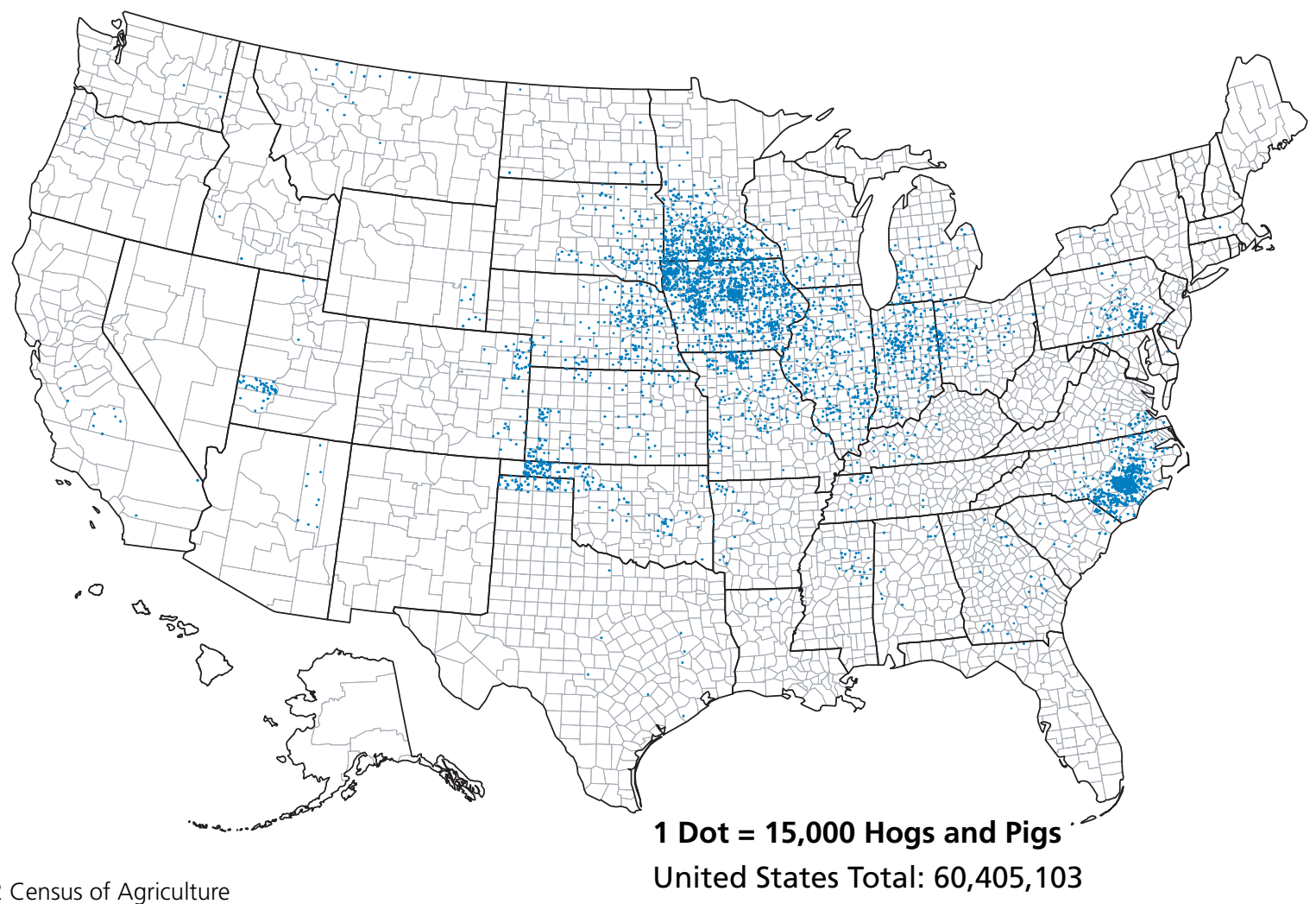


U.S. inventory of all hogs has fluctuated over the past decade (fig. 9), although it has remained rather stable in the last 2 years. The number of hogs kept for breeding has decreased by 15 percent in the last decade (fig. 10).

The number of operations with hogs declined steadily during the past decade, decreasing by 65 percent since 1994 (fig. 11). The majority of operations remains small (fewer than 100 head), but these operations account for only 1 percent of the inventory. During the past decade, there has been a steady increase in the number of large operations $(5,000$ or more head) with the exception of a slight decline in 2003. Large operations (3.3 percent of all operations) now maintain more than half of the U.S. hog inventory.

In 2004, the United States had 69,420 hog operations with a production value of $\$ 13.1$ billion (table Al.7 in appendix 1$)$.

\section{Hogs and Pigs: U.S. Inventory (December 1)}

Number $(1,000$ head)

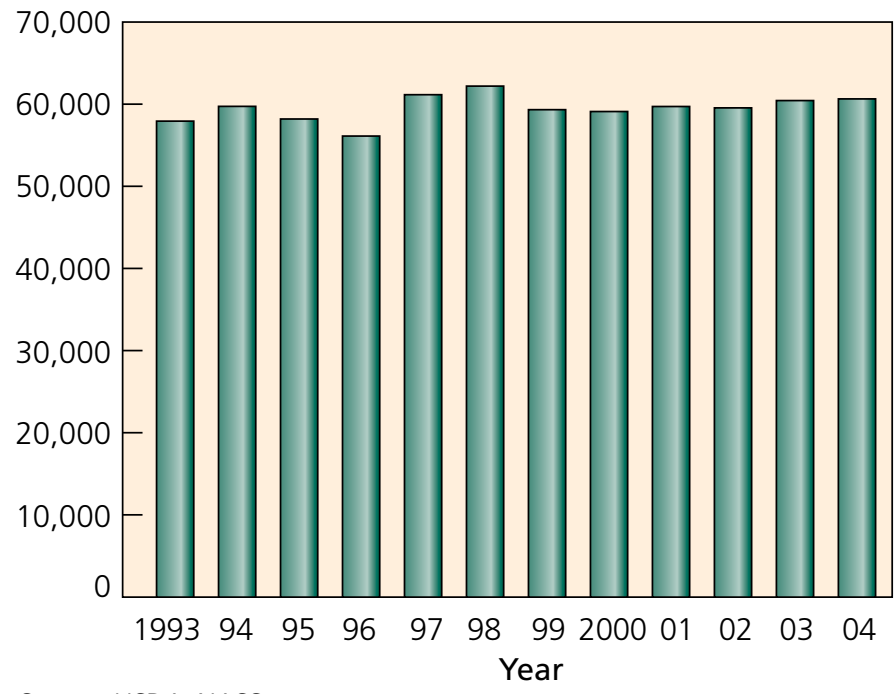

Source: USDA-NASS

Figure 9-Population of hogs and pigs in the United States, 1993-2004.

\section{All Breeding Hogs and Pigs:}

U.S. Inventory (December 1)

Number (1,000 head)

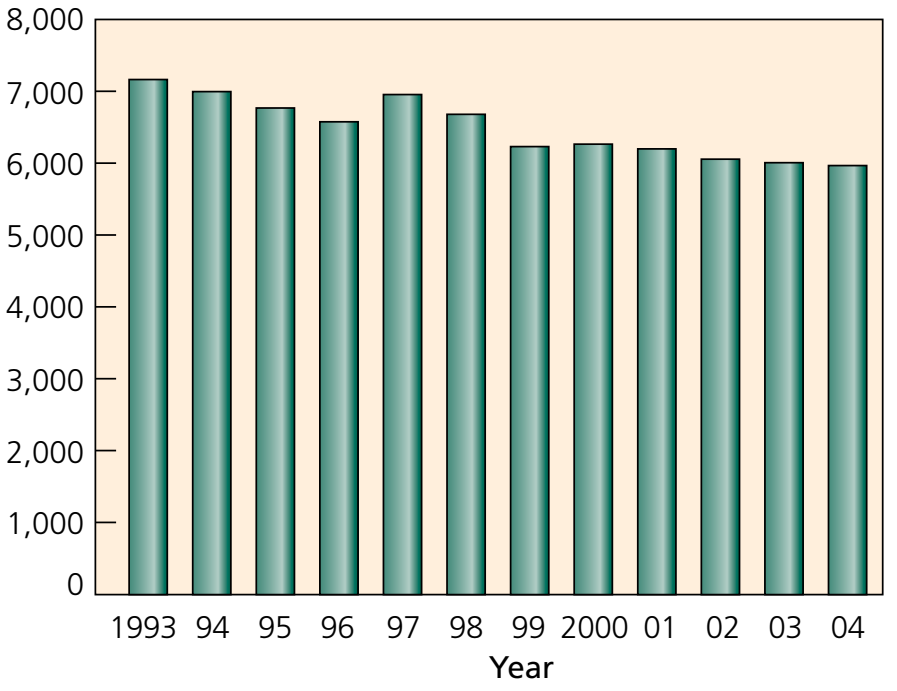

Source: USDA-NASS

Figure 10-Number of U.S. hogs kept for breeding, 1993-2004.

\section{Hogs and Pigs: U.S. Number of Operations}

Number of Operations

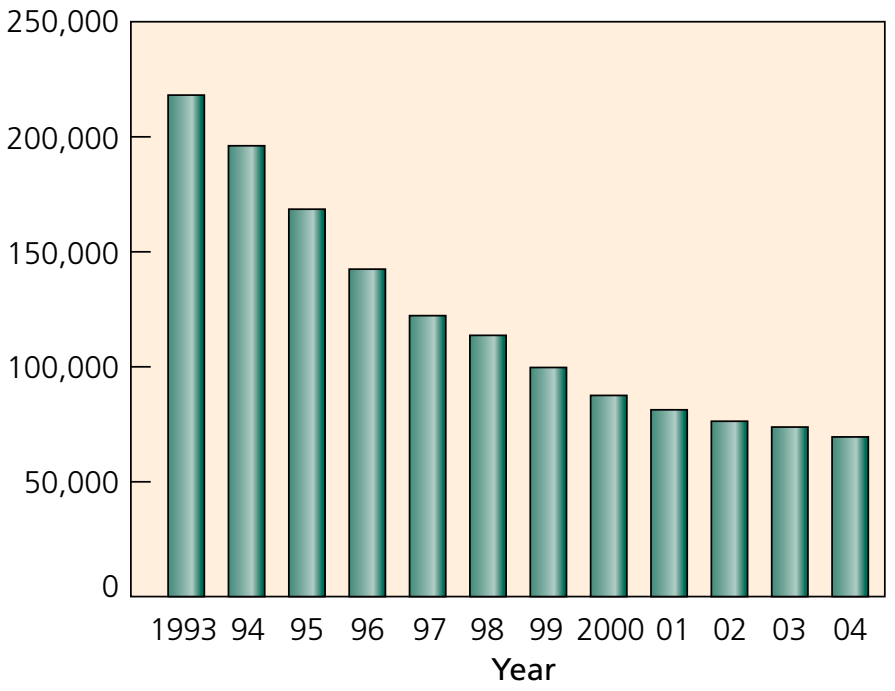

Source: USDA-NASS

Figure 11-Number of hog operations in the United States, 1993-2004. 


\section{Sheep and Goats}

The U.S. sheep industry is located primarily in the Western and Central States (map 7). Typically, the Western States are characterized by large range flocks, whereas those in the Central and Eastern States are mostly small, fenced flocks.

The number of sheep has declined steadily since the late 1980s, with the exception of a brief peak in inventory in 1990 and a small increase in January 1 , 2005 (fig. 12).

The number of operations with sheep since the late 1980s has declined gradually, although the total has remained steady in the last 5 years (fig. 13).

The January 1, 2005, total inventory of U.S. sheep and lambs was 6.1 million head. Almost a third (30.3 percent) of these sheep are located on a large number of small operations; 92.0 percent of the 67,160 total operations had fewer than 100 head of sheep and lambs (table Al.8 in appendix 1).

There were 2.52 million goats in the United States on January 1, 2005. Texas accounted for 49.6 percent of the total. There were approximately the same number of Angora goats as milk goats, 274,000 and 283,500, respectively. Meat and other goats totaled 1.97 million head.

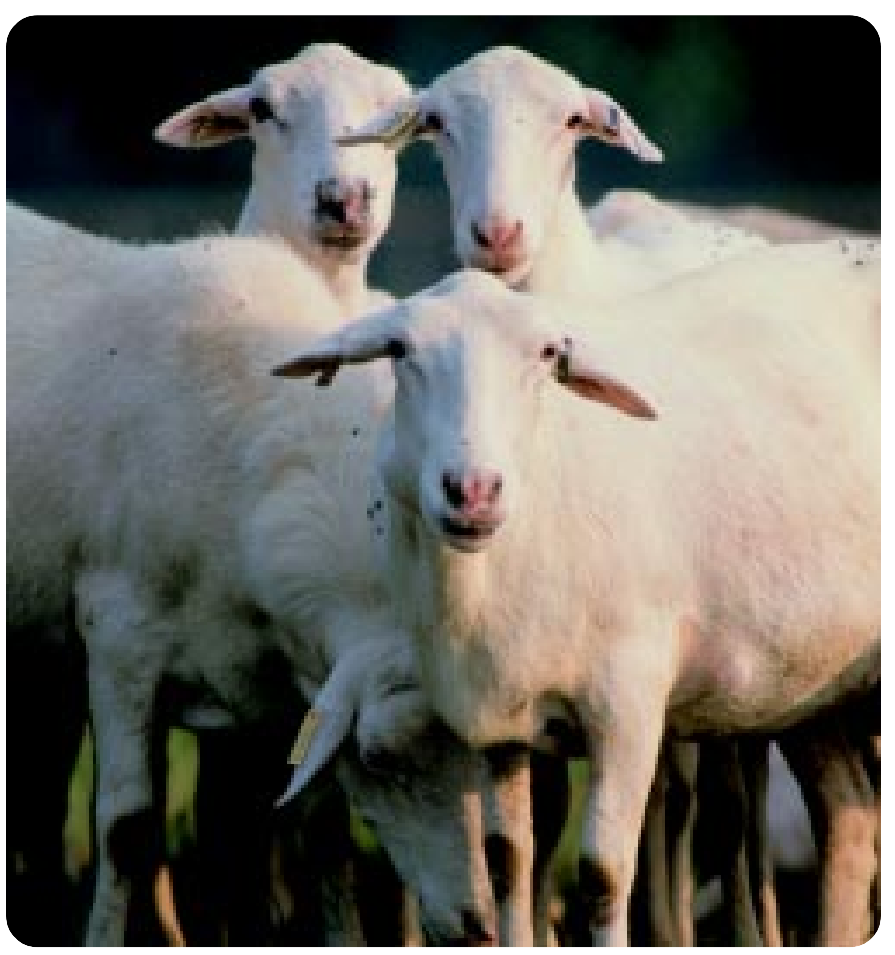

MAP 7

Sheep and Lambs-Inventory: 2002

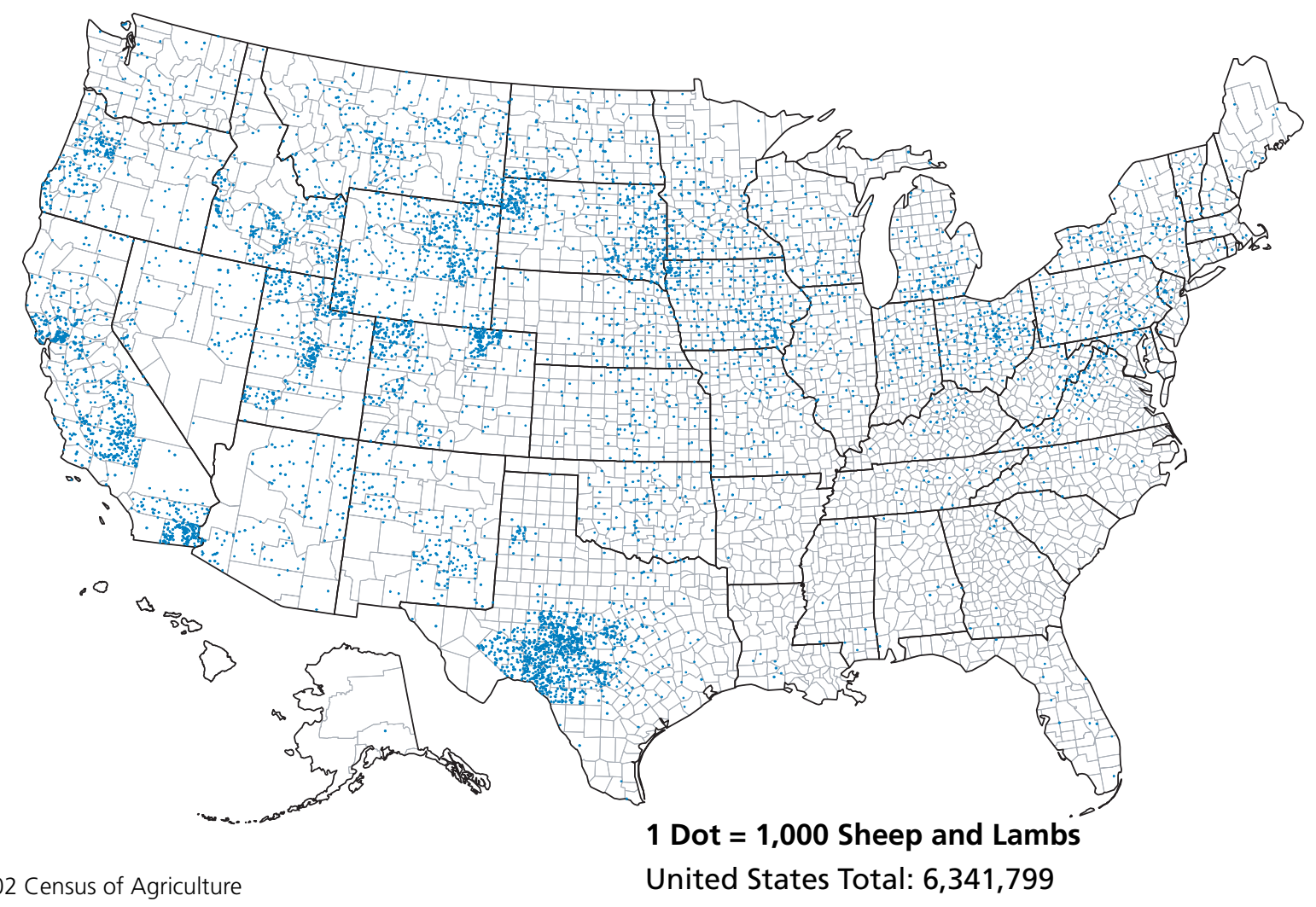

United States Total: 6,341,799 


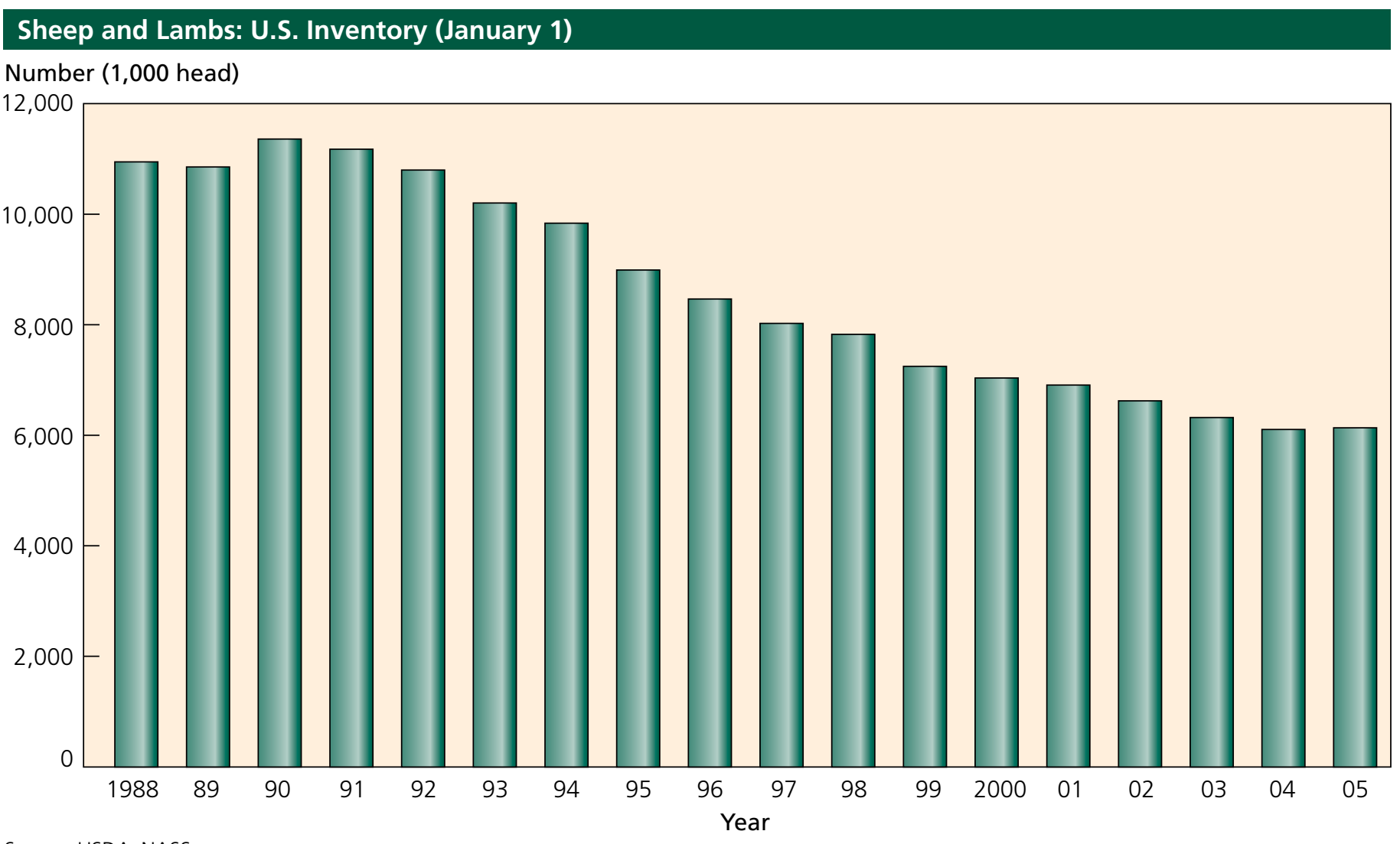

Source: USDA-NASS

Figure 12-Population of sheep and lambs in the United States, 1988-2005.

\section{Sheep and Lambs: U.S. Number of Operations}

\section{Number of Operations}

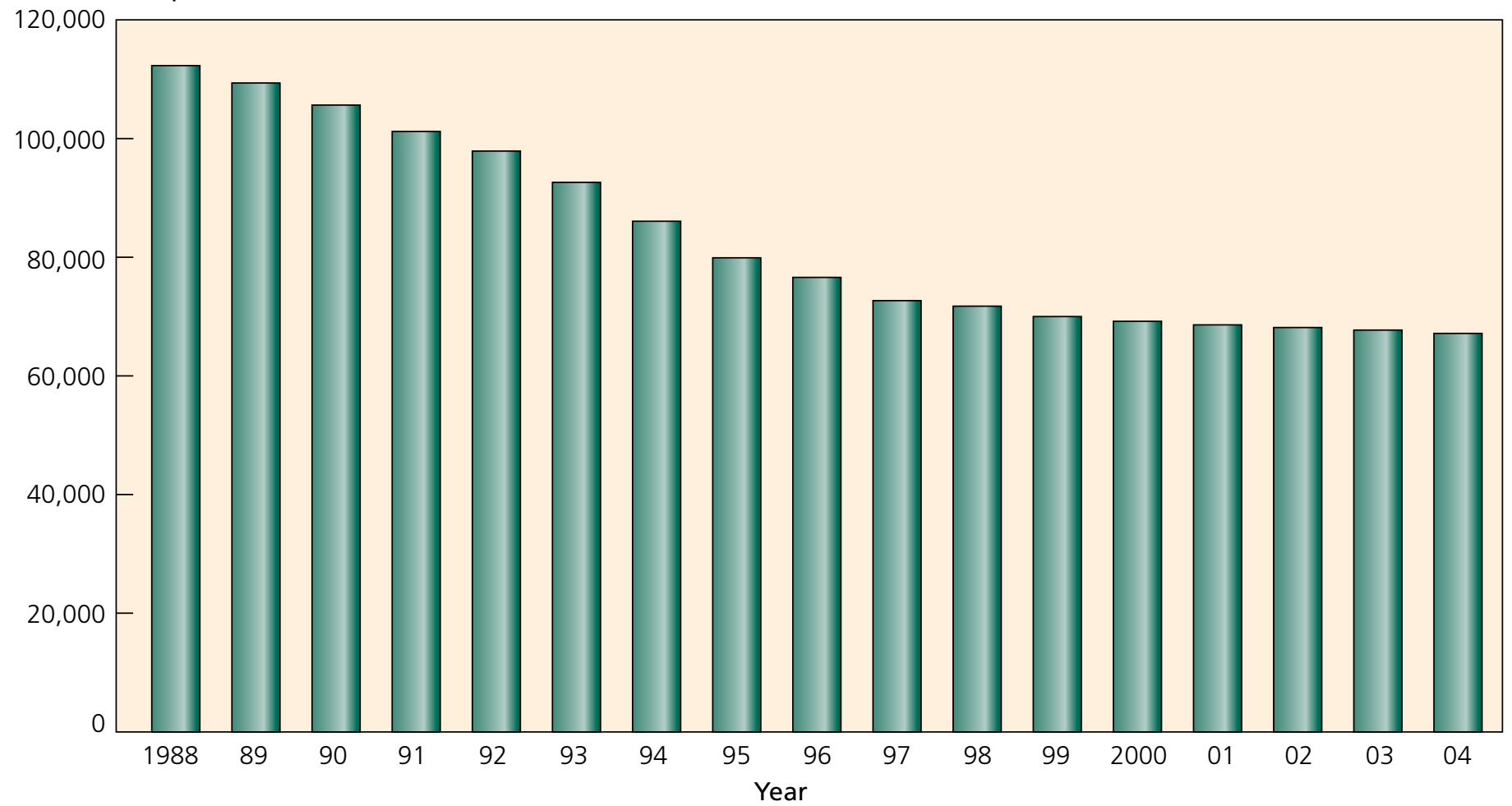

Source: USDA-NASS

Figure 13-Number of sheep operations in the United States, 1988-2004. 


\section{Poultry Industry}

Broiler production is concentrated heavily in the Nation's Southeastern States (map 8), whereas layers are dispersed more widely over the Central and Eastern States (map 9).

Turkey production is concentrated in the eastern half of the United States (map 10). Minnesota and North Carolina accounted for about a third of the total number of turkeys raised in 2004.

The broiler and layer industries are characterized by a relatively small number of large companies. USDA does not provide annual estimates of the number of companies or production sites. The broiler value of production accounted for more than two-thirds of the $\$ 28.9$ billion poultry industry in 2004. Egg production accounted for nearly one-fifth (18.4 percent) of the total value of production (table Al.9 in appendix 1).

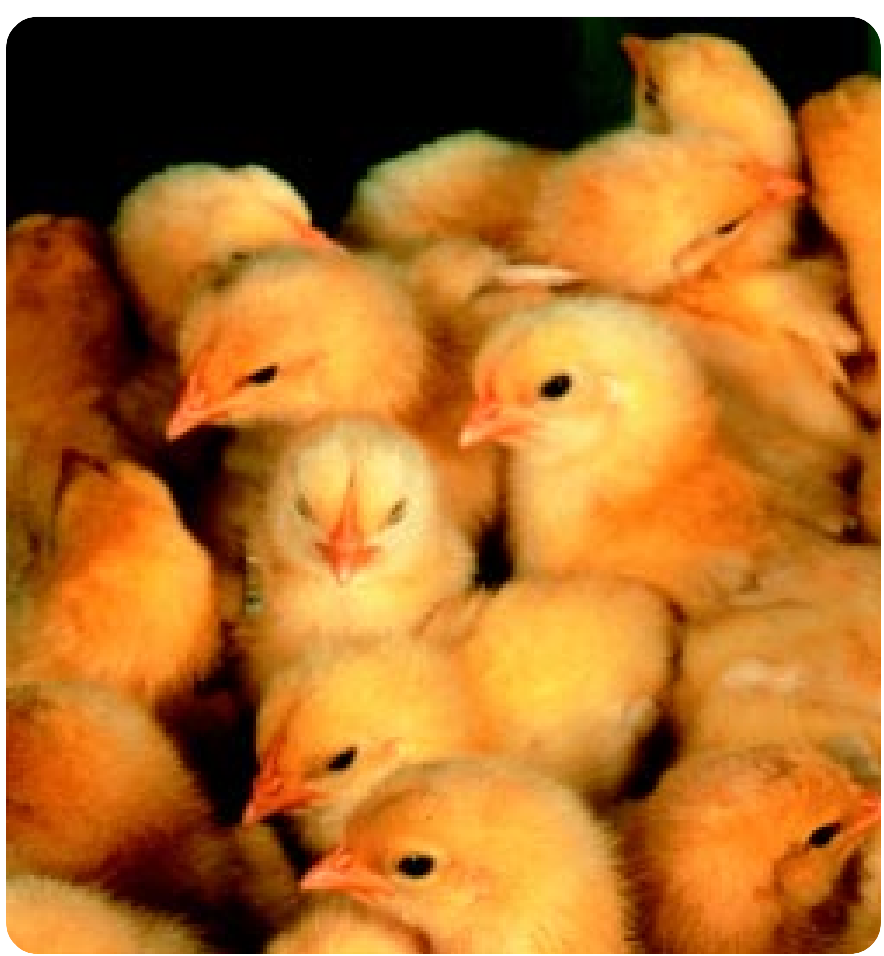

MAP 8

\section{Broilers and Other Meat-Type Chickens Sold: 2002}

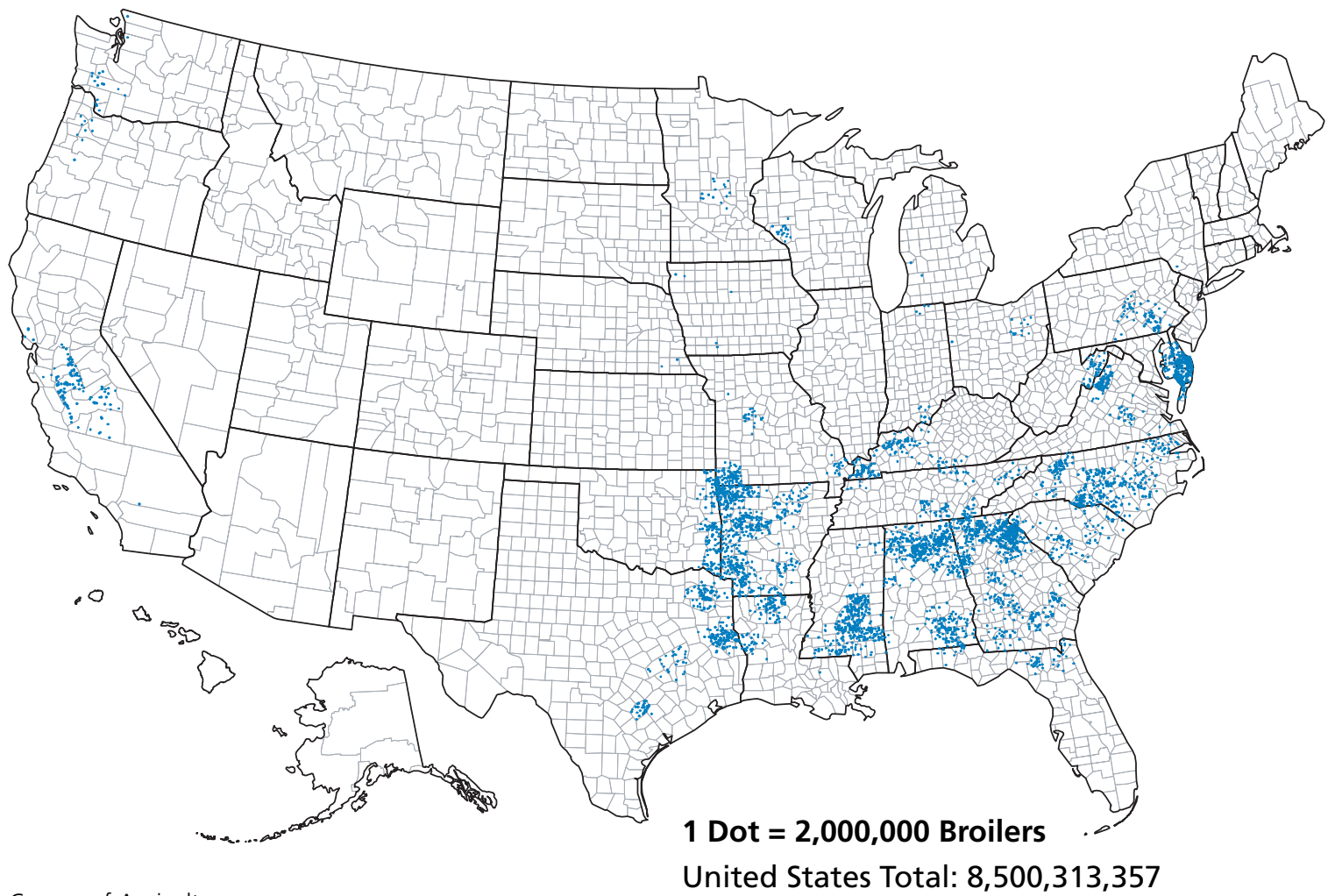




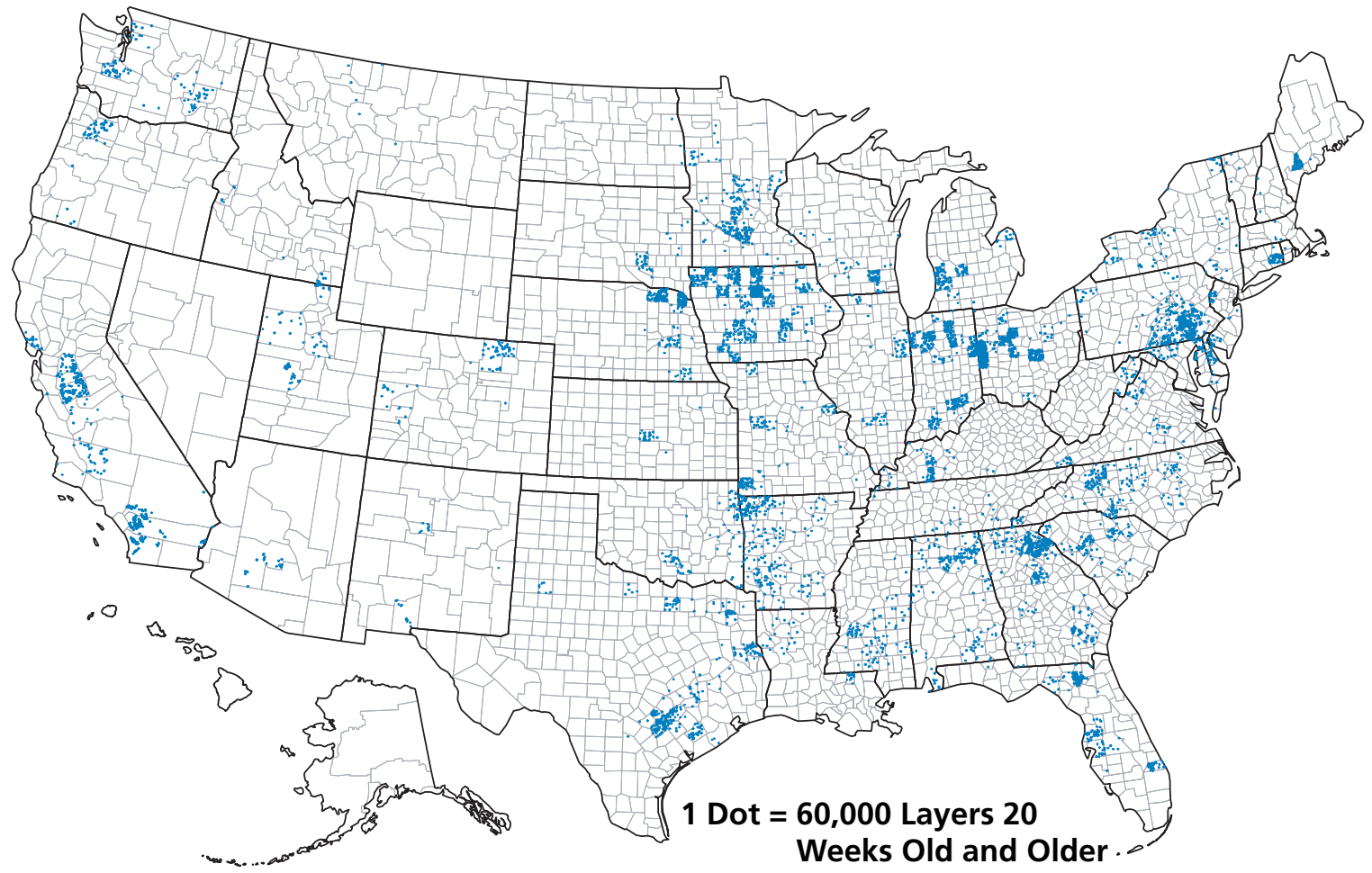

United States Total: 334,435,155

\section{MAP 10}

\section{Turkeys Sold: 2002}

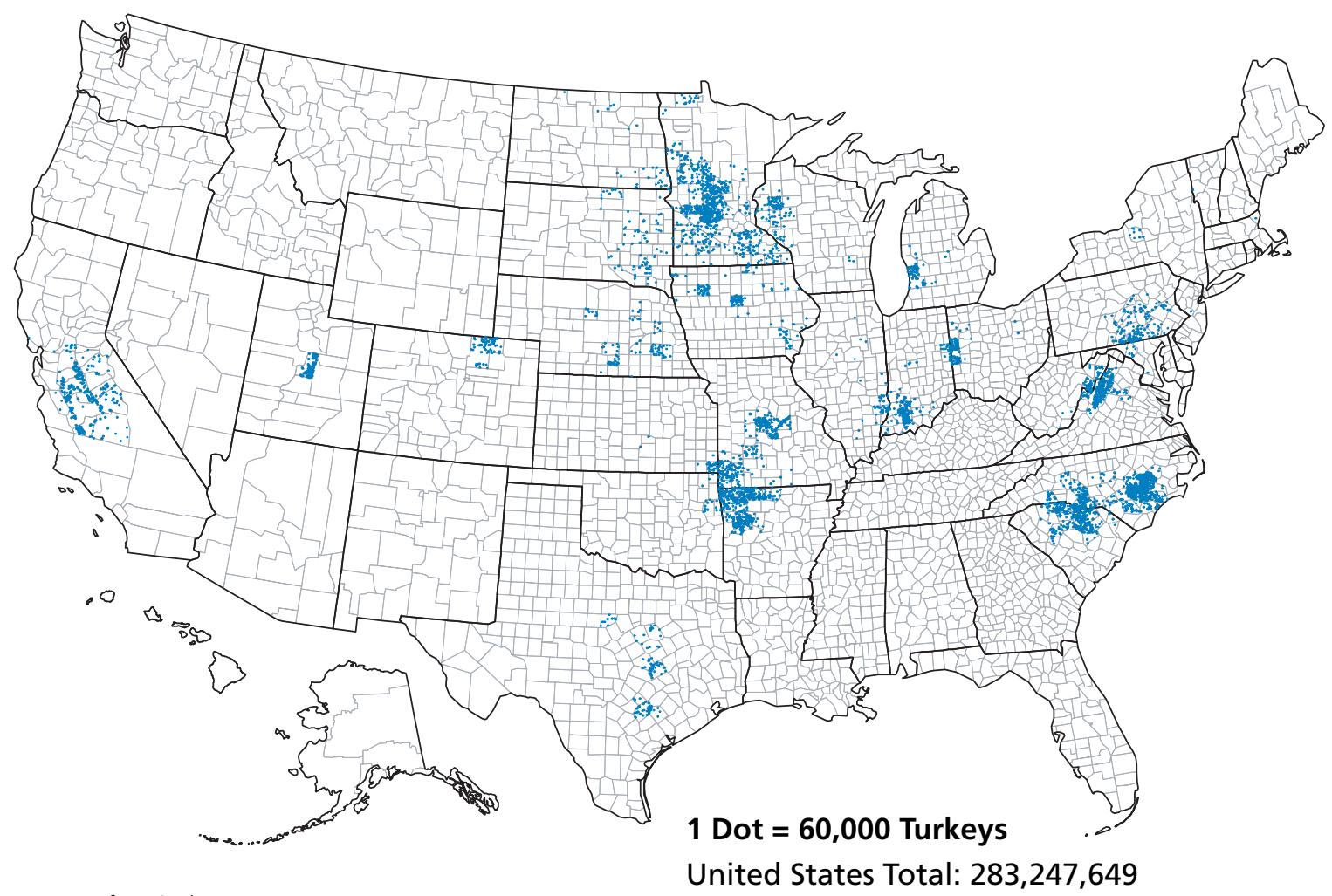




\section{Equine Industry}

Statistics on the demographics of the U.S. equine industry are sparse. USDA does not have an equine estimation program.

The 2002 Census of Agriculture showed 3.64 million horses and ponies reported from 542,223 farms. Map 11 illustrates the broad and even distribution of horses and ponies across the United States. The 2002 Census also reported 105,358 mules, burros, and donkeys located on 29,936 farms.
USDA published equine inventories located on all places (farms and nonfarms) for January 1, 1998, at 5.25 million head, and January 1, 1999, inventories of 5.32 million head (table Al.10 in appendix 1). In addition, it was estimated that 39.1 percent of the January 1, 1998, total was located on nonfarm locations. The value of sales was estimated at $\$ 1.64$ billion for 1997 and $\$ 1.75$ billion for 1998 .

There are no USDA published estimates for the number of operations with all types of equids and no information by size of operation for the United States.

MAP 11

\section{Horses and Ponies-Inventory: 2002}

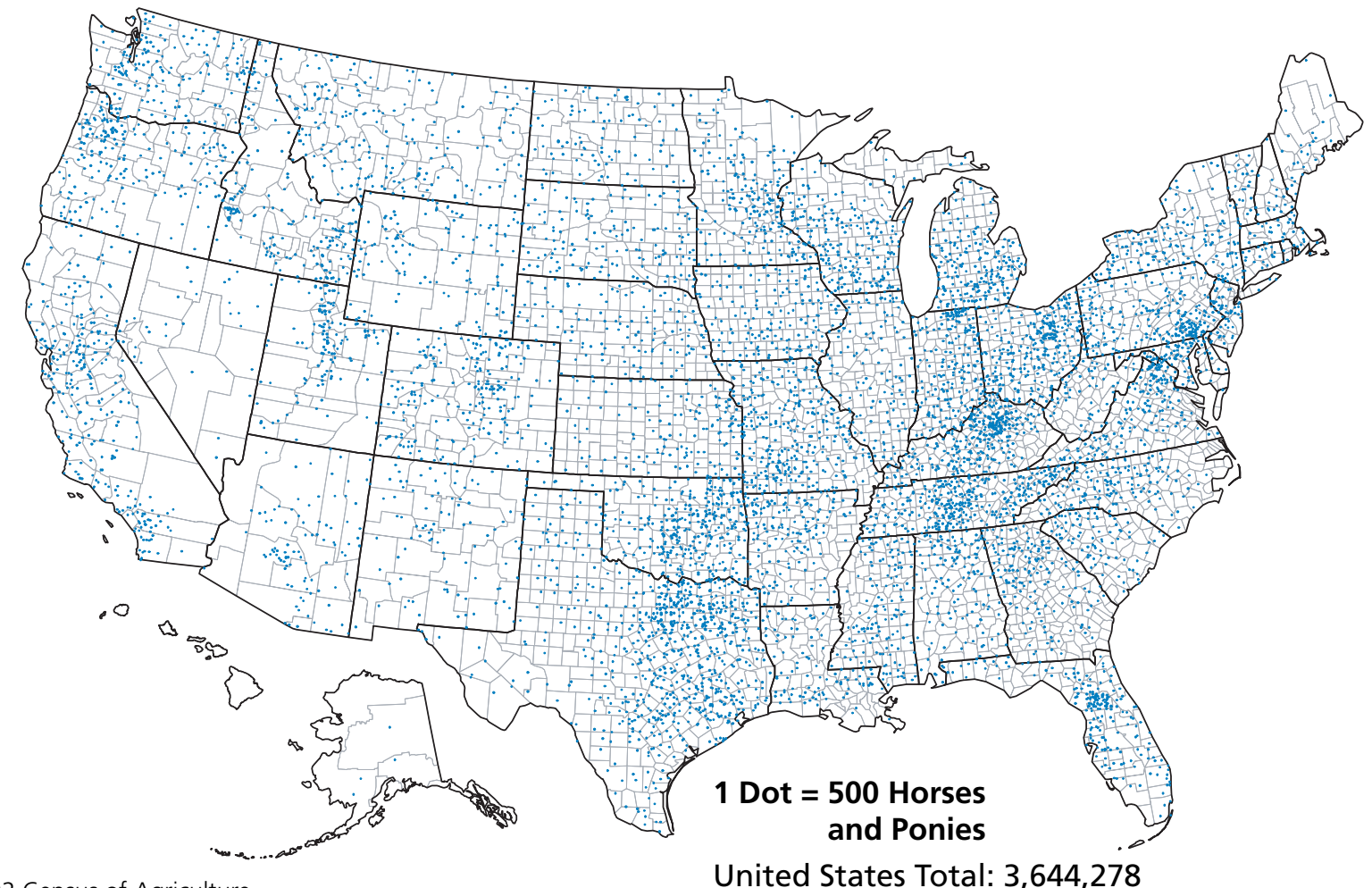

Source: 2002 Census of Agriculture

United States Total: 3,644,278

${ }^{1}$ Note: Data represented here do not include pleasure horses or equines for other purposes on nonfarm residences. 


\section{Fish and Other Aquaculture Products}

The 2002 Census of Agriculture estimated the value of fish and other aquaculture products sold at approxiimately $\$ 1.1$ billion. Combined catfish and trout sold accounted for 78.4 percent of the total pounds sold. Catfish production was concentrated (96.3 percent) in four Southern States: Alabama, Arkansas, Louisiana, and Mississippi. Mississippi accounted for 53.8 percent of total pounds of catfish sold. The total value of catfish sales for 2004 was $\$ 480.2$ million, which represents a 13-percent increase over the previous year (table Al.11 in appendix 1). Food-size catfish accounted for 93.9 percent of the total sales.

Trout production is dispersed more widely across the United States, and Idaho accounted for 34.7 percent of total pounds sold, followed by California at 10.1 percent and North Carolina at 10 percent. The total value of all trout sales, both fish and eggs, was $\$ 68.7$ million in 2004 - an increase of 7 percent from 2003.

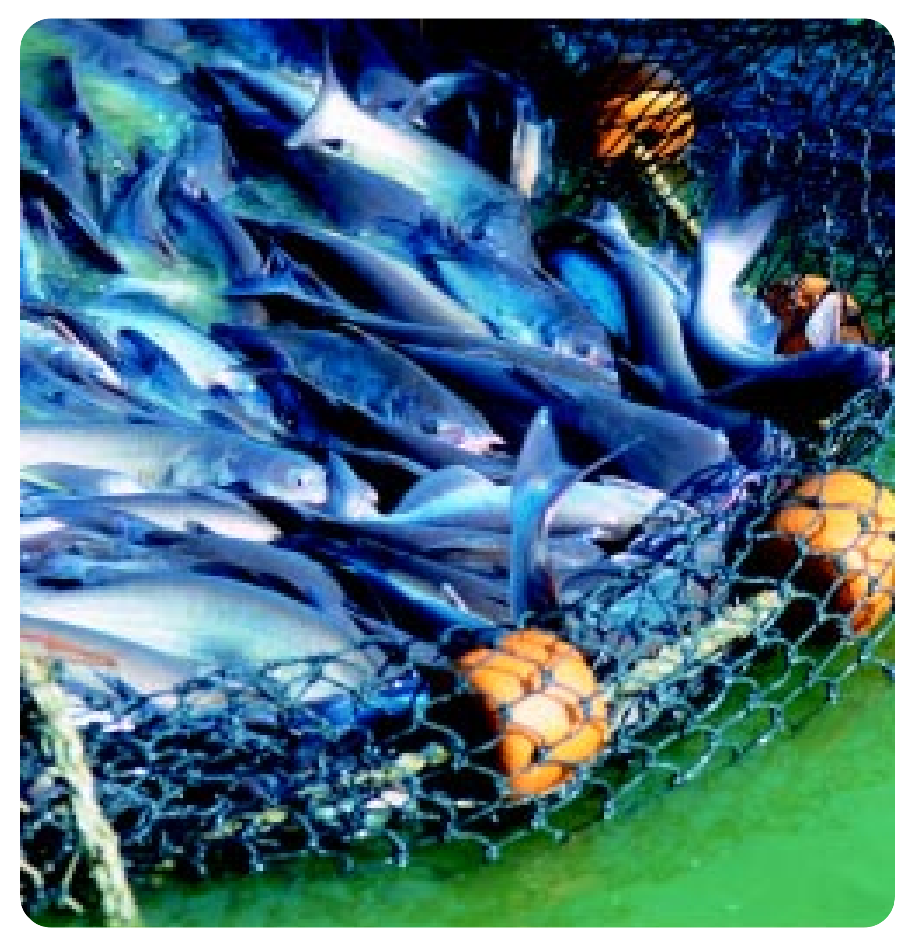

\section{Honey Production}

Honey production in 2004 from producers with five or more colonies totaled 183.6 million pounds, up 1 percent from 2003 (table Al.12 in appendix 1). This slight increase in production combined with a drop in honey prices resulted in a 2004 value of production of $\$ 201.8$ million, which is down 20 percent from the previous year. The distribution of honey production is rather widespread across the United States, although North Dakota and South Dakota accounted for 16.6 percent and 12.3 percent of the total, respectively.

\section{Miscellaneous}

The 2002 Census of Agriculture reported several miscellaneous livestock and poultry commodities (table Al.13 in appendix 1 ).

\section{Number of Livestock Slaughter Plants in the United States}

On January 1, 2005, there were 825 federally inspected U.S. slaughter plants (down from 855 plants on January 1, 2004). Federally inspected plants are those that transport meat interstate and must employ Federal inspectors to ensure compliance with USDA standards. During 2004, 689 plants slaughtered cattle (table Al.14 in appendix 1), and 13 of these plants accounted for more than 52 percent of the total cattle slaughtered. Five of the 234 plants that slaughtered calves accounted for 45 percent of the total, and 4 of the 500 plants that slaughtered sheep or lambs in 2004 produced 60 percent of the total. Hogs were slaughtered at 664 plants, 13 of which accounted for 58 percent of the total. Iowa, Kansas, Nebraska, and Texas accounted for more than 52 percent of the United States' commercial red-meat production in 2004 .

There were 2,116 State-inspected or custom-exempt slaughter plants in the United States on January 1 , 2005 , as compared with 2,239 plants on January 1 , 2004. State-inspected plants sell and transport animals exclusively intrastate. State inspectors ensure compliance with individual State standards as well as compliance with Federal meat and poultry inspection statutes. Custom-exempt plants do not sell meat but operate on a custom slaughter basis only. The animals and meat are not federally inspected, but the facilities must meet local health requirements. 
CHAPTER 3

\section{Animal Disease Eradication and Control and Certification Programs}

The following Veterinary Services (VS) programs are designed to eradicate, control, or prevent diseases that threaten the biological and commercial health of the U.S. livestock and poultry industries.

\section{Eradication Programs}

VS eradication programs include scrapie in sheep and goats, tuberculosis in cattle and cervids, pseudorabies in swine, and brucellosis in cattle and bison.

\section{Scrapie in Sheep and Goats}

Disease and Program History-Scrapie was first discovered in the United States in 1947 in a Michigan flock that had for several years imported sheep of British origin from Canada. The presence of scrapie in U.S. flocks is responsible for economic losses to producers due to lost export opportunities, increased disposal costs, and loss of byproduct sales.

Since 1952, VS has worked to control scrapie in the United States. As a result of increasing industry and public concern about transmissible spongiform encephalopathies (TSEs) and the discovery of new TSE diagnostic and control methods, VS initiated an accelerated scrapie eradication program in 2000.

Current Program - The primary aspects of the scrapie eradication program are animal identification, surveillance, tracing of positive and exposed animals, testing of sheep and goats in exposed flocks, cleanup of infected flocks, and certification of flocks.

Animal Identification-Identification of breeding sheep and culled breeding sheep is mandatory for movement off the premises. As of September 30, $2004,90,322$ sheep and/or goat premises were recorded in the scrapie national database. Of these premises, 64,040 requested and received official eartags (tags approved for use by the Animal and Plant Health Inspection Service [APHIS] in the official scrapie eradication program).

\section{Regulatory Scrapie Slaughter Surveillance}

(RSSS)-The RSSS program, initiated on April 1, 2003 , is the primary surveillance method for scrapie in the United States. RSSS identifies scrapie-infected flocks through targeted slaughter surveillance of types of sheep and goats that have been identified as having higher-than-average scrapie prevalence. These are defined as mature black- or mottle-faced sheep and any mature sheep or goat showing clinical signs that could be associated with scrapie, such as poor body condition, wool loss, or gait abnormalities. Only sheep with some sort of identification, such as USDA-approved eartags, electronic ID, backtags, and tattoos, are sampled. This arrangement allows for tracing positive animals back to the farm of origin.

During fiscal year (FY) 2004, as part of the RSSS program, 25,190 sheep and goats were tested for scrapie using immunohistochemistry on brain and/or lymphoid tissue. Of those animals, 85 were diagnosed as positive for scrapie. Tracebacks from positive animals led to 58 flocks; nearly 95 percent of these flocks had not been previously identified as having scrapie. Of the 85 positive animals, 72 were black-faced, 10 were mottle-faced, 2 were whitefaced, and 1 was unknown. Samples were collected from 34 slaughter plants in 16 States.

Under the scrapie program, positive animals are traced to their flock of origin, and the flock is placed under movement restrictions until all high-risk animals (genetically susceptible females) are removed. High-risk animals that had been moved from these flocks prior to being placed under movement restrictions are traced and tested.

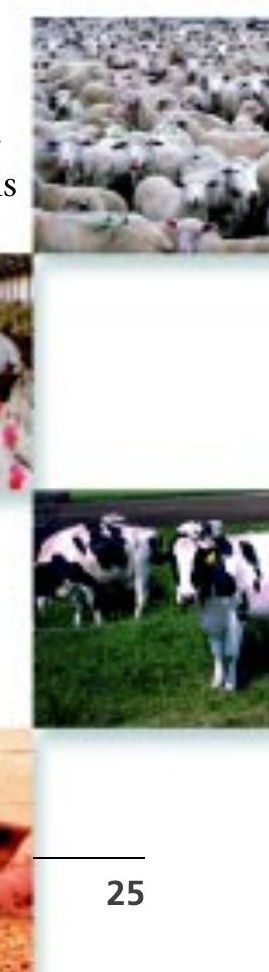


Testing Summary - In response to epidemiologic suspicions of disease, field veterinary medical officers conduct testing to determine if scrapie is present. Such cases are known as regulatory field cases. In addition to the 25,190 samples tested under the RSSS program in CY 2004, roughly 2,000 additional tests were conducted for scrapie, either by thirdeyelid testing or necropsy, in response to epidemiologic suspicions of disease.

Case and Infected Flock Summary-In FY 2004, 100 newly identified infected flocks were reported, and 368 scrapie cases were confirmed and reported by the National Veterinary Services Laboratories (table 3 ). Of the scrapie-infected or source flocks identified in FY 2004, 96 percent either tested negative and were released from movement restrictions or were put on flock plans to eliminate the disease. The other 4 percent remain in infected/source status and are still under movement restrictions. A flock plan is a strategy to reduce the risk of disease transmission within the flock. During FY 2004, 1 scrapie case in goats was reported.

Scrapie Flock Certification Program (SFCP)-The SFCP is a cooperative effort among producers, State and Federal animal health agencies, and industry representatives. Through the SFCP, a flock becomes certified if during a 5-year monitoring period no sheep in the flock is diagnosed with scrapie and no clinical evidence of scrapie is found in the flock. The program categories are described in the following paragraphs.

Complete Monitored Category-A flock in this category is approved to participate in the program.

There are two status levels for flocks in this category:

Enrolled flock: A flock entering the program is assigned enrolled status and becomes a "complete monitored enrolled flock."

TABLE 3

\begin{tabular}{l|c|c|}
\hline \multicolumn{3}{|c}{ Scrapie cases, FY $\mathbf{2 0 0 3}$ and FY $\mathbf{2 0 0 4}$} \\
\hline Test or examinations & $\begin{array}{c}\text { FY 2003 } \\
\text { (Number) }\end{array}$ & $\begin{array}{c}\text { FY 2004 } \\
\text { (Number) }\end{array}$ \\
\hline Regular necropsy & 249 & 248 \\
Validation necropsies & 66 & 48 \\
Regulatory third-eyelid & 32 & 18 \\
\hline RSSS & - & 54 \\
\hline Total & 347 & 368 \\
\hline
\end{tabular}

Certified flock: An enrolled flock that has met program standards for 5 consecutive years advances to certified status, meaning that it is unlikely to contain any sheep infected with scrapie.

Selective Monitored Category - This category, though open to any flock, was designed for producers of slaughter lambs to allow for scrapie surveillance in large production flocks. Only male animals over 1 year of age must have official identification. Producers agree to submit for scrapie diagnosis a portion of the mature animals that are culled or die, based on flock size. Additionally, an accredited veterinarian must inspect all cull ewes for clinical signs of scrapie before slaughter. Selective status is maintained indefinitely as long as the flock meets the category requirements.

Trends in Plan Enrollment-Enrollment in the SFCP has increased since 2002. As of September 30, 2004, 1,868 flocks were participating, and of these 135 were certified flocks (table 4 ). One possible reason for the increased number of certifications in 2004 was a change to the rules, which now allow rams from lower status flocks to be added to certified flocks.

Challenges-For the coming year, a major challenge is to improve methods for identifying and tracking sheep and goats through review and testing of available identification systems and integration with the National Animal Identification System. A second challenge is to upgrade the scrapie national database to improve data entry and analysis, which will lead to a better understanding of the impact the current program has on disease prevalence.

TABLE 4

\section{Scrapie Flock Certification Program} participation, 2002-04

\begin{tabular}{l|c|c|c|c|}
\hline $\begin{array}{l}\text { Fiscal } \\
\text { year, as } \\
\text { of 9/30 }\end{array}$ & Flocks & Enrolled & Certified & $\begin{array}{c}\text { Selective } \\
\text { Monitored }\end{array}$ \\
\hline 2002 & 1,539 & 1,452 & 78 & 9 \\
2003 & 1,776 & 1,663 & 105 & 8 \\
\hline 2004 & 1,868 & 1,726 & 135 & 7 \\
\hline
\end{tabular}




\section{Tuberculosis (TB) in Cattle and Cervids}

Disease and Program History-In the 1800s and early 1900s, bovine TB presented a significant health risk to people and caused considerable losses in the cattle industry. To reduce the effects of TB, the Federal Government created the Cooperative StateFederal Tuberculosis Eradication Program, initially implemented in 1917. This program is administered by U.S. Department of Agriculture-APHIS, State animal health agencies, and U.S. livestock producers.

Although TB prevalence reached very low levels in the 1990s, eradication has proved difficult. In 2000, a comprehensive Strategic Plan for the Eradication of Bovine Tuberculosis was announced in concert with an emergency declaration by the Secretary of Agriculture. A goal of final eradication was set for the end of 2003.

Current Program-In the current testing program, States, zones, or regions are classified into five categories based on prevalence of TB in cattle and bison herds (table 5). The publication "Bovine Tuberculosis Eradication: Uniform Methods and Rules" gives the minimum standards adopted and approved by the Deputy Administrator, VS-APHIS, on January 20, 2005 (<http://www.aphis.usda.gov/vs/nahps/tb/

TABLE 5

Tuberculosis accreditation categories and States in each category-end of calendar year 2004

\begin{tabular}{|c|c|c|}
\hline Category & Prevalence of TB & No. of States \\
\hline Accredited Free & $\begin{array}{l}\text { Zero for cattle } \\
\text { and bison }\end{array}$ & $\begin{array}{l}46 \text { U.S. States, } \\
\text { Puerto Rico, and } \\
\text { U.S. Virgin Islands }\end{array}$ \\
\hline $\begin{array}{l}\text { Modified } \\
\text { Accredited } \\
\text { Advanced }\end{array}$ & $\begin{array}{l}\text { Less than } 0.01 \\
\text { percent of total } \\
\text { cattle and bison } \\
\text { herds for each of } \\
\text { the } 2 \text { most } \\
\text { recent years }\end{array}$ & $\begin{array}{l}\text { Texas, California, } \\
\text { New Mexico, and } \\
\text { most Michigan } \\
\text { counties }\end{array}$ \\
\hline $\begin{array}{l}\text { Modified } \\
\text { Accredited }\end{array}$ & $\begin{array}{l}\text { Less than } 0.1 \\
\text { percent of the } \\
\text { cattle and bison } \\
\text { herds }\end{array}$ & $\begin{array}{l}11 \text { counties in } \\
\text { northern Lower } \\
\text { Michigan and parts } \\
\text { of } 2 \text { other counties }\end{array}$ \\
\hline $\begin{array}{l}\text { Accredited } \\
\text { Preparatory }\end{array}$ & $\begin{array}{l}\text { Less than } \mathbf{0 . 5} \\
\text { percent of the } \\
\text { total number of } \\
\text { cattle and bison } \\
\text { herds }\end{array}$ & - \\
\hline Nonaccredited & $\begin{array}{l}\text { Either unknown } \\
\text { or } \mathbf{0 . 5} \text { percent or } \\
\text { more of the total } \\
\text { number of cattle } \\
\text { and bison herds }\end{array}$ & - \\
\hline
\end{tabular}

tb-umr.pdf $>$ ). To retain or improve their status, States, zones, or regions must comply with reporting requirements (annually for Accredited Free and Modified Accredited Advanced, semiannually for Modified Accredited and Accredited Preparatory).

In addition, surveillance is conducted primarily through the collection and testing of suspicious granulomas at slaughter establishments.

Disease/Program Status: 2003-04-At the end of 2004, 46 U.S. States, Puerto Rico, and the U.S. Virgin Islands were considered Accredited TB Free (table 5). California, New Mexico, and Texas were classified as Modified Accredited Advanced. During FY 2004, Michigan was granted split-State status, with an area of northeastern Lower Michigan classified as Modified Accredited and the rest of the State classified as Modified Accredited Advanced.

Activities in specific States follow.

California-After being downgraded from Accredited TB Free status to Modified Accredited Advanced status in 2003, California completed a 3-county-area test of 691 herds comprising 886,504 individual animals. More than 13,000 head of cattle were destroyed during depopulation of the affected herds and for diagnostic necropsy examinations conducted on skin-test suspects and/or reactors in unaffected herds. California regained Accredited TB Free status in April 2005.

Michigan-Three of the six infected U.S. cattle herds discovered in 2004 were in Michigan. One beef herd and two dairy herds were identified in northeastern Lower Michigan as a result of area testing. The most probable source of these infections is spill-over to the cattle from an endemic infection in free-ranging white-tailed deer. In Michigan, several additional wildlife species have been infected with $\mathrm{TB}$, although the role these animals play in disease transmission remains unclear.

As of December 31, 2004, a total of 33 cattle herds and 1 captive cervid herd in Michigan had been identified as TB infected. These figures include three premises that were deemed reinfected following depopulation (and subsequent repopulation of the two beef herds) or completion of a test-and-remove program (one dairy herd). Annual surveillance and movement testing is conducted on the 1,100 herds located in the Modified Accredited zone; a random surveillance plan currently tests approximately 900 
herds throughout the Modified Accredited Advanced zone annually. Future Modified Accredited Advanced zone surveillance will be risk based (targeted) and will focus on herds in closer proximity to the area where TB is endemic.

Wild deer numbers have been reduced in the Modified Accredited zone, and the apparent prevalence of TB has decreased in recent years (based on surveillance of hunter-killed deer). Deer feeding and baiting are banned in seven counties in the northeastern portion of Michigan's Lower Peninsula to help reduce the spread of TB in deer. In the Modified Accredited zone, APHIS-Wildlife Services has constructed fences surrounding onfarm feed-storage areas to mitigate risk of TB transmission from deer to cattle. Movement restrictions (and subsequent testing) should diminish the risk of spreading $\mathrm{TB}$ from the endemic area (Modified Accredited zone) of Michigan to other parts of the State. Michigan will soon require official (State) identification for all cattle movement (including to slaughter), and the State has recently applied for TB-Free status for the Upper Peninsula.

New Mexico and Arizona-During 2004, two newly affected premises were discovered at dairy-calf growing operations in New Mexico and Arizona. The affected herd in Arizona was detected through interstate testing requirements. The New Mexico herd was found via traceback from the infected animal in the Arizona herd. Such premises pose substantial problems for the national TB program. Differences among operations in identification and records systems of young dairy heifers and steers have hindered epidemiologic tracing of infected and exposed cattle in these investigations. Both of these dairy-calf operations are responsible for supplying commercial dairies with large numbers of replacement heifers throughout the United States.

A plan to test all dairies in eastern New Mexico, beef herds within a 3 -mile radius of affected premises, dairies with epidemiologic links to the affected premises, and dairies that supplied a significant number of calves or that received any calves from the dairycalf raising facility was formulated and implemented in 2003 and 2004. By September 2004, 65 dairies and all the targeted beef herds had been tested (approximately 110,000 head) without identifying additional affected herds. New Mexico is also developing a request to regionalize the State because neither of its affected dairies has opted for depopulation.
Texas-One newly affected dairy was found in Texas during that State's massive active surveillance project during 2004. In late 2002, Texas adopted a TB eradication strategy that included five critical elements designed to enhance case-finding surveillance and to mitigate the risk of continuing exposure from outside sources. By early October of 2004, Texas had tested all of its dairies (772 herds with 334,947 animals) and 330 purebred beef herds $(31,852$ animals) for a total of 1,102 herds and 366,799 cattle. This testing disclosed a single infected animal in a 1,500-head dairy herd, which was depopulated.

Slaughter Surveillance-During the last 4 years, granuloma submissions collected at slaughter increased from 1,028 in 2000 to 6,367 in 2004. Of the 6,367 total samples in $2004,5,326$ (83.7 percent) came from 5.73 million adult cattle killed in 100 plants. These plants accounted for 99 percent of all adult cattle killed in FY 2004. The national granuloma submission rate for adult cattle at the end of 2004 was 9.29 submissions per 10,000 adult cattle killed. This rate represents a continued improvement in adult-cattle submission rates as compared to adultcattle rates in past years.

Cervids-There were no TB-infected captive or farmed cervid herds found in 2000 and 2001; three were found in 2002, none in 2003, but one was discovered in 2004 . These numbers are encouraging, considering that a total of 41 infected cervid herds have been disclosed in the United States since 1991, and only 4 infected herds have been found this century. Of those affected herds, 30 were depopulated (including the herd found in 2004) and 11 were tested and qualified for release from quarantine. In $2004, T B$ recurred in 1 of the 11 herds released from quarantine. That herd was depopulated, as noted above.

During 2004, a working group of State and Federal personnel developed a surveillance plan for captive cervids that was presented to, and conditionally approved by, cervid industry leadership. This surveillance plan is integral to the TB eradication program's designation of any individual State's TB status. The plan outlines necessary procedures for achieving and advancing through the different TB status levels (e.g., Modified Accredited to Accredited Free). Implementation of the plan awaits completion of a Uniform Methods and Rules (UM\&R) for cervids. 
Challenges-The target for slaughter surveillance is 10,000 granuloma submissions per year from cattle. Slaughter surveillance coverage continues to improve, with increasing numbers of granuloma submissions.

Despite enhanced efforts and funding, the goal of TB eradication from cattle, bison, and cervids by the end of 2003 was not achieved. As 2004 began, a number of factors were disconcerting to State-Federal livestock health officials and industry stakeholders: the loss of TB-Free status in California, New Mexico, and Texas; lack of further improvement regarding the wildlife reservoir in Michigan; concerns that lines of dairy replacement heifers were being infected at a low but continuous level; and low sampling rates of TBsuspicious lesions at some major adult-animal slaughter plants. Consequently, the USDA-APHISVS Comprehensive Strategic Plan for the Eradication of Bovine Tuberculosis is being updated.

\section{Pseudorabies in Swine}

Disease and Program History-Until 1962, in the United States pseudorabies virus (PRV) was considered to cause a mild and often subclinical infection, except in baby pigs. However, in 1962 a virulent strain of PRV appeared in Indiana and spread across pig farms in the Midwest. By the mid-1970s, pseudorabies was widespread with concentrated outbreaks in the Midwest's major pork-producing States. Pork producers demanded that infected herds be quarantined and that movement of infected pigs be controlled. As a result, States without pseudorabies wanted to be classified as PRV free to facilitate the interstate movement of their hogs.

The Livestock Conservation Institute (now the $\mathrm{Na}$ tional Institute for Animal Agriculture) set up a task force in the 1980s that defined two State stages and established the National Pseudorabies Control Board to oversee the stages and determine the status of each State. In 1989, USDA-APHIS published the program standards for an eradication plan.

The main goal of the program was to eradicate pseudorabies from domestic commercial production swine by 2000 . By 1999, the U.S. infection rate was down to less than 1 percent of all swine herds, or about 1,000 herds. With the market for pork severely depressed in 1999, the Accelerated Pseudorabies Eradication Program was established to remove the last infected domestic commercial herds, through depopulation, by the end of 2004 .
Current Program-Conducted in cooperation with State governments and swine producers, the National Pseudorabies Eradication Program eradicated pseudorabies from domestic commercial herds in all States, Puerto Rico, and the U.S. Virgin Islands by the end of 2004. Pseudorabies program measures (see <http://www.aphis.usda.gov/vs/nahps/pseudorabies $>$ ) are based on prevention, vaccination (now largely discontinued), disease surveillance, and eradication, and primary activities include surveillance, herd certification, and herd cleanup. These are minimum standards developed by VS and endorsed by swine health practitioners and State animal health officials in cooperation with the United States Animal Health Association (USAHA). Active surveillance components include testing market and cull swine, breeding animals moved interstate, imported breeding swine, and feral and transitional swine being moved. Transitional swine are defined as captured feral swine or domestic swine in contact (or potentially in contact) with feral swine. The program also has passive and outbreak surveillance components. If an infected swine herd is identified, pseudorabies is eliminated by complete depopulation, as documented in the Pseudorabies Program Standards (see <http:// www.aphis.usda.gov/vs/nahps/pseudorabies $>$ ).

There are five stages in the eradication program, beginning with a preparatory phase in stage I and culminating in the pseudorabies-free stage V. States in stages I, II, or III demonstrate progress in herd cleanup consistent with the goal of eradication. Stage I status applies to States for 24 to 28 months. States in stages II, III, IV, and V must be recertified at 12 to 14-month intervals.

Disease Status: 2003-04-In FY 2004, all 50 States, Puerto Rico, and the Virgin Islands filed with the PRV control board to renew their status or apply for improved status. These filings were analyzed to ensure testing of the breeding herd population was adequate and that the feral-transitional swine management plan was complete, as required by pseudorabies program standards.

As of December 31, 2004, there were no known domestic production swine herds infected with PRV in the United States. Nationally, eight transitional herds were disclosed through surveillance as infected with PRV during 2004.

Challenges-The greatest challenge to eliminating $\mathrm{PRV}$ is the sporadic appearance of the virus in feral 
pigs, as well as small domestic herds (primarily in the South) that are exposed to feral swine. An estimated 3 million feral swine are located in at least 30 States.

\section{Brucellosis in Cattle and Bison}

Disease and Program History-Since 1934, the goal of the Cooperative State-Federal Brucellosis Eradication Program has been to eliminate brucellosis from the domestic livestock population of the United States. The program's UM\&R sets forth minimum standards for States to achieve eradication (for details, see <http://www.aphis.usda.gov/vs/nahps/brucellosis $>$ ).

In 1957, testing disclosed 124,000 brucellosis-infected cattle herds in the United States. By 1992, only 700 herds were known to be affected, and as of December 31, 2004, there was only 1 known brucellosis-affected domestic cattle herd under quarantine.

Current Program-The brucellosis eradication program is based on active surveillance of cattle and bison herds by State. States are designated brucellosis free when none of their cattle or bison is found to be infected for 12 consecutive months while under an active surveillance program.

The Market Cattle Identification (MCI) program and the Brucellosis Ring Test (BRT) are the two main components of the national brucellosis surveillance program. Each State is required to maintain surveillance at certain levels to maintain its brucellosis State status (see table 6). Each State must test at least 95 percent of test-eligible cattle (cows and bulls 2 years of age and older) going to slaughter, with at least 90percent traceback of any animals that respond positively to testing (reactors) and successful case closure on at least 95 percent of these tracebacks. These specifications apply to both Class Free and Class A States. BRT surveillance must be conducted at least two times per year in all commercial dairy herds in Class Free States and at least four times per year in Class A States. In addition, Class A States must conduct first-point testing (market testing).

Disease Status: 2004-As of December 31, 2004, 48 States, Puerto Rico, and the U.S. Virgin Islands were officially declared free of brucellosis (table 6). Two States-Texas and Wyoming - had an infection rate of less than 0.10 percent and earned Class A status. Texas achieved Class A State status in August 1994 and has been working to attain Class Free State status. Wyoming lost its Class Free State status in
TABLE 6

\begin{tabular}{|c|c|c|}
\hline Category & Infection rate & No. of States \\
\hline $\begin{array}{l}\text { Brucellosis } \\
\text { free }\end{array}$ & $\begin{array}{l}\text { No cattle or bison } \\
\text { found to be infected } \\
\text { for } 12 \text { consecutive } \\
\text { months while under } \\
\text { an active surveillance } \\
\text { program }\end{array}$ & $\begin{array}{l}48 \text { States, Puerto } \\
\text { Rico, U.S. Virgin } \\
\text { Islands }\end{array}$ \\
\hline Class A & $\begin{array}{l}\text { Herd infection rate } \\
\text { less than } 0.10 \\
\text { percent. [1 herd } \\
\text { per } 1,000]\end{array}$ & $\begin{array}{l}2 \text { (Texas and } \\
\text { Wyoming) }\end{array}$ \\
\hline Class B & $\begin{array}{l}\text { Herd infection rate } \\
\text { between } 0.10 \text { percent } \\
\text { and } 1.0 \text { percent }\end{array}$ & 0 \\
\hline
\end{tabular}

Note: States or areas not having at least Class B status are considered 'No Status.'

February 2004 after the disclosure of a second brucellosis-affected herd within a 12-month (consecutive) period of time. Missouri qualified for Class Free State status in February 2004.

During 2004, Missouri had one brucellosis-affected herd, Texas had one affected herd, and Wyoming had three affected herds. The herd in Missouri was immediately depopulated and a thorough epidemiologic investigation-including area, contact, and trace herd testing-was successfully completed within the 60day requirement. No additional brucellosis-affected herds were found; therefore, according to program regulations, Missouri maintained its Class Free State status.

The program regulations stipulate that if a single affected herd is found in a Class Free State, the State may retain its Class Free status if it meets two conditions, which must be satisfied within 60 days of the identification of the affected animal. First, the affected herd must be immediately quarantined, tested for brucellosis, and depopulated as soon as practicable. Second, an epidemiologic investigation must be performed, and the investigation must confirm that brucellosis has not spread from the affected herd. All adjacent herds, source herds, and contact herds must be epidemiologically investigated, and each of those herds must receive a complete herd test with negative results.

Texas disclosed a brucellosis-affected herd in August 2004. This herd was not depopulated and remains under quarantine pending completion of the required 


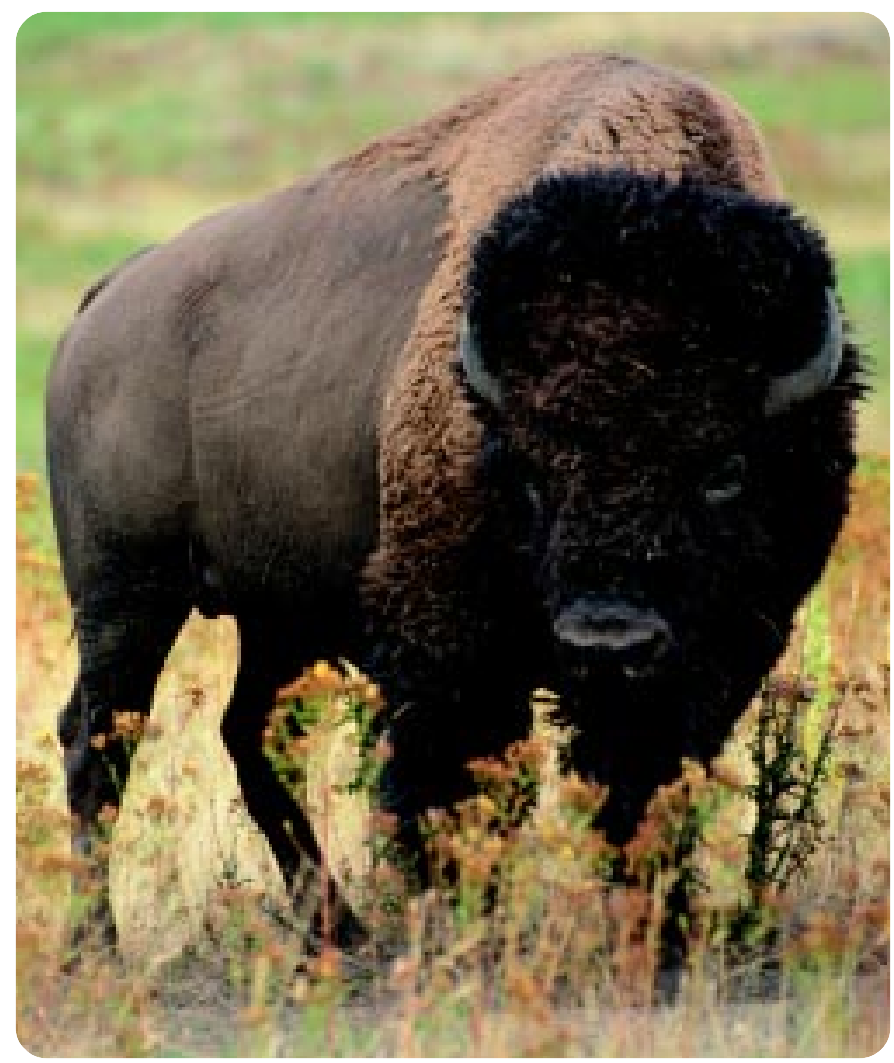

number of negative herd tests and completion of the epidemiologic investigation.

The three brucellosis-affected herds disclosed in Wyoming were all depopulated. These three herds likely became infected through exposure to freeranging elk and bison herds in the greater Yellowstone area that are known to be infected with brucellosis. In one case, DNA fingerprinting of Brucella culture from the infected cattle matched the DNA fingerprinting of Brucella cultures from the elk herd in adjacent elk feeding grounds. Wyoming is working to regain its brucellosis Class Free State status.

Approximately 9.1 million cattle were tested for brucellosis in FY 2004. Of these, approximately 770,500 (8.5 percent) were sampled on farms or ranches and about 8.3 million (91.5 percent) were tested under the MCI program.

MCI surveillance continues to be effective in finding reactor animals; new affected herds have been identified primarily through market testing. Of the 8.3 million MCI blood tests conducted in FY 2004, approximately 5.5 million samples $(66.3$ percent $)$ were collected at slaughter plants, and approximately 2.8 million (33.7 percent) were collected during firstpoint testing at livestock markets. First-point testing at markets is conducted primarily in the Nation's Central and Southern regions, where the majority of States that have recently attained Class Free status and one Class A State are located. Class A States are required to conduct first-point testing as part of their efforts toward achieving Class Free status.

Surveillance using the brucellosis milk surveillance test detected no brucellosis-affected dairy herds in FY 2004. Based on available data, 200 suspicious BRT laboratory reports resulted in 65 herds being bloodtested for a herd blood-test rate of approximately 32.5 percent. Repetitive BRTs were conducted in the majority of herds not blood-tested. Negative repetitive BRTs and epidemiologic investigations revealing no evidence of infection in the herd led to successful closures on these cases. Other herdsuspicious brucellosis milk surveillance tests were mainly the result of Brucella abortus Strain 19 vaccination titers.

About 4.04 million calves were vaccinated for brucellosis with RB51 in FY 2004. Approximately 10,100 head of adult cattle were vaccinated in FY 2004 pursuant to the finding of affected herds in the area.

Challenges-The only known focus of Brucella abortus infection left in the Nation is in bison and elk in Yellowstone. APHIS is cooperating with State and Federal agencies to implement a bison management plan that will maintain a wild, free-ranging bison population while minimizing the risk of transmitting brucellosis from bison to domestic cattle on public and private lands in Montana adjacent to Yellowstone National Park. The U.S. Department of the Interior; the States of Idaho, Montana, and Wyoming; and USDA agreed in a Memorandum of Understanding to the goal of eliminating brucellosis from the greater Yellowstone area while maintaining a free-roaming bison herd. The Record of Decision for Final Environmental Impact Statement and Bison Management Plan for the State of Montana and Yellowstone National Park was signed on December 20, 2000.

APHIS has assisted Wyoming with funding to vaccinate elk on elk feeding grounds in an effort to reduce the prevalence of brucellosis. APHIS has also provided funds for habitat improvement to keep elk dispersed and away from cattle and feeding grounds. Eliminating brucellosis from elk and bison remains a high priority of APHIS. Efforts to develop new, safe, and effective vaccines as well as vaccine-delivery systems for bison and elk are continuing. 


\section{Control Programs}

\section{Chronic Wasting Disease (CWD) in Cervids}

Disease and Program History-First recognized in 1967 as a clinical "wasting" syndrome in mule deer at a wildlife research facility in northern Colorado, CWD was identified as a TSE in 1978. There is no known relationship between CWD, which occurs in cervids, and any other TSE of animals or people.

In the mid-1980s, CWD was detected in free-ranging deer and elk in contiguous areas of northeastern Colorado and southeastern Wyoming. In May 1999, CWD also was found in free-ranging deer in the southwestern corner of Nebraska (adjacent to Colorado and Wyoming) and later in other areas in western Nebraska. Since 2002, CWD also has been detected in wild deer in south-central Wisconsin, southwestern South Dakota, the western slope of the Rocky Mountains in Colorado, southern New Mexico, northern Illinois, and eastern and central Utah.

The first CWD-positive farmed elk herd in the United States was detected in 1997 in South Dakota. Through December 31, 2004, 28 additional CWDpositive farmed elk herds and $5 \mathrm{CWD}$-positive farmed deer herds have been found, for a total of 34 infected farmed cervid herds.

Current Program-APHIS-VS and State CWD surveillance in farmed animals began in late 1997 and has increased each year since. APHIS-VS pays laboratory costs for all surveillance testing of farmed cervids. Responses to onfarm CWD-positive cases include depopulation or quarantine. Additionally, VS conducts traceforward and traceback epidemiologic investigations.

A proposed rule for a CWD herd-certification program for farmed-cervid operations was published for comment in the Federal Register on December 24, 2003. Program goals are to control and eventually eradicate CWD from farmed cervid herds. The program proposes to certify herds that demonstrate 5 years of CWD surveillance with no evidence of disease. The proposed program requirements include fencing, identification, inventory, and surveillance. The rule proposes to limit interstate movement of farmed cervids to herds enrolled in the herd-certification program. State programs meeting or exceeding
Federal standards will be included in the Federal program. This program will be implemented in 2005 .

APHIS-VS also has supported CWD surveillance in wildlife since 1997. Since the national "Plan for Assisting States, Federal Agencies, and Tribes in Managing Chronic Wasting Disease in Wild and Captive Cervids" was adopted in June 2002, APHIS-VS has cooperated with the International Association of Fish and Wildlife Agencies to promote uniform, nationwide surveillance while allowing flexibility to meet individual State situations and needs.

In FY 2003, the CWD program received line-item funding, which allowed APHIS-VS to participate in the development of CWD surveillance plans and to pay testing costs for more than 90,000 samples collected nationwide during the 2002-03 hunting season. In that same fiscal year, APHIS-VS provided CWD-related funding for the 2003-04 hunting season through cooperative agreements. Most of the cooperative agreements were with the States' wildlife agencies, and 50 States received funding. Final reports are being received now, so the total numbers of animals and samples tested have not yet been compiled.

In FY 2004, funds were available for similar agreements and, again, all 50 States took advantage of the cooperative agreement funding. APHIS also provided funds to Native American tribes to hire regional tribal biologists and to assist individual tribes with CWD activities.

Disease Status: 2003-04-From 1997 through 2004, CWD had been found in 29 farmed elk herds and 5 farmed deer herds. Of these 34 herds, 7 were in South Dakota, 4 in Nebraska, 12 in Colorado, 1 in Oklahoma, 1 in Kansas, 2 in Minnesota, 1 in Montana, and 6 in Wisconsin. More than 12,000 animals were tested in FY 2003, and more than 15,000 animals were tested in FY 2004.

Of the 34 positive herds identified as of December 31, 2004, 3 remained under State quarantine and 30 had been depopulated. The quarantine was lifted from one herd that underwent rigorous surveillance for over 5 years with no further evidence of disease.

Challenges-The key challenges in managing CWD result from the fact that cervids fall under multiple jurisdictions. In 2002, at the request of Congress, an interagency group was convened to develop a management plan to assist States, Federal agencies, and 
Native American tribes in managing CWD in captive and wild herds. Currently, this plan is implemented by State and Federal agencies, as budgets permit. A progress report on the implementation of the plan was completed and presented to Congress in May 2004.

Additional challenges are related to the difficulties associated with the testing of wild cervids. High sample throughput and more rapid test technology were needed to meet the needs of wildlife agencies. By expanding its contract group of State and university laboratories, NVSL now have 26 laboratories approved to conduct CWD testing. In addition, the Center for Veterinary Biologics has approved four CWD antigen test kits based on enzyme-linked immunosorbent assay (ELISA), allowing faster testing and greater throughput for surveillance testing of wild cervids.

\section{Johne's Disease in Cattle}

Disease and Program History-Bovine paratuberculosis (Johne's disease) is caused by the bacterium Mycobacterium avium subspecies paratuberculosis (MAP). In addition to cattle and other ruminants, many species of domestic and wild animals worldwide have been diagnosed with Johne's disease. Clinical signs of Johne's disease include decreased milk production, weight loss, and diarrhea.

In 1993, USAHA proposed a Johne's disease herdcertification program. However, because of the costs associated with testing all animals in a herd and other issues, the program was not adopted. In 1997, the USAHA's national Johne's disease working group appointed a committee to design a more affordable and flexible program based on sound scientific knowledge. The result was the U.S. Voluntary Johne's Disease Herd Status Program for cattle. Instead of trying to certify herds free of Johne's disease, the program provides minimum requirements to identify low-risk herds. These guidelines were used as a model for the Uniform Program Standards of the Voluntary Bovine Johne's Disease Control Program (VBJDCP) approved by VS in 2002 (see <http://www.aphis.usda.gov/vs/nahps/johnes/ johnes-umr.pdf $>$ ).

Current Program - The VBJDCP is a cooperative State-Federal-industry effort administered by States and supported by the Federal Government and industry. The program's objective is to provide national standards for controlling Johne's disease. The program has three basic elements:

1. Educating producers about the cost of Johne's disease and providing information about management strategies that prevent, control, or eliminate it; 2 . Working with producers to establish good management strategies on their farms; and

3. Herd testing and classification to help separate test-positive herds from test-negative herds. Herd classification is determined by the number and years of testing for MAP, the causative agent of Johne's disease, in the herd.

The goal of the VBJDCP is to reduce the spread of MAP to noninfected herds and reduce disease prevalence in infected herds.

Program Status: 2003-04-There are 43 States that participate fully in the VBJDCP. More than 970 herds have been enrolled in the test-negative component of the program. More than 6,100 herds have enrolled in the Johne's disease control program. There are 45 States with laboratories approved for Johne's disease serology testing, and 34 States have laboratories approved for MAP fecal culture or DNA testing. In 2004, these laboratories conducted 673,299 ELISA tests and 101,786 fecal cultures (table 7).

Challenges-Increasing and maintaining producer participation in the VBJDCP is difficult for several reasons. Because firm data on the true economic costs of the disease are unavailable, many producers are reluctant to spend large amounts of money without knowing the benefits. Additionally, discrepant

TABLE 7

\begin{tabular}{l|r|r|r|r}
\hline Johne's disease control program statistics, 2000-04 & \multicolumn{3}{c}{ Year } \\
\hline Number & $\mathbf{2 0 0 0}$ & $\mathbf{2 0 0 1}$ & $\mathbf{2 0 0 2}$ & $\mathbf{2 0 0 3}$ \\
\hline States in full compliance with VBJDCP & NA & NA & 22 & 35 \\
\hline Herds in Johne's control programs & 1,952 & 1,925 & 3,248 & 3,268 \\
\hline Johne's test-negative herds & 390 & 514 & 631 & 5,189 \\
\hline ELISA tests performed & 359,601 & 342,045 & 592,350 & 480,586 \\
\hline Cultures performed & 44,961 & 43,218 & 98,094 & 96,222 \\
\hline
\end{tabular}


test results can be confusing and become a deterrent for producers not familiar with the disease and testing issues.

\section{Trichinae in Swine}

Disease and Program History-In the mid-1980s, three factors provided a powerful rationale for developing industry-supported programs to improve food safety in the U.S. pork industry. First, the prevalence of Trichinella in U.S. swine had reached such a low level (less than 1 percent) that disease-free status could be envisioned. Second, U.S. pork industry leaders recognized that international markets were closed to U.S. pork products because of the inaccurate perception that U.S.-produced pork had a comparatively high risk of harboring Trichinella spiralis. Finally, the development of a rapid, ELISAbased diagnostic test provided a relatively inexpensive tool that could be used for verification testing in a control program.

In the United States, the prevalence of T. spiralis in pigs has dropped sharply due to changes in swine production practices. The National Animal Health Monitoring System (NAHMS) 1990 National Swine Survey and Swine '95 study reported T. spiralis infection rates in the United States of 0.16 percent and 0.013 percent, respectively. The NAHMS Swine 2000 study reported a 0.007 percent infection rate. Because modern pork-production systems have all but eliminated trichinae as a food-safety risk, alternatives to individual carcass testing to demonstrate that pork is free of T. spiralis were explored via trichinae pilot programs.

Current Program-The U.S. Trichinae Certification Program (USTCP), initiated as a pilot program in 1997, is based on scientific knowledge of T. spiralis epidemiology and numerous studies demonstrating how specific "good production practices" can prevent pigs' exposure to this zoonotic parasite. The program is consistent with recommended methods for control of Trichinella in domestic pigs, as described by the International Commission on Trichinellosis.

Three USDA agencies-APHIS, Food Safety and Inspection Service (FSIS), and Agricultural Marketing Service (AMS) - collaborate to verify that certified pork-production sites manage and produce pigs according to the requirements of the program's "good production practices." USDA also verifies the identity of pork from the certified production unit through slaughter and processing.

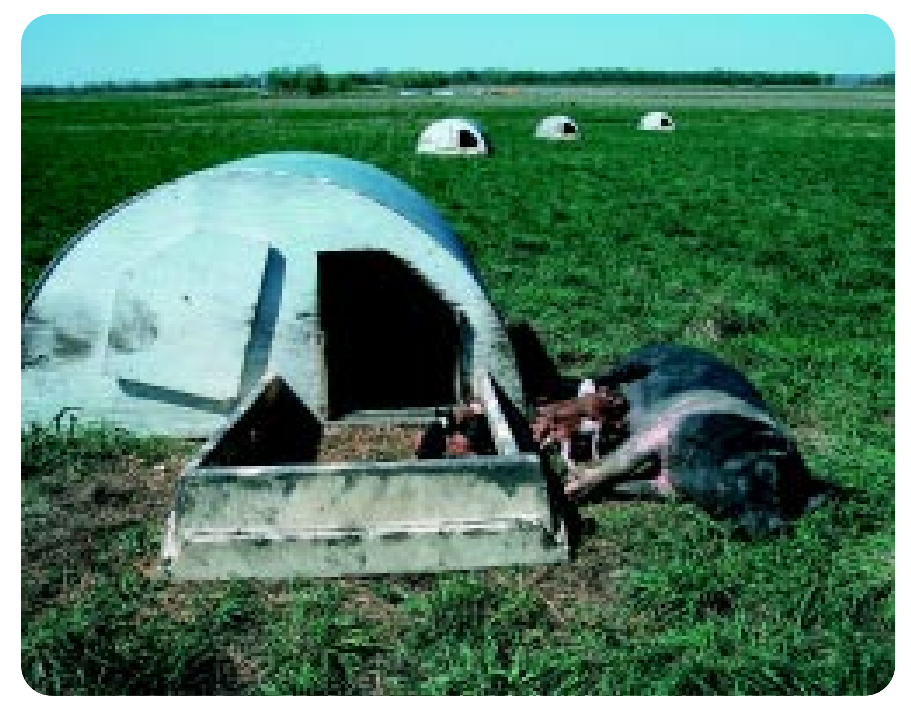

Production sites participating in the USTCP may be certified as "trichinae safe" if sanctioned production practices are followed. The onfarm certification mechanism establishes a process for ensuring the quality and safety of animal-derived food products from farm through slaughter and is intended to serve as a model for the development of other onfarm quality and safety initiatives.

Uniform program standards detailing the requirements of this certification program have been developed, and additional Federal regulations in support of the program are being developed. The completion of the pilot phase described here will lead to implementation of a federally regulated program throughout the United States.

Program pilot sites (swine nurseries and growers or finishers) are located in Colorado, Illinois, Iowa, Kansas, Minnesota, Missouri, Oklahoma, and South Dakota. However, site enrollment continues. States were selected based on their willingness to participate and on market locations.

Program Status: 2002-04-Based on risk factors related to exposure of swine to T. spiralis, an objective audit that could be applied to pork production sites was developed for onfarm production practices. USDA regulates the audits to ensure that program standards are met and certifies that specified good production practices are in place and maintained on the audited pork-production sites. The onfarm audit includes aspects of farm management, biosecurity, feed and feed storage, rodent control programs, and general hygiene. 
In the pilot study, objective measures of these good production practices were obtained through review of production records and an inspection of production sites. Production site audits were performed by veterinarians trained in auditing procedures, Trichinella risk-factor identification, and Trichinella good production practices. Of the 461 production-site audits performed from 2000 to part way through 2004, 450 audits (97.6 percent) indicated compliance with good production practices as defined in the program. These sites were granted status as "enrolled" or "certified" in the program (see table 8 for data for 2002-04).

Program sites will be audited on a regular scheduledepending on their status-as established by official standards of the pilot USTCP. USDA maintains oversight of the auditing process by qualifying program auditors and by conducting random spot audits. Spot audits verify that the program's good production practices are maintained between scheduled audits and ensure that the audit process is conducted with integrity and consistency across the program.

Early in the pilot study, an ELISA was conducted on meat-juice samples collected at slaughter to perform verification testing of swine raised on certified sites. Verification testing was random testing of a statistically valid sample of swine from trichinae-certified production sites. The entire certified population delivered to the slaughter plant on a yearly basis was used to determine the total number of samples needed. This testing was performed to verify that swine coming from trichinae-certified production sites were free of Trichinella. Trained laboratory technicians at the slaughter plant performed the early stage verification testing. Verification testing of 11,713 swine from farms in the pilot USTCP resulted in 11,712 negatives and 1 positive by ELISA. The one positive ELISA result was determined to be a false positive when a 5 -gram sample of diaphragm from the carcass was tested by artificial digestion.

The program calls for swine slaughter facilities to segregate pigs and edible pork products that originate from certified sites from pigs and edible pork products that originate from noncertified sites. This process is verified by FSIS. Swine slaughter facilities processing pigs from certified sites are responsible for conducting verification testing to confirm the trichinae-free status of pigs originating from certified production sites. On a regular basis, statistically valid samples of pigs from certified herds are tested at
TABLE 8

Numbers of veterinarians trained and sites audited during 2002, 2003, and 2004

\begin{tabular}{l|r|r|r} 
& $\mathbf{2 0 0 2}$ & $\mathbf{2 0 0 3}$ & $\mathbf{2 0 0 4}$ \\
\hline $\begin{array}{l}\text { Newly trained and } \\
\text { qualified accredited }\end{array}$ & & & \\
veterinarians & 7 & 7 & 25 \\
\hline Site audits performed & 200 & 81 & 82 \\
\hline
\end{tabular}

slaughter to verify that practices to reduce onfarm trichinae-infection risks are working. This process verification testing is performed using a USDAapproved tissue or blood-based postmortem test and is regulated by AMS.

Challenges-The program's current challenge is the approval process and publication of the USDA regulation that will establish trichinae certification as an official USDA voluntary program for onfarm riskmitigation certification in the U.S. pork industry.

\section{Swine Health Protection Inspection Program Disease and Program History-The Swine Health} Protection Act, Public Law 96-468, serves to regulate and ensure that all food waste fed to swine is properly treated to kill disease organisms. Raw meat is one of the primary media through which numerous infectious or communicable diseases of swine can be transmitted-especially exotic animal diseases such as foot-and-mouth disease, African swine fever, classical swine fever, and swine vesicular disease.

Current Program-In accordance with Federal regulations, food waste may be fed to swine only if it has been treated to kill disease organisms. Treatments must be made at facilities possessing valid permits issued by VS or by the chief agricultural or animal health official of the State (if the State permits feeding food waste to swine). In 2004, 20 States prohibited feeding food waste to swine; 30 States and Puerto Rico allowed and issued permits to operate garbage treatment facilities. Licensed operations must follow regulations regarding the handling and treatment of garbage, facility standards (rodent control, equipment disinfection), cooking standards, and recordkeeping. In addition, licensed operations are required to allow Federal and State inspections.

Program Status: 2003-04-During FY 2004, there were on average 2,757 licensed food-waste cooking and feeding premises in the United States. During the year, 12,723 routine inspections and 1,330 
reinspections were made on licensed premises in States that permitted the treatment and feeding of food waste to swine. An additional 347 prelicensing inspections were made on either new food-waste feeders or on facilities getting back into the business.

Because of increased awareness and threats of potential incursions of foreign animal diseases, most States increased efforts to ensure that all food-waste feeders were properly licensed. To this end, 25,422 searches for nonlicensed food-waste feeders were made by field personnel. Through these efforts, 239

nonlicensed feeders were found, of which 154 were subsequently licensed or some other adjustment was made without involving a Federal or State enforcement action. 


\section{CHAPTER 4 Animal Health Initiatives}

This chapter brings special attention to particular events and highlights of 2004, including bovine spongiform encephalopathy (BSE) enhanced surveillance, the initiation of the National Animal Identification System (NAIS), the creation and implementation of the National Animal Health Surveillance System (NAHSS), the continued implementation of the infectious salmon anemia (ISA) program, and the development of the National Animal Health Laboratory Network (NAHLN).

\section{BSE Enhanced Surveillance Plan}

In response to the Canadian case of BSE in May 2003 and the December 2003 discovery of BSE in a Washington State cow imported from Canada, the Animal and Plant Health Inspection Service (APHIS), Food Safety and Inspection Service (FSIS), and the Food and Drug Administration developed an enhanced national BSE surveillance plan. This onetime effort (which began June 1, 2004) called for the testing of a minimum of 268,500 cattle from targeted high-risk populations during a 12-to 18 -month period. The enhanced national BSE surveillance plan calls for providing a geographic representation of the U.S. cattle population. The program also helps to define whether BSE is present in the Nation's cattle population. Note: Chapter 5 describes BSE surveillance in the United States prior to the implementation of the enhanced surveillance plan.

\section{High-Risk Population Estimates}

Because clinical BSE takes years to develop after exposure and cannot be detected until shortly before clinical signs are apparent, older animals were targeted for testing. Adult cattle were defined as those 30 months of age or older, as evidenced by the eruption of at least one of the second set of permanent incisors.
Using available data, it was estimated that the U.S. high-risk cattle population numbered approximately 446,000 animals in 2004. This estimate included adult cattle

Condemned at slaughter for signs of central nervous system (CNS) illness;

- Moribund, dead, or nonambulatory disabled (FSIS data 2002);

- Reported for foreign animal disease (FAD) investigations because of CNS abnormalities (APHIS data);

Dead onfarm from unknown causes;

- Euthanized because of lameness or injury; and

- Known to have shown signs of incoordination or severe depression before death (National Animal Health Monitoring System data).

\section{Sample Collection}

Samples are being collected primarily at concentration points, such as rendering and slaughter facilities, especially salvage facilities. Samples also are collected from individual animals onfarm and at livestock auctions, veterinary clinics, diagnostic laboratories, and public-health laboratories.

To guide the collection of samples, the following criteria were established to define types of high-risk cattle to be sampled:

1. Cattle designated as "highly suspicious for BSE" (according to VS Memorandum No. 580.16) were investigated as an FAD with samples submitted to the National Veterinary Services Laboratories (NVSL) for testing for BSE.
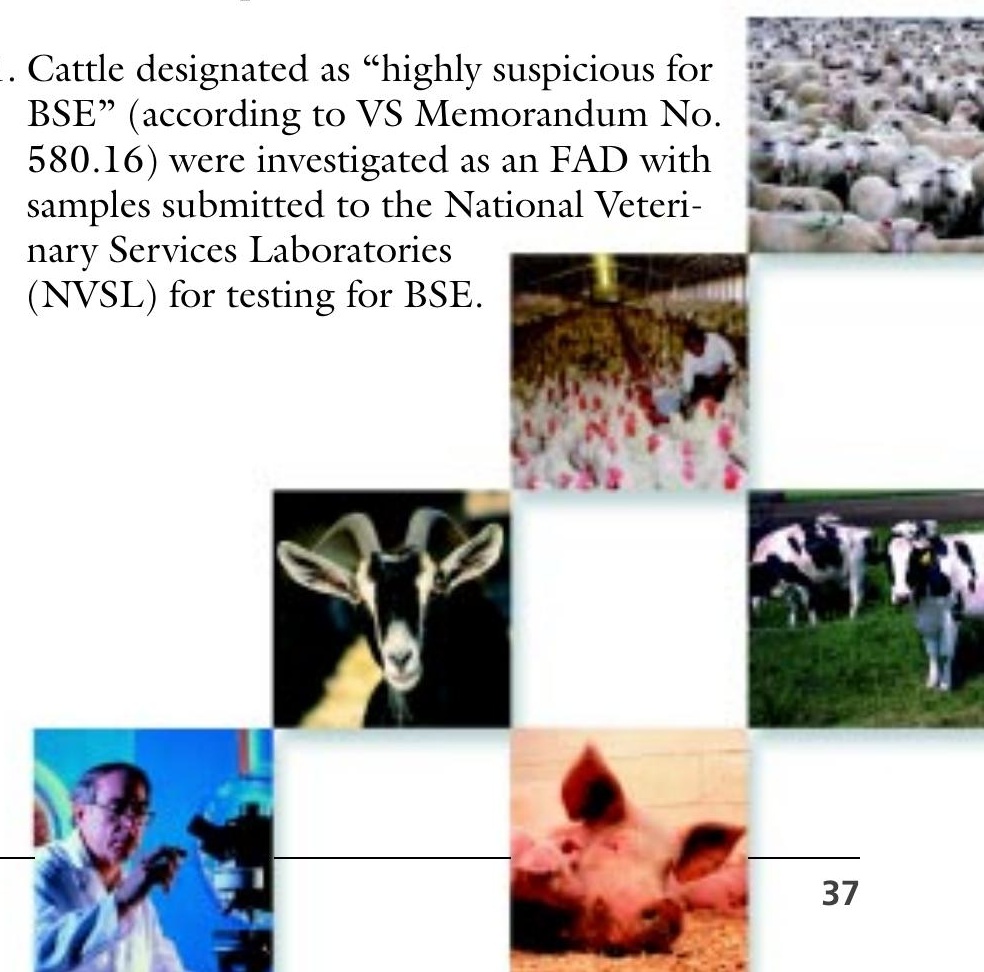
2. Nonambulatory cattle:

a. Cattle unable to rise from a recumbent position (downer) or unable to walk, including, but not limited to, those with broken appendages, severed tendons or ligaments, nerve paralysis, fractured vertebral columns, or metabolic conditions.

b. Cattle severely weakened although able to stand and walk for brief periods.

3. CNS clinical signs and/or rabies negative:

a. Diagnostic laboratories - samples submitted due to evidence of CNS clinical signs.

b. Public-health laboratories-rabies-negative cases.

c. Slaughter facilities-animals condemned, antemortem, at slaughter because of CNS signs.

d. Onfarm-cattle showing CNS signs.

4. Cattle exhibiting other signs that may be associated with BSE: Cattle condemned, euthanized, or dead as a result of a moribund condition, tetanus, emaciation, injuries, or nonambulatory conditions.

5. Dead cattle: Any dead cattle from which a specimen of diagnostic quality was obtained and the cause of death and/or clinical signs prior to death, if known, did not preclude it from the targeted population.

The State of last residence of animals from which samples are collected is recorded. The State and premises in which a sample is collected are not necessarily an animal's State and premises of last residence. Every effort is made to record an animal's State of last residence accurately.

Samples from the targeted high-risk population are tested at NVSL and participating network laboratories. The laboratories use a rapid-screening test approved by the Center for Veterinary Biologics (CVB). CVB also has approved four other screening test kits. Any samples with inconclusive results undergo supplemental testing at NVSL by immunohistochemistry.

Table 9 provides a characterization by submission category of the 155,489 samples tested throughout the last 7 months of 2004. During that 7 months of surveillance, three samples were inconclusive via rapid-screen testing. These three samples were confirmed as negative by immunohistochemistry.
TABLE 9

\begin{tabular}{|c|c|}
\hline \multicolumn{2}{|c|}{$\begin{array}{l}\text { Number of samples from the targeted high-risk } \\
\text { populations tested by submissions category, } \\
\text { June 1-December 31, } 2004\end{array}$} \\
\hline Submission type & Samples \\
\hline Highly suspicious & 18 \\
\hline Nonambulatory & 15,003 \\
\hline Dead & 127,344 \\
\hline CNS signs $^{1}$ & 47 \\
\hline Other clinical signs & 455 \\
\hline Rabies suspect & 82 \\
\hline Antemortem condemned ${ }^{2}$ & 6,692 \\
\hline Apparently normal & 0 \\
\hline Missing 3 & 5,846 \\
\hline Total & 155,489 \\
\hline \multicolumn{2}{|c|}{$\begin{array}{l}{ }^{1} \text { Cattle condemned antemortem at slaughter for CNS signs are not } \\
\text { included in this category. } \\
2 \text { All samples from cattle condemned at antemortem inspection are } \\
\text { included in this category (e.g., cattle condemned as nonambulatory at } \\
\text { antemortem inspection are included here, not in the separate } \\
\text { nonambulatory category above). } \\
{ }^{3} \text { Submission type information is not currently available for these cattle. } \\
\text { Data-entry efforts are currently underway to make this information } \\
\text { available. }\end{array}$} \\
\hline
\end{tabular}

Editor's Note: In 2005, additional tests of all three inconclusive samples were conducted. One sample was determined to be positive, and the other two were confirmed negative.

\section{Education and Outreach}

APHIS updated existing BSE educational materials and processes and developed new ones, including a complex press kit of information for the media. In addition, APHIS worked with other Federal and State agencies as outlined in a new education and outreach plan, which included the development of a new Web site for BSE information (<http:// www.aphis.usda.gov/lpa/issues/bse_testing/ index.html $>$ ). These outreach efforts informed producers and affiliated industries of the surveillance goals and encouraged reporting of suspect or targeted cattle onfarm and elsewhere.

\section{NAIS}

Livestock in the United States have been identified through a variety of systems, but until recently there were no uniform standards for a system that could be used throughout the Nation. On December 30, 2003, the Secretary of Agriculture announced that the U.S. Department of Agriculture (USDA) would prioritize implementation of a verifiable system of national animal identification for use across the entire 
country. Such a system was already under development by USDA.

Administered by APHIS, the NAIS is a cooperative State-Federal-industry program designed to track an animal's movements from birth to death. The NAIS integrates three key components: premises identification, animal identification, and animal tracking.

As animal identification and location records are collected through the NAIS, State and Federal animal health officials will be able to manage disease surveillance and control programs more effectively and efficiently. The System also will enable animal-health officials to implement electronic permitting for intraand interstate animal movement, allowing a faster, more comprehensive response to disease outbreaks. Eventually, the NAIS will allow animal health officials to identify all animals and premises that have had contact with a foreign or domestic animal disease of concern within 48 hours of an initial presumptivepositive diagnosis.

NAIS will track domestic animal species that could directly or indirectly impact the health status of our Nation's livestock and poultry populations. To ensure the success of this undertaking, species working groups have been established for beef and dairy cattle, bison, camelids, cervids, equine, goats, poultry, sheep, and swine. These groups are composed of industry and government representatives and provide input to USDA regarding identification require-

ments. These requirements differ for some species and are therefore established through species-specific standards. Through species working groups, stakeholders have direct input into the development of these standards.

\section{Premises Identification}

Identifying locations or premises where animals reside or are managed is a first essential step in tracking animals. Therefore, USDA focused on establishing a Standardized Premises Registration System (SPRS) in 2004. After completing an independent review of federally funded systems, APHIS selected a system developed by the Wisconsin Livestock Identification Consortium and modified it for use at the national level. APHIS funded more than 40 different State and Tribal cooperative agreements to support the premises identification effort in 2004. States and Tribes use this system to assign nationally unique Premises Identification Numbers (PINs) to farms, ranches, livestock markets, and other locations.
States and Tribes could also use other premises registration systems, as long as these systems were certified as being in compliance with national standards.

At their option, States and Tribes that received funds conducted field trials for administering animal identification and collecting animal-movement data. By the end of 2004, 27 States and 2 Tribes could assign PINs, 19 States were using the SPRS, and 8 States and 2 Tribes were using compliant premises registration systems. As of December 31, 2004, approximately 20,000 premises were registered through the standardized or compliant registration systems.

\section{Animal Identification}

For the NAIS to succeed, all participants in animal industries will need to voluntarily and whole-

heartedly adopt the standardized premises and animal numbering systems. On November 8, 2004, APHIS published a rule in the Federal Register to recognize officially the use of the 15-character Animal Identification Number (AIN), 13-character Group/Lot Identification Number, and 7-character PIN. These new numbering systems are key elements of the NAIS, and publication of this rule allows producers to transition into the use of a one-number-for-oneanimal system. Under this rule, for example, a producer could use the AIN to identify an animal for an interstate movement permit, the tuberculosis eradication program, the brucellosis eradication program, and, potentially, a breed registry.

Note: The publication of this rule did not change the requirements defining which animals must be officially identified, nor did it require that producers use the new numbering systems. The rule merely ensured that the new numbering systems were recognized as official, allowing those who wanted to use such systems to do so.

\section{NAHSS}

NAHSS is a Veterinary Services (VS) initiative designed to integrate existing animal-health monitoring programs and surveillance activities into a comprehensive and coordinated system. NAHSS is charged with enhancing the collection, collation, and analysis of animal-health data and facilitating timely and efficient dissemination of animal-health information. As 
one of many components within and outside of agriculture, NAHSS augments the Nation's ability to detect the early signs of biological threats.

Coordinating and integrating U.S. animal-health monitoring and surveillance efforts was a primary recommendation of the 2001 Animal Health Safeguarding Review, a combined effort of the National Association of State Departments of Agriculture and APHIS-VS. In 2002, VS responded to this recommendation by forming the National Surveillance System Issue Group, which developed critical action plans necessary for the transition to NAHSS. Several of these key activities were completed in 2004, including identifying a National Surveillance Coordinator, establishing a National Surveillance Unit (NSU), and forming a NAHSS steering committee. The NAHSS Steering Committee consists of representatives from livestock and poultry industries, State animal-health agencies, diagnostic laboratory organizations, academic institutions, private practitioner organizations, and relevant Federal agencies.

Other actions addressed in 2004 included an internal survey conducted to capture ideas and opinions critical for creating a common vision for national animal-health surveillance and developing of NAHSS "Outlook," a bimonthly internal communication that provides updates on current NAHSS information to VS employees.

In December 2004, the NAHSS Steering Committee, in collaboration with the National Surveillance Coordinator and NSU, finalized a strategic plan for national animal-health surveillance. The NSU was charged with providing the primary coordination for implementing the NAHSS strategic plan (see <http:/ /www.aphis.usda.gov/vs/ceah/ncahs/nsu>). Four primary goals were established:

1. Early detection and global risk surveillance for FADs,

2. Early detection and global risk surveillance for emerging diseases,

3. Enhanced surveillance for current program diseases, and

4. Monitoring and surveillance for diseases of major impact on production and marketing.

Specific objectives, actions, responsible parties, and target dates were also developed for each of these goals. Progress made in 2004 toward meeting objectives included the

Development of the NAIS;

- Development and implementation of enhanced BSE surveillance for FY 2004, FY 2005, and options for FY 2006;

Development of a classical swine fever (CSF) surveillance plan;

Validation and deployment of new testing assays and reagents to NAHLN laboratories;

- Coordination with the Department of Homeland Security on the planning and implementation of the National Biosurveillance Integration System;

Evaluation of existing animal-health surveillance databases and data sources, and consideration of options for integration;

Establishment of new types of protocols to retrieve data more effectively from existing databases;

Development of a comprehensive and searchable animal-health surveillance system inventory; and

Evaluation of new technologies to enhance electronic scanning and analysis of emerging-issues data.

ISA

ISA was first identified in Norway in 1984 and subsequently detected in farmed Atlantic salmon (Salmo salar) in New Brunswick, Canada, in 1996. By 1997, the viral disease had spread to several Canadian farms in a three-bay management area. In 1999, 24 Canadian sites were affected by ISA, including 9 of 12 sites on the west side of Deer Island (McGeachy and Moore 2003). These sites are near U.S. farmed salmon operations, including some within $2 \mathrm{~km}$ of the U.S border.

The proximity of ISA virus-infected sites has raised concerns for the U.S. farmed salmon industry for several reasons. First, since the early 1990s, some companies have operated salmon farms on both sides of the international border. Boats, fish, equipment, and personnel move across the border freely. Second, water circulation models and molecular virusmonitoring surveys suggested that diluted concentrations of virus particles released from southern Deer Island could reach U.S. salmon farms via the mouth of Maine's Cobscook Bay. The likelihood of waterborne transmission appeared substantial. Third, sea lice are documented as ISA virus vectors. Early life stages of the lice, carried in strong tidal currents, could transmit the virus. 


\section{Infectious Disease Standards}

In 2001, ISA virus infection was detected at salmon sites in Cobscook Bay. In December 2001, the Secretary of Agriculture declared an ISA disease emergency, which permitted funds to be allocated to APHIS to assist Maine's salmon industry over a 2year period. Between the beginning of the outbreak and the emergency declaration, a group of fish health veterinarians and biologists developed ISA disease control standards based on existing New Brunswick ISA policies and practices implemented by the Norwegian salmon industry. The final standards were published in early 2002 as the USDA-APHIS Infectious Salmon Anemia Disease Program Standards.

The standards delineate seven requirements for participating in the ISA program, which provides both disease control stipulations and compensation. These seven standards require farms to

Develop a veterinarian-client-patient relationship; Participate in State-mandated surveillance; Develop and implement biosecurity protocols for marine sites, processing plants, and vessels;

Develop action plans for ISA prevention and control;

Participate in a statewide sea-lice control program; Report complete inventory and fish health information; and

Cooperate with program officials via periodic biosecurity audits.

\section{Biosecurity and Surveillance}

Biosecurity is a key component of the ISA program. Many important risk factors identified in the transmission of ISA are related to biosecurity issues, including handling and disposal of processing waste, blood, and stun-water; mortality removal and disposal; controlling movements of vessels, equipment, and human site traffic; maintenance and use of disinfection stations; and sea-lice management.

The initial goal of surveillance is the prompt detection of ISA virus infection. Surveillance is a mandatory activity at all Maine salmon sites and is performed by the site veterinarian at a frequency dictated by the ISA status of the site. These inspections, required at least monthly, include a visual overview of the site, a review of mortality records, the collection and submission of at least 10 moribund or freshly expired salmon, and a completed submission form that is sent to an APHIS-approved laboratory.
Biosecurity audits are performed semiannually on all sites in Cobscook Bay, yearly on all lower risk sites, and seasonally on vessels. Audit reports identify observed strengths and weaknesses, make recommendations for improvements, and prioritize response times by apparent relative risk.

\section{Program Implementation}

The ISA Program was implemented in early January 2002 in partnership with the Maine Department of Marine Resources, which has the legal authority to issue quarantines and "kill orders," regulates site leasing, and offers enforcement resources in Maine's near-shore marine waters. Because fish in a reported 16 of the 17 active cage sites in Cobscook Bay had already been infected in 2002, a strategy of complete, baywide depopulation was undertaken immediately. More than 1 million salmon had either died or been depopulated before the start of the program, and an additional 1.6 million first-year fish were destroyed in the program's first 2 weeks. The baywide eradication helped prevent the virus from traveling farther west along the Maine coast to approximately 20 other sites situated in marine waters up to 100 miles west of Cobscook Bay. After the depopulation, all cages, nets, feeding equipment, and other farming equipment and vessels were cleaned and disinfected during a planned 3.5-month fallow of the entire bay.

Six farms in the bay's southern half were repopulated in May 2002 at reduced density and with a single year-class of salmon. Industry and government commitment to strict biosecurity, surveillance, and pest-management protocols proved effective. Despite an ongoing succession of many new cases in the neighboring Canadian Province of New Brunswick, sites in Maine were free of ISA for 13 months. However, in June 2003, surveillance testing indicated early ISA virus infection in salmon from one cage at each of two sites in Cobscook Bay. Fish in the infected cages were harvested and/or culled within 2 weeks of detection. Fish in three more cages on those two sites ultimately were declared positive by the end of 2003, although the course of infection was controlled (table 10). Both farms brought the majority of their fish to market, under profitable conditions, without any indication of further spread of infection to neighboring farms.

Between January 2002 and December 2004, 8,790 samples were collected during 941 inspections at 24 sites along Maine's northeastern coast. In all, 73 


\begin{tabular}{|c|c|c|c|c|}
\hline & 2002 & 2003 & 2004 & Total \\
\hline Samples & 1,962 & 3,187 & 3,641 & 8,790 \\
\hline Inspections & 189 & 371 & 381 & 941 \\
\hline Sites & 20 & 22 & 21 & NA \\
\hline Site audits & 22 & 21 & 13 & 56 \\
\hline Vessel audits & 8 & 11 & 0 & 19 \\
\hline $\begin{array}{l}\text { Cages confirmed } \\
\text { positive }\end{array}$ & 0 & 5 & 17 & 22 \\
\hline $\begin{array}{l}\text { Confirmed cages } \\
\text { removed }\end{array}$ & 0 & 5 & 17 & 22 \\
\hline $\begin{array}{l}\text { New confirmed } \\
\text { sites }\end{array}$ & 1 & 2 & 6 & 9 \\
\hline Fish depopulated & $1,560,000$ & 52,000 & 101,000 & $1,713,000$ \\
\hline
\end{tabular}

biosecurity site audits and 25 vessel audits were conducted. The decrease in vessel audits in 2004 reflects the U.S. acceptance of vessel audits performed by government officials in New Brunswick.

The acceptance of biosecurity audits is a result of bilateral negotiations with Provincial and Federal government officials in New Brunswick, which have led to a more unified and cooperative approach to ISA control. The United States and Canadian negotiations also have resulted in sharing of diagnostic protocols, including validation and interlaboratory visits, coordinated sea-lice management programs, and sharing of data, including hydrography, diagnostic test results, and site-specific information. This sharing of information has facilitated joint epidemiologic studies between the two countries.

During 2004, surveillance, diagnosis, and control efforts were complicated by the emergence of several new strains of ISA virus in Maine, including a nonpathogenic strain closely resembling a similar strain in Europe. In addition, recent epidemiologic findingssupported by tidal modeling and geographic information system (GIS)-assisted evaluation of environmental risk factors - led to a new binational bay management strategy to be implemented starting with the next year-class of smolts.

\section{Reference}

McGeachy, S. M.; Moore M. J. 2003. Infectious salmon anemia in New Brunswick: an historical perspective and update on control and management practices (1997-2002). In: Miller, Otis; Cipriano, Rocco, tech. coords. International response to infectious salmon anemia: prevention, control, and eradication: proceedings of a symposium; 3-4 September 2002; New Orleans, LA. Tech. Bull. 1902: $145-153$.

\section{NAHLN}

The NAHLN is part of a national strategy to coordinate the capabilities of Federal, State, and university laboratories. By combining Federal laboratory capacity with the facilities, professional expertise, and support of State and university laboratories, the NAHLN will enhance the response to animal health emergencies, including bioterrorist events, emerging diseases, and FADs.

The NAHLN is a cooperative effort among the American Association of Veterinary Laboratory Diagnosticians (AAVLD), APHIS, and the Cooperative State Research, Education and Extension Service (CSREES). The NAHLN is directed by a steering committee made up of representatives from these three organizations and the National Assembly of Chief Livestock Health Officials.

Key elements of the NAHLN include

- Standardized, rapid diagnostic techniques that can be used at the State, regional, and national level;

Secure communication, alert, and reporting systems;

Modern equipment and experienced personnel trained in the detection of emergent and foreign diseases, including outbreaks initiated by bioterrorists;

National training, proficiency testing, and quality assurance programs;

Upgraded facilities to meet biocontainment and physical security requirements; and

- Support of regional and national animal health emergency training exercises that test and evaluate the communication and reporting protocols of the network.

The NVSL serve as the central reference laboratories, coordinating activities and participating in method validation, as well as providing assistance, materials, and prototypes for many NAHLN elements. State and university laboratories perform surveillance testing when nonemergency testing is required and provide important surge capacity during disease outbreaks. In the latter capacity, these labs identify infected animals, help perform epidemiologic investigations, and conduct followup surveillance to 


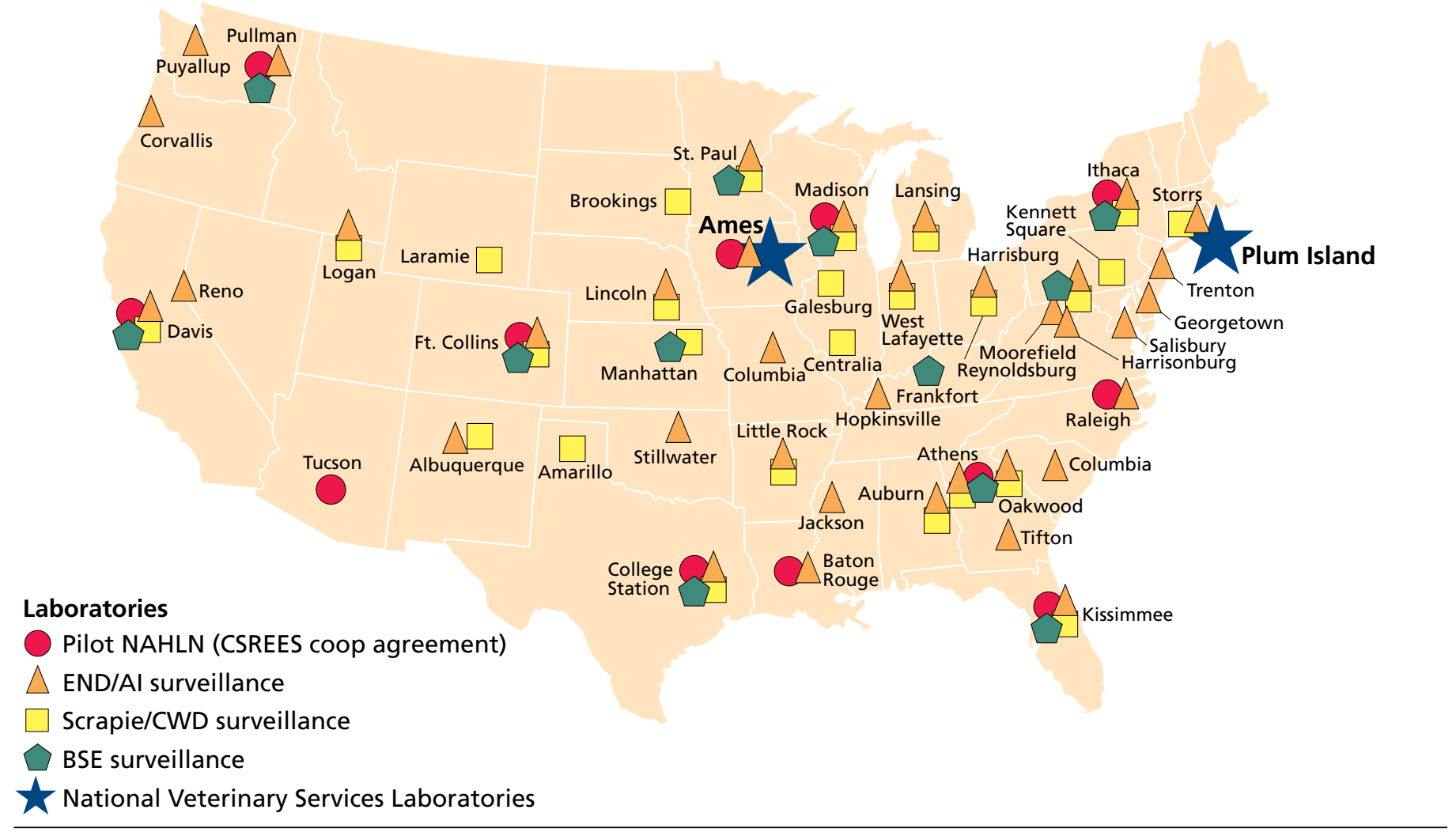

Figure 14-National Animal Health Laboratory Network in the United States.

maintain or restore "free status" for impacted areas at the end of outbreaks.

Many network laboratories are located within colleges of veterinary medicine, which provide additional expertise on disease agents. In addition, laboratories within veterinary colleges at land-grant universities are able to collaborate with extension specialists, who provide educational support to veterinarians, producers, and the general public.

In 2002, 12 State and university diagnostic laboratories were selected by APHIS and CSREES to enter into cooperative agreements funded by the Department of Homeland Security. These agreements formally initiated the network and focused on rapid assays for eight FADs: African swine fever, avian influenza, CSF, contagious bovine pleuropneumonia, exotic Newcastle disease (END), foot-and-mouth disease, lumpy skin disease, and rinderpest.

The NAHLN has evolved into a multifaceted laboratory network. Each facet focuses on a different disease but uses a common platform for testing. During 2002 and 2003, APHIS established contracts with State and university diagnostic laboratories to assist with chronic wasting disease and scrapie testing. In 2004, as a result of cooperative relationships developed during the 2001-03 END outbreak in California, 30 State and university diagnostic laboratories signed agreements to assist USDA with national END-surveillance testing. Also in 2004, a network consisting of 12 laboratories was established to assist with BSE surveillance. By the end of 2004, the NAHLN encompassed 44 State and university laboratories in 37 States (fig. 14).

APHIS has provided support and various services to NAHLN State and university laboratories, including lab equipment, training in diagnostic techniques, proficiency tests, reference reagents, and electronic communication-reporting tools. CSREES has proposed continued and increased merit-based infrastructure funding for the network. State and university laboratories have enhanced laboratory biosecurity and physical security; collaborated in the design of reporting and emergency tools; and, with facilitation from the AAVLD, improved laboratory quality assurance. 
The NAHLN likely will expand in the next few years by

Increasing the numbers and geographic dispersion of participating laboratories,

Developing the ability to test more pathogens and toxins,

Adding testing technologies, and

Increasing test-volume capacity per laboratory.

The result will be an increase in the U.S. capacity to detect and respond to disease agents that threaten the Nation's food supply and public health. 


\section{CHAPTER 5}

\section{Foreign Animal Disease (FAD) Prevention, Surveillance, and Emergency Response}

FAD outbreaks involving agricultural pathogens that harm livestock and crops can have a profound impact on America's infrastructure, economy, and export markets. Veterinary Services (VS) is charged with preventing FADs in the United States, rapidly detecting FADs should they occur, and responding effectively to control or eradicate them.

\section{Prevention Methods}

VS has the authority and responsibility to prevent and exclude FADs by prohibiting imports of animals, animal products, veterinary biologics, and other materials that pose a risk of introducing diseases. VS bases its FAD exclusion activities on the results of risk assessments that examine the disease status of the exporting country, information about the country's surveillance systems and other infrastructure, and documentation from site visits (see chapter 6). U.S. import requirements and provisions of the Bioterrorism Act are enforced at ports-of-entry by CBP Agriculture Specialists. Every day, these specialists screen thousands of passengers, all types of cargo, and international mail at more than 140 ports-ofentry. At some ports, detector dogs search for hidden items. At other ports, officials use low-energy $\mathrm{x}$ rays that detect the presence of organic materials, such as fruits and meats. As part of CBP, agriculture is also an integral part of various automated targeting systems used to identify and track the contents of containers before they reach U.S. shores. Personnel from USDA, FDA, and CBP work together at the National Targeting Center to analyze information based on scientific risk-assessment and pathway analysis and identify shipments for further inspection. In addition, VS veterinarians conduct point-of-entry inspections and require quarantines of live animals and birds offered for import. Such port inspections reduce the chance that diseased animals, contaminated animal products, or disease vectors such as ticks and mosquitoes could enter the country.

In addition, constant monitoring of international FAD events and conditions that might lead to disease emergence is vital in preventing disease incursions.
This global animal health information is collected from many sources, including

International organizations, such as the World Organisation for Animal Health (OIE) and the Food and Agriculture Organization of the United Nations;

Information received from Animal and Plant Health Inspection Service (APHIS), Foreign Agricultural Service, and Food Safety and Inspection Service personnel stationed overseas;

Ongoing monitoring of news reports; and

- Information received from other Government agencies, such as the Armed Forces Medical Intelligence Center, which gathers information on the status of both human and animal diseases throughout the world.

APHIS' International Services (IS) unit is implementing the International Safeguarding Information Program, which is designed to place IS personnel (both Foreign Service officers and Foreign Service nationals) in jobs at many new duty stations around the world. The role of individuals placed in these positions is to gather specific pest and disease information. VS personnel scan open-source electronic information for FAD information and then assess, analyze, and process risk events for agency decisionmakers. VS also prepares impact worksheets for new occurrences of commercially important diseases in foreign countries and examines an affected country's production and trade in potentially infective products, the potential for U.S. exposure, and trade implications.



\section{FAD Surveillance and Investigations}

Efforts to detect FAD events in the United States include field investigations, disease-specific surveillance programs, and diagnostic laboratory surveillance. FAD field investigations are conducted by specially trained Federal, State, or private accredited veterinarians. VS operates disease-specific surveillance programs for the following diseases: bovine spongiform encephalopathy (BSE), exotic Newcastle disease (END), classical swine fever (CSF), avian influenza (AI), and infectious salmon anemia. A national animal health laboratory network has been developed recently to provide screening of routine and specific-risk samples for FADs. In addition, the National Animal Health Surveillance System (NAHSS), coordinated by VS' National Surveillance Unit, will improve early detection and global risk surveillance of FADs. The NAHSS 2005 strategic plan (<http://www.aphis.usda.gov/vs/ceah/ncahs/ nsu/nahss/NAHSS_Strategic_Plan_2005_0216. pdf $>$ ) contains specific objectives to this end. Those objectives include enhancing domestic and global surveillance to identify elevated risks and encouraging the development and application of new technologies for early and rapid disease detection.

In 2004, 1,013 investigations of FADs or emerging disease incidents were performed in 47 States and Puerto Rico (table A2.1 in appendix 2). Colorado, Texas, and New Mexico reported the most investigations-300, 142, and 102, respectively. Also, 34 States and Puerto Rico each conducted 5 or more investigations.

From 1997 through 2004, the number of investigations per year ranged from a low of 254 in 1997 to a high of 1,013 in 2004 (fig. 15). The peak in 2004 is related to the large number of investigations conducted in the southwestern United States in response to an outbreak of vesicular stomatitis, a viral disease causing fluid-filled blisters around the nose, mouth, and teats in many livestock species and also affecting humans.

In bovines, the presence of abnormal central nervous system (CNS) signs is considered suggestive of BSE. In 2004, VS performed 100 investigations of abnormal CNS signs in bovines.
Number of FAD/EDI Investigations by Year

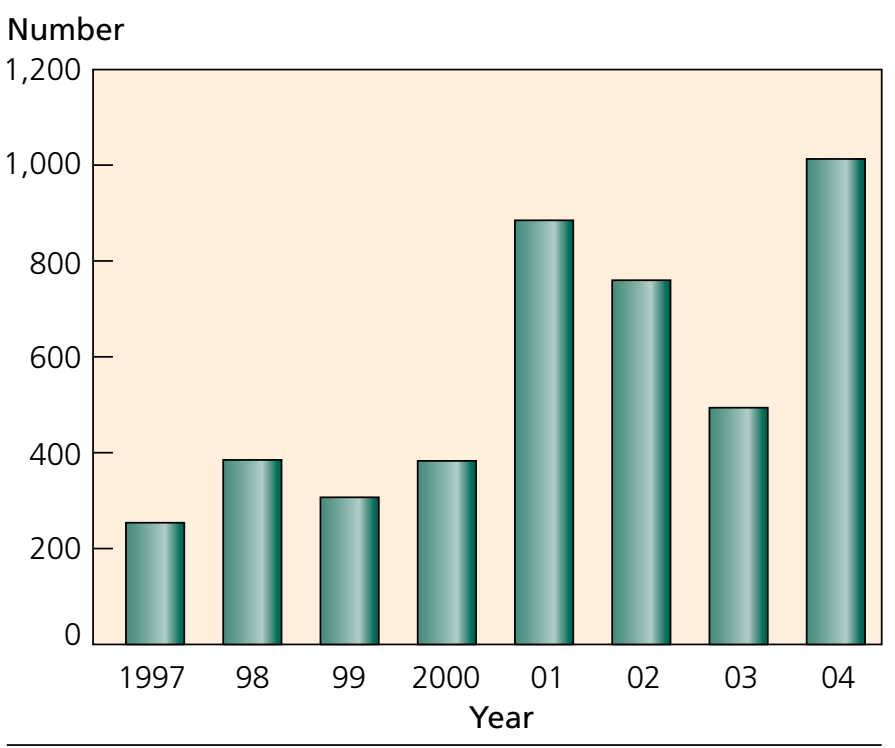

Figure 15-Number of FAD and emerging disease investigations, by year, 1997-2004.

Vesicular conditions were the most common complaint investigated. There were 689 vesicular complaints, of which 511 were in horses, donkeys, and mules and 178 in other species (e.g., ruminants and swine). Generally, vesicular conditions in species other than equines are considered suggestive of footand-mouth disease (FMD) as well as vesicular stomatitis (table A2.2 in appendix 2).

Samples were submitted under Priority 1 status to the National Veterinary Services Laboratories (NVSL) for 10 of the 1,013 investigations conducted in 2004. Specimens submitted under Priority 1 are processed through diagnostic testing protocols in the most expedient way possible regardless of the time of day or the day of the week.

Of the 1,013 investigations performed in 2004, 299 resulted in a confirmed FAD finding with 295 diagnosed positive for vesicular stomatitis in Colorado, New Mexico, and Texas. Diseases of fish and crustaceans represented the other four diagnosis-positive FAD investigations in 2004 and were diagnosed as spring viremia of carp, white spot syndrome, and Taura syndrome. 


\section{FAD-Specific Surveillance Programs}

VS conducts surveillance specifically for AI, BSE, cattle ticks, END, CSF, tropical bont tick (TBT), and screwworm to improve detection of disease and to document U.S. freedom from specific diseases. Brief descriptions of the programs are provided below.

\section{END}

The development of a national END surveillance program began in late 2003 and continued into 2004. The two primary goals of END surveillance are to (1) facilitate early detection of END in commercial and noncommercial poultry populations across the United States and (2) identify at-risk populations to enhance targeted surveillance activities. Surveillance relies on reporting of sick birds by owners and on active screening for birds entering the country illegally.

2002-03 END Outbreak-On October 1, 2002, END was confirmed by a laboratory in California and NVSL in backyard chickens in Southern California. In addition, small localized outbreaks occurred in Arizona, Nevada, New Mexico, and Texas. On September 16, 2003, END was declared eradicated from California and the entire United States.

The END outbreak resulted in the depopulation of 3 million layers, 1.3 million spent hens, and 149,247 pet and hobby birds, including gamefowl.

Nearly 7,700 personnel contributed to the eradication of END from these five States, amounting to 450,000 work-days of effort. It took 11 months to eradicate END from five States at an approximate cost of $\$ 175$ million.

END Surveillance in 2004-In 2004, NVSL approved 30 laboratories to perform real-time reverse-transcriptase-polymerase chain reaction assays for END virus. Active surveillance of the live-bird market system and shows and fairs, as well as passive surveillance of samples submitted to diagnostic laboratories, resulted in the testing of 7,678 samples during 2004, all of which were negative for END. In addition, through the California Avian Health Program, 11,099 submissions were tested for END (table 11). Samples originated from commercial operations, backyard flocks, feedstores, custom slaughter facilities, auction markets, pet/exotic premises, wild birds, gamebirds, laboratories, swapmeets, and educational facilities. Also in 2004, nearly 200
TABLE 11

Number of samples tested for END in 2004, by sample origin

\begin{tabular}{l|r}
\hline Sample origin & Number \\
\hline Commercial operations & 4,685 \\
Backyard flocks & 2,298 \\
Feedstores & 1,421 \\
Custom slaughter facilities & 652 \\
Auction markets & 616 \\
Pet/exotic premises & 572 \\
Wild birds & 344 \\
Gamebirds & 157 \\
Laboratories & 150 \\
Swapmeets & 148 \\
Educational facilities & 56 \\
Total & 11,099 \\
\hline
\end{tabular}

farm managers, representing more than 600 commercial poultry farms, participated in the Poultry Worker Biosecurity Training Program, enabling them to train their workers in the use of proper biosecurity practices.

\section{Avian Health Program}

Following the release of the Southern California END quarantines in 2003, VS and the California Department of Food and Agriculture introduced the Avian Health Program. It seeks to prevent the introduction of END virus and other avian disease agents through active outreach, education, and voluntary surveillance. Outreach activities include presentations to commercial and backyard poultry producers, feed stores, pet stores, swapmeets, auctions, bird clubs, Future Farmers of America and 4-H groups, veterinary associations, animal-control agencies, fairs and exhibitions where poultry and birds are on display, custom slaughter markets, gamebird producers, and anywhere poultry or pet birds are kept. Education efforts include in-person as well as online biosecurity training and certification with avianhealth and disease-recognition information, biosecurity videos in English and Spanish for commercial, backyard, and other poultry owners, and educational flyers presenting the risks of disease introduction and benefits to poultry owners from practicing good biosecurity.

\section{Low-Pathogenicity Al Program-}

Commercial Industry Program-Most commercial poultry operations are monitored for certain highprofile diseases through the National Poultry 
Improvement Program (NPIP). The provisions of NPIP establish standards for evaluating poultry breeding stock and hatchery products for hatcherydisseminated and egg-transmitted diseases. In 2003, APHIS published its final rule for a U.S. Avian Influenza Clean classification (all subtypes) on exhibition poultry and gamebirds, and for primary breeder flocks for chicken egg-type breeding flocks and chicken and turkey meat-type breeding flocks under the NPIP program. Proposed rule changes for expanding the AI Program were finalized in 2004 for implementation in 2005. These changes call for the inclusion of table-egg producers and meat-type chicken and turkey producers (monitoring of $\mathrm{H} 5$ and H7 AI virus subtypes) into the monitoring system.

Live-Bird Markets System Program-Based on input from the United States Animal Health Association's committee on the transmissible diseases of poultry, a Uniform Standards document was finalized in 2004 relating to the control of $\mathrm{AI}$ and eradication of the viruses that cause low-pathogenicity AI from live-bird markets. This program relies on AI testing of all birds going into the market system (testing at farms, distributors, and markets); registering producers, dealers, and haulers; recording bird transfers at all marketing stages; and identifying birds.

Biosecurity for the Birds Program-As part of an enhanced national surveillance plan for END, VS undertook an outreach and education program aimed at noncommercial poultry owners. Named Biosecurity for the Birds, the program established broad goals for promoting the importance of practicing biosecurity to prevent the introduction and spread of poultry disease. The program also urges bird owners to report any unusual signs of disease or unexpected deaths among their birds by calling VS toll free.

Target Audience - The program's campaign began with benchmark research conducted through two Web sites. Some 350 interviews with owners of small flocks were conducted. Findings indicated that nearly 70 percent of respondents did not know very much about END, and almost 65 percent did not think they could recognize AI. More than half of respondents owned 50 or fewer birds, and more than half said they were unfamiliar with biosecurity practices. The research also provided information about media outlets of interest, which was useful in planning an advertising campaign.
Outreach Products-Program-sponsored ads emphasized that practicing biosecurity is the key to preventing disease. APHIS' Legislative and Public Affairs unit placed advertisements with agriculturerelated papers, magazines, radio stations, Web sites, rural electric cooperative publications, newsletters, and newspapers serving Hispanic, Vietnamese, Filipino, Native American, and Amish communities. Puerto Rico and the Virgin Islands were also targeted for advertising. In total, the advertising campaign reached a circulation of more than 80 million persons. In addition, the specialist coordinating the outreach work created feedbag labels to encourage feed manufacturers to put biosecurity information on small feed packages.

Besides placing conventional advertisements, VS provided educational materials to more than 35 States. Future Farmers of America students also distributed literature at more than 30 fairs and poultry shows. At the start of the campaign, VS sent information packets to over 53,000 accredited veterinarians who might see avian diseases in their practice, and staffed biosecurity-related exhibits at major veterinary conferences throughout the campaign.

VS produced more than 1 million copies of brochures and leaflets on END, AI, and backyard biosecurity in English and Spanish. Posters and displays were also created for display at fairs, conferences, and exhibits. A program Web site was developed (<http:// www.aphis.usda.gov/vs/birdbiosecurity>), and a video on backyard biosecurity in English and Spanish was produced for distribution in 2005 .

\section{BSE Program}

The United States has had an active surveillance program for BSE since May 1990. Through BSE surveillance, cattle are sampled from populations in which the disease most likely would be detected. OIE has established guidelines for the number of samples that should be tested each year (see <http:// www.oie.int $>$ ). For the United States, OIE recommends a surveillance level of 433 samples per year. However, USDA wanted the extra measure of security that a higher sampling level would provide and therefore maintained surveillance far above the OIErecommended level since 1994.

Determining the populations in which BSE would most likely be detected is based on the epidemiology of the disease, including potential clinical signs, BSE's relatively long incubation period, and the inability to 
detect infection in young cattle. Surveillance samples include field cases of cattle exhibiting signs of neurologic disease, cattle condemned at slaughter for neurologic reasons, rabies-negative cattle submitted to public health laboratories, and neurologic cases submitted to veterinary diagnostic laboratories and teaching hospitals. Nonambulatory cattle ("downer cattle" or fallen stock) have been sampled since 1993 (or FY 1994) (fig. 16). This figure provides the number of samples submitted to NVSL for BSE testing over the past decade. No cases of BSE were detected among the samples collected from cattle of U.S. origin. However, in December 2003, one case of BSE in Washington State was detected in a cow imported from Canada. Note: The FY 2004 data cover only the period prior to the "enhanced" BSE surveillance program, which was discussed in chapter 4 .

\section{Cattle Tick Program}

In place since 1943, VS' cattle tick program is designed to identify tick incursions, eradicate them, and prevent their spread. Systematic quarantine zones along the Rio Grande River in Texas are a vital component of this effort. To prevent the introduction of cattle ticks into the United States, horseback patrols near the U.S.-Mexican border apprehend stray cattle and horses. In FY 2004, APHIS apprehended 60 stray and smuggled animals ( 16 cattle and 44 horses) from Mexico, 21 of which were infested with cattle ticks. During 2004, APHIS quarantined 94 premises for tick infestation, 20 of which were outside quarantine zones. These figures represent a significant increase in ticks over 2003 levels, when VS detected 19 infestations, 4 of which were outside the quarantine zone.

To help prevent wildlife (e.g., deer and elk) from reintroducing ticks to vacated pastures, APHIS places medicated baits in infected pastures. In the past, APHIS used only corn feeders medicated with acaricide to eradicate ticks in wildlife. However, because of the Food and Drug Administration's (FDA) ban on medicated corn feeds during hunting season (November through February), APHIS has initiated the use of four-poster roller treatment feeders. Four-poster feeders apply acaricide to the head, neck, and ears of deer and elk as they feed.

\section{BSE Surveillance — NVSL Bovine Brain Submissions FY 93-04 (through 5/31/04)}

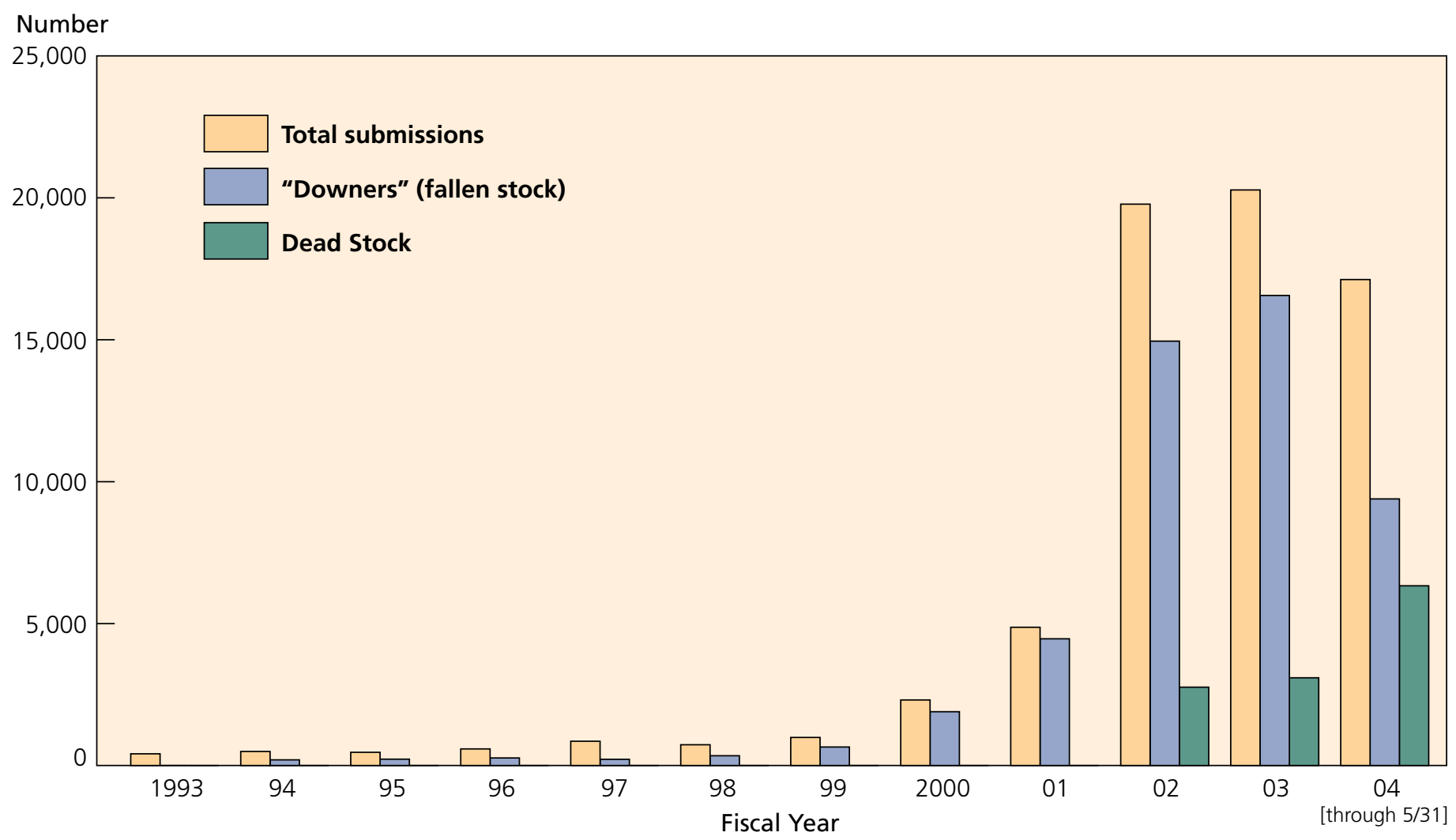

Figure 16-Number of samples submitted to VS for BSE testing, by fiscal year, 1993-2004. 


\section{TBT}

This species transmits the fatal livestock and wildlife disease heartwater and the cattle disease acute bovine dermatophilosis (a skin infection). These diseases are not themselves contagious but are transmitted by the ticks. The TBT is endemic in the Caribbean. APHIS believes that much of the recent interisland spread of the TBT has occurred through movement of infested migratory birds, in particular cattle egrets. Because these egrets can fly between the Caribbean and Florida, there is a significant chance that they could bring TBTs to the Continental United States.

Not eradicating TBTs from St. Croix increases the risk of their spread to other U.S. Caribbean islands and eventually to Southeastern States. If the TBT established itself in the United States, there is a great likelihood that previously eradicated Caribbean islands could be reinfested. A 1993 risk assessment of the impact of the introduction of the TBT estimated losses of over \$1 billion (in 2004 dollars). The appraisal would significantly increase if it included losses due to internal quarantine of the State, trade embargoes, or the losses associated with human recreational activities, such as hunting.

APHIS is in the process of eradicating TBTs from St. Croix and conducting surveillance activities on other islands such as St. Thomas and Puerto Rico. By enhancing surveillance and eradicating infestations of this pest, APHIS hopes to have no TBT infestations in the United States. FAD Diagnosticians have been sent out to the Caribbean to conduct heightened surveillance activities. Imported reptiles (e.g., turtles) are inspected for ticks at ports-of-entry such as Miami.

\section{Screwworm Eradication}

Cochliomyia homnivorax (Coquerel), the New World cattle screwworm, is found only in warm climates throughout the Americas. It is an obligatory parasite that feeds on tissue or fluids of all warmblooded living animals, including humans. The pest has been eradicated from the southeastern United States (1959), southwestern United States (1966), Mexico (1991), Belize and Guatemala (1994), El Salvador (1995), Honduras (1998), Nicaragua (1999), Costa Rica (2000), and Panama up to the Canal Zone (2001), using the sterile insect technique. The eradication of screwworms in North and Central America has had a significant and positive impact on Panama and on U.S. livestock producers.
A permanent barrier of prevention was established along with the permanent barrier for FMD in the Provinces of Darien and Comarca Kuna Yala in Panama. These provinces are by law regulated in animal production as a measure to reduce possible introduction of FMD into Panama. To maintain the barrier, an agreement was signed by the United States and Panama to build a screwworm-rearing facility to produce the sterile insects needed to maintain the barrier zone. A $\$ 40$ million screwworm mass-rearing facility in Panama is now under construction. The plant is expected to go into operation in early 2006.

In August 2003, the Government of Panama came into an agreement with the Government of Colombia to extend the dispersal of sterile flies 20 nautical miles into Colombia. The result of this activity was so positive that Colombian officials and livestock producers in Colombia expressed interest in a nationwide screwworm-eradication program.

The goal to eradicate screwworm in the United States, Mexico, and Central America has been accomplished with the barrier established in the isthmus of Panama and a buffer zone 20 nautical miles into Colombia. No case of screwworm was found in Panama from April to December 2004. Dispersal of sterile screwworm flies is ongoing as a preventive measure at the rate of about 36 million flies per week.

The National Veterinary Services Laboratories (NVSL) perform identifications for suspected screwworm infestations in the United States. The following tabulation lists the number of submissions NVSL received for myiases/suspected screwworms in each of the past few years.

\begin{tabular}{lcc} 
Year & $\begin{array}{c}\text { Number of } \\
\text { submissions }\end{array}$ & $\begin{array}{c}\text { Number of } \\
\text { positives }\end{array}$ \\
\hline 2001 & 161 & 0 \\
2002 & 102 & 0 \\
2003 & 74 & 0 \\
2004 & 74 & 0 \\
\hline
\end{tabular}

\section{CSF Surveillance}

The United States has been free of CSF since 1978. Should the disease be reintroduced, however, VS relies on two main surveillance systems for detecting CSF in domestically raised commercial swine. The first system is reporting by private practitioners, producers, diagnosticians, and slaughter inspectors of all suspicious cases that display clinical signs similar to an 
FAD. Suspicious cases reported to either the State Veterinarian or VS' Area Veterinarian-in-Charge (AVIC) initiate an FAD field investigation (see previous section). The second system entails CSF testing by VS' Foreign Animal Disease Diagnostic Laboratory (FADDL) of sera and tissues submitted from various sources, mostly diagnostic labs and VS field Veterinary Medical Officers. In CY 2003, FADDL tested 17,524 serum samples and 1,037 tissue samples from 35 States. In CY 2004, 17,188 serum samples and 1,166 tissue samples-a number of which were taken from feral swine-were tested for CSF. All samples were negative.

\section{The National Veterinary Stockpile (NVS)}

An NVS steering committee was formed in 2004 to make recommendations regarding vaccine formulations, products, reagents, storage and distribution as is stipulated in the Response Planning and Recovery Section of Homeland Security Presidential Directive 9 (HSPD 9). The purpose of the committee is to serve the Deputy Administrator, U.S. Department of Agriculture (USDA), VS in an advisory capacity concerning the composition of the stockpile.

As the leader of a Sector-Specific Agency (HSPD-7), the Secretary of Agriculture has responsibility for protection of the agricultural and food (meat, poultry, and egg products) infrastructure. USDA fulfills this responsibility in coordination with the Secretaries of Homeland Security and Health and Human Services, the U.S. Attorney General, and the Administrator of the Environmental Protection Agency to ensure that the combined Federal, State, and local response capabilities are adequate to respond quickly and effectively to a terrorist attack, major disease outbreak, or other disaster affecting the national agricultural or food infrastructure.

The goal of the NVS is to provide the best possible protection against the intentional or unintentional introduction of an FAD or the occurrence of a natural disaster affecting animal agriculture and the food system, which could have catastrophic health and economic effects throughout the United States.

By the end of 2004, the United States, in partnership with Canada and Mexico, had banked FMD virus vaccine in the North American FMD Vaccine Bank and had begun banking virus vaccine for AI.

\section{The Changing World of Emergency Management}

The $21^{\text {st }}$ century brought new threats and challenges for U.S. agriculture. Increased risks of disease associated with dramatic increases in global trade have brought a greater urgency to prevent, prepare for, respond to, and recover from all types of hazards that threaten American agriculture.

USDA has taken aggressive steps to protect our Nation by integrating the capabilities and resources of the Federal Government, States, Tribes, local communities, and private organizations into a seamless all-hazards National Emergency Management System.

The policy framework of the system includes HSPD 5, 7, 8, and 9; the National Response Plan (NRP); USDA Departmental Regulations (specifically 1800001); and VS mandates. HSPDs 5, 7, 8, and 9 are summarized as follows:

HSPD 5-Management of domestic incidents: National Incident Management System (NIMS) is established and Incident Command System (ICS) is used by all Federal agencies.

HSPD 7-Critical Infrastructure Identification, Prioritization, and Protection: DHS coordinates emergency preparedness and response.

HSPD 8-National Preparedness: The Federal Government provides assistance for all hazards to States and local entities. States and local entities follow the NIMS, which includes preparedness for and response to any major event.

HSPD 9-Defense of U.S. Agriculture and Food: This directive recognizes that agriculture is a critical infrastructure component and establishes a national policy to defend agriculture and food systems against terrorist attacks, major disasters, and other emergencies.

NIMS is a comprehensive incident response system developed by DHS at the request of HSPD 5 . NIMS is the Nation's first-ever standardized approach to incident management and response. NIMS unifies Federal, State, Tribal, territorial, and local lines of government into one coordinated effort. ICS protocols are critical components of NIMS and provide a 
common foundation for training and other efforts by communicating and sharing information with other responders and with the public. ICS orders resources to assist with response efforts and integrates new technologies and standards to support incident management. The goals are to have all of the Nation's emergency responders use a common language and a common set of procedures whether working individually or together.

The NRP establishes a comprehensive all-hazards approach to enhance the ability of the United States to manage domestic incidents. The plan incorporates best practices and procedures from incident-management disciplines-homeland security, emergency management, law enforcement, firefighting, public works, public health, responder and recovery worker health and safety, emergency medical services, and the private sector-and integrates them into a unified structure. It forms the basis of how the Federal Government coordinates with State, Tribal, and local governments and the private sector during incidents.

The NRP establishes agriculture as one of 12 critical infrastructures or Emergency Support Functions (ESFs), in which all steps in food production, from the farm to the table, are recognized for their contribution to the U.S. economy and public health.

ESF-1 1, Agriculture and Natural Resources, is an annex to the NRP. There are four functional categories and responsibilities associated with ESF-11, including provisions for nutrition assistance, animal and plant disease and pest response, assurance of the safety and security of the commercial food supply, and protection of natural and cultural resources and historic properties. APHIS coordinates animal and/ or plant disease and pest responses. ESF-11 also mandates that APHIS ensure that animal, veterinary, and wildlife issues in natural disasters are supported in coordination with the emergency support function that covers public health and medical services (ESF$8)$.

The broadening of APHIS' mission to include allhazards emergency preparedness and response has brought an uncommon challenge for APHIS. The new mission includes implementing the mandated roles and responsibilities related to all-hazards emergency management. APHIS-VS does not regulate emergency management per se but works to ensure that agricultural preparedness is a part of the national perspective.
APHIS has taken proactive steps to integrate emergency management procedures. ICS methods have been used by the agency to manage large-scale emergency disease control operations since 2002. In addition, all agency personnel have taken mandatory ICS training. Congress appropriated funds in FY 2003 APHIS Emergency Management for the establishment of Area Emergency Coordinators to provide emergency management guidance to State and local animal health officials. VS is building capacity in the field of emergency management to quickly become an integrated member of the national emergency management/homeland security community.

\section{FAD Emergency Response}

The U.S. emergency response to FAD events involves a partnership between various Federal, State, Tribal, local, and private-sector cooperators. Written response plans and guidelines address all areas of an emergency response, such as the initial field investigation; local disease control and eradication activities; emergency management, including line of command, planning, logistics, and resources; and interagency coordination. An effective emergency response requires extensive preparation and coordination. Emergency preparedness includes activities such as monitoring response plans, workforce training, and test exercises.

\section{Overview}

Most disease incidents begin with a suspicious event or unusual situation. In the animal health arena, the first lines of defense and detection are those individuals who work directly with livestock on a routine basis, such as brand inspectors, market workers, owners and producers, or private veterinarians, including accredited veterinarians. Findings that suggest FADs are reported to the Federal AVIC or the State Veterinarian, who initiate investigations.

The State and Federal counterparts work cooperatively on all FAD investigations. Standard procedures exist for investigating all suspect and confirmed FADs. Whenever there is any report that a disease may be of foreign origin, the Federal AVIC or State Veterinarian in that State will immediately assign the most readily available FAD Diagnostician to conduct a complete investigation. Trained at the USDA research center at Plum Island, NY, these diagnosticians are skilled in recognizing clinical signs of FADs and in collecting appropriate samples to send to NVSL in Ames, the FADDL, or both. 
If the field diagnosis indicates that the incident is highly likely to be an FAD, initial response activities are begun immediately. At the local level, these actions include State quarantining of the premises, interviewing the producer, instituting biosecurity measures, assessing the most probable source of infection, and determining the possible spread of disease through contact, movement, and inventory records. In most cases, the initial response to a highly likely or presumptive case of FAD will be activated using the local, State, and Federal agricultural authorities of the affected States. The Secretary of Agriculture has broad authority and discretion for responding to and eliminating animal disease. When needed, USDA authorities will be used to augment those of the States and to provide a portion of the funding for the response.

National policy for FAD eradication is coordinated within VS using the National Animal Health Emergency Management System (NAHEMS) guidelines. These guidelines are designed for use at any of three levels of response commensurate with the severity of the outbreak, including a local or limited response, a regional response, and a national response. During an FAD outbreak, VS evaluates the disease situation in the United States and works to implement controls or "regionalize" any remaining affected areas. In this way, disease eradication resources are focused in key areas, and animals in other parts of the country can be classified disease free, making them eligible for interstate movement, slaughter, and export. VS also works with agricultural officials in other countries and with OIE to relay critical disease-monitoring information and to keep export markets open for animals or regions certified disease free.

After the disease has been eradicated from the country, APHIS officials meet with Federal, State, Tribal, and local cooperators to assess FAD response activities. Such assessments aid in the development of new strategies for sharing resources and improving response efforts.

\section{NAHEMS in Detail}

NAHEMS is a Federal-State-industry partnership established in 1996 to improve the Nation's ability to respond to animal health emergencies. As part of this system, VS, in collaboration with its partners, has written a series of guidelines that provide an operational framework for use in dealing with an animal health emergency in the United States. Topics covered in these guidelines include

- Field investigations of animal health emergencies, - Implementation of an animal emergency response using the ICS,

Disease control and eradication strategies and policies,

- Operational procedures for disease control and eradication,

- Site-specific emergency management strategies for various types of facilities,

Administrative and resource management, and

Educational resources. 



\section{CHAPTER 6}

\section{Foreign Animal Disease (FAD) Status Evaluations: Regionalization, Risk Assessment, and Rulemaking}

\section{Background}

Before a country is allowed to import for the first time live animals or animal-origin commodities into the United States, VS personnel carefully evaluate the disease status of the exporting country and the risk of introducing FADs into the United States through a regionalization process. This process provides a systematic method for evaluating an exporting country-or a specific region within the country-for the presence of FADs and the likelihood that, if an FAD is found, the disease will be introduced into the United States. The presence of an FAD in an exporting country does not necessarily preclude trade with that country if the country employs effective regionalization controls among its own regions. Before a trade decision is made, Animal and Plant Health Inspection Service (APHIS) specialists establish remaining regionalization criteria, undertake a risk assessment, and devise suitable mitigation measures. If the risk of introducing FAD through importation is determined to be sufficiently low, then Veterinary Services (VS) initiates a rulemaking process that culminates in trade of the animals or products.

In October 1997, VS published these regionalization procedures, referred to as the "regionalization rule and policy statement."

The regionalization policy states that the United States will recognize the animal health status of (a) regions within countries or (b) regions composed of groups of countries rather than recognizing only regions defined by national boundaries, as the United States has done in the past.

\section{Initiation of the Regionalization Process}

The regionalization process begins when the Deputy Administrator in charge of APHIS' VS receives a request from the Chief Veterinary Officer of a government seeking authorization to export animals, animal products, or both to the United States. The request may refer to the entire country or region or may define subregions within the larger region. The request must be accompanied by information addressing the 11 risk factors defined in Title 9 Code of Federal Regulations (CFR), Part 92.2, as they pertain to each subregion under consideration. These risk factors are

Authority, organization, and infrastructure of the veterinary services organization in the region;

- Disease status of the region;

Status of adjacent regions with respect to the agent;

Extent of an active disease-control program;

- Vaccination status of the region;

Degree to which the region is separated from adjacent regions of higher risk through physical or other barriers;

- Extent to which movement of animals and animal products is controlled from regions of higher risk and the level of biosecurity regarding such movements;

Livestock demographics and marketing practices in the region;

- Type and extent of disease surveillance in the region;

Diagnostic laboratory capabilities; and

- Policies and infrastructure for animal disease control in the region (e.g., emergency response capacity). 


\section{Data Evaluation Process}

The regionalization request and supporting data are forwarded to the National Center for Import and Export (NCIE). NCIE is the VS unit with primary responsibility for international trade issues. These responsibilities include issuing import permits for animals and animal products, participating in negotiations with foreign governments on provisions for animal health certificates for animals and animal products, providing a liaison with the World Organisation for Animal Health (OIE), and coordinating the evaluation of animal health status for regionalization requests.

The Regionalization Evaluation Service Import, part of NCIE, is responsible primarily for coordinating the evaluation of animal health status with the import risk analyses for regionalization requests. Case managers coordinate responses to individual requests and serve as primary contact for the requesting countries.

After receiving the initial information, the case manager assembles a review team. Team members are drawn from various sources to obtain a wide range of technical expertise and program representation. Sources include the Centers for Epidemiology and Animal Health, International Services (IS), National Veterinary Services Laboratories, and other program staff as appropriate. The team includes individuals with technical expertise on the disease, commodity, and the country making the request.

Team members evaluate submitted information and provide comments to the case manager based on the evaluation and application of the 11 risk factors. Comments (1) address issues related to the risk of exporting disease agents to the United States, (2) identify both the strengths and weaknesses of the requesting country's veterinary system, and (3) identify and define data gaps in the information.

The case manager synthesizes the team comments and coordinates an official response to the designated contact in the requesting country. Often, the initial response amounts to a request for additional information.

\section{Verification Through Site Visits}

Once the initial review team deems the submitted information sufficient to justify proceeding with the evaluation, a site visit is planned to verify and complement the information provided and review local conditions. The team visits the site prior to completing the risk assessment. When possible, the site-visit team includes members of the initial review team. In addition, when the request is submitted simultaneously to Mexico, Canada, and the United States, the team may include veterinary officials from all three countries. A representative from the office of a State Veterinarian also participates.

\section{Risk Assessments}

Risk assessments are conducted using information provided by the requesting country, scientific literature, and information gathered during the site visit. The assessment can be either quantitative or qualitative and is compatible with the general guidelines provided by OIE (Terrestrial Animal Health Code, Part 1, Chapter 1.3.2).

The choice of approach depends on the nature of the request. In this regard, VS historically has conducted qualitative assessments when evaluating a country or region for a particular disease-free status and in many cases for commodity assessments. The qualitative approach is often more appropriate when data are inadequate for numerical evaluation and risk calculations would imply false precision. In cases where the qualitative assessment does not define risk clearly enough for a transparent decision, it may be further supported by a quantitative assessment.

Quantitative assessments also may be conducted as a first approach. However, if the initial information about the region, disease, or commodity suggests that a qualitative assessment lacks precision or documentation, a quantitative assessment is undertaken. For example, the practice of vaccination in a region may mask the active presence of a given disease. In this case, the analysis would require a quantitative, commodity-based approach using region-specific serologic data and vaccination records. 


\section{Rulemaking}

Once a risk assessment is complete, the rulemaking process begins. This process is coordinated by the Regulatory Analysis and Development branch of APHIS' Policy and Program Development unit. The draft rule undergoes legal and policy reviews within APHIS, other U.S. Department of Agriculture offices, and, occasionally, external groups such as the Food and Drug Administration and the Office of the U.S. Trade Representative. A proposed rule is published for public comment, and APHIS personnel consider those comments in the next part of the rulemaking process. As part of U.S. obligations under the World Trade Organization-Sanitary and
Phytosanitary Measures (WTO-SPS) agreement, all proposed rules that may affect trade are notified to the WTO to allow U.S. trading partners the opportunity to comment. However, if there is a need to implement an emergency SPS measure to prevent the transmission of a disease or pest from a foreign country, the United States may notify the WTO after implementation.

A proposed rule's provisions usually are implemented by a final rule in which APHIS' analysis of the public comments is presented and the content of the comments is addressed. For a more detailed description of the process, visit the VS-NCIE Web site: <http:/ /www.aphis.usda.gov/vs/ncie/country.html>. 


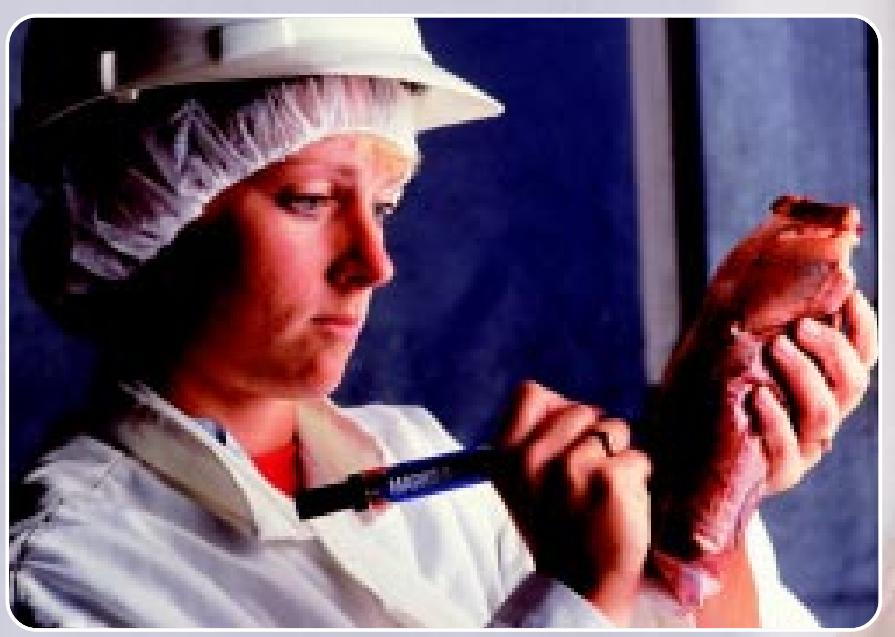




\section{CHAPTER 7 \\ U.S. Export Certification Procedures}

\section{Overview}

Veterinary Services (VS) oversees the export of live animals, their germ plasm (including embryos and semen), and also many animal products. VS' export functions include inspections of live animals and products at ports, inspection of export isolation facilities, and certification of live animals, veterinary biologics, and animal products intended for export.

VS also negotiates export protocols with foreign countries for the exportation of U.S. live animals and animal products. APHIS' International Regulation Retrieval System (IREGS) compiles information on foreign country requirements. This information is available online at

- http://www.aphis.usda.gov/NCIE/iregs/products (for animal products), and

- http://www.aphis.usda.gov/NCIE/iregs/animals (for live animals).

U.S. exporters can and should verify that the foreign country's import requirements listed in the IREGS system are current by contacting their State's VS area office at <http://www.aphis.usda.gov/vs/ area_offices.htm>, and

The Foreign Agricultural Service (FAS) officer located at the U.S. Embassy in the importing country (see <http://www.fas.usda.gov/scriptsw/ fasfield/ovs_directory_search.asp $>$ ).

Exporters should also consult the Food and Agricultural Import Regulations and Standards reports issued by FAS for more than 60 countries, found on the Web at <http://www.fas.usda.gov/itp/ofsts/ fairs_by_country.asp $>$.
For live-animal shipments, a veterinarian accredited by VS conducts required tests and prepares an export health certificate. For animal-product shipments, company officials complete the required export documents. Then the documents are forwarded to the VS area office for review and certification by either the Area Veterinarian-in-Charge (AVIC) or the export veterinary medical officer. However, if the exporter cannot meet all of the importing country's requirements, VS may contact the country's import officials in an attempt clarify the protocols in question. If a failure to clear customs is due to a new or changed inspection procedure or standard, the exporter is encouraged to contact the Animal and Plant Health Inspection Service (APHIS)-International Services (IS) or FAS field officers for the respective country (see <http://www.fas.usda.gov/scriptsw/fasfield/ ovs_directory_search.asp $>$ ).

VS also provides technical support when an exported U.S. product is detained at a foreign port. IS officials stationed overseas and FAS officers attempt to verify why the product is being detained to determine what, if anything, can be done to facilitate the shipment and to assist the exporter in obtaining any necessary documentation. Usually the matter is resolved and a waiver issued, allowing the shipment to be released to the importer. In some cases, however, the shipment is returned to the United States or destroyed and disposed of overseas. 


\section{Export Health Certificates and Health Statements}

Generally, export certificates are issued by the VS Area office. Staff at those offices undergo training to ensure consistency in the certification process and to make certain that the import protocols of foreign countries are understood and followed.

VS issues export certificates for many types of products. Normally, certification statements cover issues of particular animal species or diseases. For instance, a statement may document that the United States is free of foot-and-mouth disease. Statements also may include limited remarks about if and how a product was processed to eliminate micro-organisms of concern to the importing country.

The Center for Veterinary Biologics issues Certificates of Licensing and Inspection to biological manufacturers as an aid to foreign product registration. These certificates confirm that manufacturers are licensed with the U.S. Department of Agriculture (USDA) under the Virus-Serum-Toxin Act, that facilities and products have been inspected by USDA, and that there are no restrictions on the distribution of the manufacturers' products.

Many countries require both public-health and animal-health statements before a product is imported. U.S. agencies work together to facilitate this process when jurisdictions overlap. USDA's Agricultural Marketing Service certifies many different types of dairy products and table eggs. USDA's Food Safety and Inspection Service (FSIS) inspects meats, meat products, poultry, poultry products, and different types of egg products intended for human consumption. Again, VS approves the animal health statements and then FSIS certifies inspected products for export. The Food and Drug Administration (FDA) certifies most other types of foods. The U.S. Department of the Interior's U.S. Fish and Wildlife Service certifies some wild animals and wild-animal products. The National Marine Fisheries Service provides certification for fish meal and some aquaculture and seafood products; FDA and USDA-APHIS certify other aquaculture products.

Embryos, semen, cattle, horses, bison, cervids, sheep, goats, swine, poultry, and pet birds fall under USDA export protocols. Established requirements must be met to export these animals and animal products (see Title 9 Code of Federal Regulations [CFR], Part 91).
Except for animals transported by land to Canada and Mexico, cattle, horses, bison, cervids, sheep, goats, and swine must be exported from the United States via an approved port and be accompanied by an export health certificate. In addition, these animals must be transported to the port in vehicles that have been cleaned and disinfected according to APHIS regulations. If for any reason the animals have to be unloaded while en route to the port, unloading must be done under APHIS supervision at cleaned and disinfected facilities approved by VS to ensure that the animals are not exposed to any infectious agents. At the port, animals must enter an approved export inspection facility and remain there for at least 5 hours. While at the export inspection facility, and within 24 hours of export, all animals are inspected by an APHIS veterinarian.

Export health certificates for live animals must be issued by an accredited veterinarian. Certificates identify each individual animal and include species, breed, sex, age, and, if applicable, breed registration name and number, tag number, tattoo markings, or other natural or acquired markings. The certificate also must state that the animals were inspected and declared healthy. All test results and certification statements required by the importing country must be listed in the export health certificate, and the certificate must be endorsed by an authorized APHIS veterinarian.

When requested, APHIS also provides certification for dogs, cats, and laboratory animals leaving the country. Pertinent regulations appear in 9 CFR 91. VS helps exporters meet the receiving country's import requirements and certifies that the exporter has done so. These export health certificates can be issued by a licensed veterinarian unless the importing country requires specifically that an accredited veterinarian issue the certificates. These certifications also must include proper identification of the animals and animal products in question and must contain testing results and certification statements as required by the importing country. 


\section{CHAPTER 8 Epidemiologic Events in 2004}

This chapter documents important animal-health events that occurred in the United States in 2004, including surveillance for high-pathogenicity avian influenza (HPAI) in Washington State, an HPAI outbreak in Texas, the bovine spongiform encephalopathy (BSE) case investigation in Washington State, and an outbreak of spring viremia of carp.

\section{Avian Influenza (AI) in the United States}

AI viruses of subtype $\mathrm{H} 5$ or $\mathrm{H} 7$ are of particular concern because of their tendency to be or become highly pathogenic. In the past, only HPAI has been of trade significance. However, recent proposed changes in the World Organisation for Animal Health (OIE) Terrestrial Animal Health Code call for recognizing all viruses of $\mathrm{H} 5$ or $\mathrm{H} 7$ subtypes as potential animal health risks to be reported to the OIE. Thus, VS responds similarly to both HPAI and lowpathogenicity avian influenza (LPAI).

Since 1986, the Animal and Plant Health Inspection Service (APHIS) and State officials have monitored live-bird markets in the Northeastern United States for the presence of AI viruses. During 2004, H7N2 virus was isolated from markets in New York, New Jersey, and Connecticut, and $\mathrm{H} 7 \mathrm{~N} 3$ and $\mathrm{H} 5 \mathrm{~N} 8$ viruses were isolated from markets in New York.

The recurrence of LPAI in U.S. commercial poultry during the past decade has temporarily closed many foreign markets to U.S. poultry and poultry products.

In February 2004, a low-pathogenicity H7N2 AI virus was isolated in a 12,000-bird noncommercial broiler flock in Delaware. This flock had an epidemiologic link to a New Jersey live-bird market.

Extensive surveillance detected a single positive commercial flock of 72,000 4-week-old broilers located 5 miles from the Delaware flock. Although there was no epidemiologic link between the two premises, the H7N2 viruses found at both locations were indistinguishable. No other AI-positive flock was detected.
The positive premises were depopulated, cleaned, and disinfected.

In March 2004, LPAI H7N2 virus was confirmed in a Maryland flock of 118,000 6-week-old broilers. The infection was detected as a result of a premovement testing program established in response to the LPAI H7N2 infections discovered the previous month in Delaware. The Maryland flock was depopulated. In addition, 210,000 2-week-old broilers located within 1 mile of the positive premises - and owned by the same company-were preemptively depopulated as a proactive step to prevent spread of infection. Molecular studies showed that the H7N2 virus from the Maryland flock was related to recent H7N2 viruses from the live-bird markets in the Northeastern United States but differed from the Delaware H7N2 virus.

In May 2004, routine serologic surveillance detected antibodies to H7N3 in two commercial breeder (chicken) premises and one small backyard flock in Texas, although none of the flocks showed clinical signs of infection. Attempts to isolate the virus were unsuccessful, and extensive surveillance did not identify additional positive flocks. All three flocks were destroyed.

\section{HPAI Surveillance in Washington State}

In April 2004, the presence of HPAI H7N3 virus in the Frazer Valley, British Columbia, Canada, prompted the U.S. Department of Agriculture (USDA) to activate the incident command system to conduct AI surveillance along the U.S-Canadian border in Washington State.
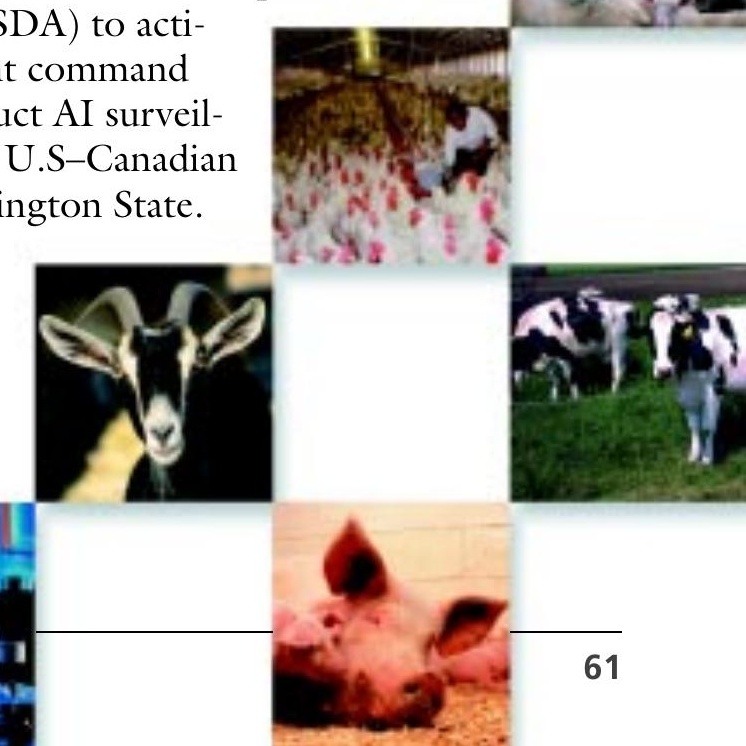
Voluntary testing of backyard and commercial flocks within a 10-mile zone adjacent to the Canadian border generated 1,621 specimens for real-time reverse-transcriptase-polymerase chain reaction testing and 2,863 serum samples for detection of AI virus antibodies. No H7N3-positive flocks were detected.

\section{HPAI Outbreak in Texas}

On February 16, 2004, AI virus infection was diagnosed in chickens submitted to the Texas Veterinary Medical Diagnostic Laboratory. The chickens sampled had come from a flock of approximately 6,600 broilers. Located in Gonzales County, TX, this premises supplied birds to live-bird market retail premises in Houston. An immediate response by the Texas Animal Health Commission (TAHC) aimed at LPAI began on February 17.

However, on February 23, the National Veterinary Services Laboratories (NVSL) reported that an AI virus of subtype $\mathrm{H} 5 \mathrm{~N} 2$ was isolated from specimens collected at the infected premises. Although the mortality caused by the virus was low, it was determined to be HPAI virus based on amino acid profile at the hemagglutinin cleavage site. Virus pathogenicity tests completed at NVSL on March 1 characterized the virus as avirulent.

Response: Control and Eradication-TAHC initiated the response to LPAI on February 17 and

Depopulated the infected premises, Investigated infected premises contacts, Controlled movement from all contact premises, and

Performed active surveillance (serologic) of all premises within $16 \mathrm{~km}$ of the index premises.

The amplified response to HPAI H5N2 began on February 23 and

Established a joint TAHC-USDA incident command post,

Controlled movement in an area within $8 \mathrm{~km}$ of the index premises, Expanded surveillance activities,

Increased the number of surveillance teams and support staff,

Implemented the Geographic Information System and the Emergency Management Response information system, and

Initiated a statewide public awareness campaign.
Final Surveillance-A 4-week surveillance plan for Texas was developed on February 27, 2004, to demonstrate "freedom" from H5N2 AI virus in the surveillance area and live-bird market system. The plan was initiated on March 2, 2004, and established three zones in the surveillance area: affected, surveillance, and buffer zones. Samples were required

Four times a week for 4 weeks from all live-bird market supplier premises,

- Four times a week for 4 weeks from all avian premises in the affected zone (within $8 \mathrm{~km}$ of the index premises),

- Samples were collected during week 1 and again in week 4 from all avian premises in the surveillance zone (within 8 to $16 \mathrm{~km}$ of the index premises), and

During weeks 3 and 4 (one collection each week) from noncommercial premises within $1.5 \mathrm{~km}$ of commercial premises located in the buffer zone (within 16 to $50 \mathrm{~km}$ from the index premises).

All samples collected during the 4-week surveillance period tested negative for HPAI H5N2 virus. In all, 3 quarantines and 59 hold orders were put in place. Tables 12 and 13 summarize the number of premises sampled during the surveillance period.

TABLE 12

\begin{tabular}{|c|c|c|}
\hline \multicolumn{3}{|c|}{$\begin{array}{l}\text { Response activities to HPAl-infected premises } \\
\text { in Texas, } 2004\end{array}$} \\
\hline Activity & $\begin{array}{c}\text { Infected } \\
\text { premises (IP) } \\
\text { (cumulative) }\end{array}$ & $\begin{array}{l}\text { Date last } \\
\text { IP disclosed }\end{array}$ \\
\hline & 3 & February 22 \\
\hline $\begin{array}{l}\text { Euthanasia and } \\
\text { disposal (E\&D) }\end{array}$ & 6 & $\begin{array}{l}\text { Date of last E\&D } \\
\text { February } 23\end{array}$ \\
\hline $\begin{array}{l}\text { Cleaning and } \\
\text { disinfection (C\&D) }\end{array}$ & 6 & $\begin{array}{l}\text { Date of last C\&D } \\
\text { March } 11\end{array}$ \\
\hline
\end{tabular}

TABLE 13

\begin{tabular}{c|c|c|c|c|c|c}
\hline Sampling & \multicolumn{9}{c}{ Samples } \\
& \multicolumn{9}{c}{ Serum } & \multicolumn{2}{c}{ Swab } & \multicolumn{2}{c}{ Tissue } \\
\hline \multirow{2}{*}{ Premises } & (neg) & (pos) & (neg) & (pos) & (neg) & (pos) \\
\hline 357 & 3,608 & 19 & 3,685 & 5 & 8 & 3 \\
\hline
\end{tabular}


Controlled Movements-Controlled movement of birds to the live-bird market retail premises was allowed beginning March 6, 2004. Movement permits were issued to suppliers whose flocks had been sampled repeatedly (at least two times in addition to the initial round of surveillance testing) and tested negative for AI virus. Retail premises were inspected weekly, and birds were examined. Birds were not allowed to leave retail premises unless slaughtered.

Movement of eggs and birds from controlled zones to other facilities (hatcheries, egg processors, live-bird markets, and feedstores) was allowed by permit beginning March 11, 2004. Before movement permits were issued, VS required that birds on the origin premises be sampled and test negative for AI virus during the initial survey and at least twice during the final surveillance.

Quarantine and Hold Order Release-Quarantines placed on the three infected premises (index flock and two live-bird markets) were released on March 30,2004 , following confirmation of negative test results on all surveillance samples. Hold orders placed on commercial and noncommercial poultry operations in the affected zone and on live-bird market suppliers were lifted effective March 30, 2004, following confirmation of negative test results on all surveillance samples.

Public Information-A comprehensive information campaign implemented a variety of distribution methods to alert and inform the poultry industry and the public about the outbreak, AI, and biosecurity methods. Feedstores within $50 \mathrm{~km}$ of the index premises were visited and provided display materials and factsheets in Spanish and English. Information updates and AI and biosecurity factsheets were distributed via a TAHC e-mail database of more than 20,000 members that included media outlets, government agencies, private and public stakeholders, school professionals, and veterinarians. Regular mail also was used to reach poultry trade associations and private veterinary practitioners. See chapter 5 for information on the current U.S. AI surveillance program.

\section{Washington State BSE Case Investigation}

On December 23, 2003, USDA-APHIS announced that samples taken from a 6.5-year-old Holstein cow in Washington State had tested positive for BSE. This preliminary diagnosis by the NVSL was confirmed on December 25, 2003, by the Central Veterinary Laboratory in Weybridge, UK.

The cow in question had first come under scrutiny when delivered to a slaughter plant in Moses Lake, WA, on December 9, 2003. Her status was identified as nonambulatory and attributed to complications from calving 10 days previously. However, per the USDA-APHIS BSE surveillance protocol regarding nonambulatory animals, a brain sample was taken from the animal and submitted to NVSL for testing. In addition, all potential high-risk materials from the cow were diverted from the human food supply to inedible rendering.

The United States' investigation included a complete traceout of the cow's progeny, birth cohort, and feed cohort, in accordance with OIE guidelines. A Canadian investigation was initiated after it was determined that the cow's birth herd was from an Alberta dairy farm.

The Food and Drug Administration (FDA) - the agency responsible for tracing rendered animal materials-located more than 20 tons of feedstuff potentially contaminated by materials from the infected cow. The feedstuff was contained, and none of it entered the animal-feed manufacturing system. The FDA investigation concluded that all locations that handled materials from the infected cow complied with the feed ban regulations.

The cow's birth herd was traced by USDA and the Canadian Food Inspection Agency (CFIA). The cow had been part of a shipment of 81 cattle exported from Canada to Washington State on September 4, 2001. The remainder of the cattle shipment was located or was determined to be dead. These animals were not part of the infected cow's birth herd.

The animals subject to culling (birth cohorts) under OIE guidelines were those animals born into the infected cow's birth herd 1 year before and 1 year after the infected cow's birth (April 1997). CFIA's traceout investigation concluded that 57 animals 
were born into the birth herd between April 1996 and April 1998. Twenty-seven of these animals were traced and confirmed dead; 25 (including the infected cow) had been exported to the United States; 2 were untraceable; and 3 were still in Alberta. These three animals were humanely destroyed, and all three tested negative for BSE.

CFIA also investigated possible feed sources that may have infected the index cow. Although results were not conclusive, they suggested that the source was a dairy ration (produced before the 1997 feed ban) that contained meat and bone meal from a local renderer.

Epidemiologic tracing in the United States located 255 "animals of interest" that were or could have been from the birth herd in Alberta, Canada. These animals were identified on 10 premises in 3 States in the Pacific Northwest (Washington, Oregon, and Idaho). All 255 animals were depopulated and tested negative for BSE.

The infected cow's two most recent calves were traced to two locations in Washington State. A heifer, born on November 9, 2002, was located on the index herd premises, depopulated, and tested negative for BSE. The most recent progeny was a bull calf, born on November 29, 2003, and was located in a rearing facility. Since the bull calf did not have any individual identification, all 449 bull calves on the premises were euthanized. The bull calves were not tested for BSE because they were all younger than the minimum age recommended for testing.

\section{Spring Viremia of Carp (SVC)}

Considered a foreign animal disease in the United States, SVC was diagnosed in the spring of 2002 at a private koi farm with facilities in North Carolina and Virginia. The farm was depopulated, cleaned, and disinfected in 2003. Also in 2002, SVC virusexposed feral carp were found in the Mississippi River drainage at Cedar Lake, WI, in the St. Croix and Apple Rivers, and in Pool 10 of the Mississippi River.

In 2003, the U.S. Fish and Wildlife Service conducted SVC surveillance as part of its ongoing National Wild Fish Health Survey, including locations around the known risk areas identified in 2002. Samples collected near the North Carolina-Virginia farm tested negative for SVC by serology and virus isolation. Samples taken near Chicago from the Calumet-Sag Channel-part of the Mississippi River drainage-tested positive for SVC by virus isolation.

\section{SVC Occurrences}

During 2004, SVC was confirmed in koi carp at two U.S. premises via voluntary submissions to diagnostic laboratories. The first case occurred in a backyard pond in Snohomish County, WA. The pond had no connection to natural waterways; however, koi purchased from a pet shop that spring had been introduced to the pond and may have been the source of infection. Approximately 100 goldfish in the pond showed no clinical signs of disease. The pond was depopulated, cleaned, and disinfected. The traceback that led to the pet store was undertaken, but no further SVC cases were identified. Subsequently, the pond has been restocked and is being monitored for SVC.

The second SVC case in 2004 occurred at a koi carp farm in Pike County, MO. The outbreak occurred after the introduction of koi in June. Within 2 weeks of the koi introduction, nearly 70 percent of the farm's 500 susceptible fish were dead. Tracebacks to the farm of origin and intermediate transport facilities yielded negative results. All ponds and raceways on the operation were depopulated and disinfected. Nonsusceptible species were restocked into the raceways, and no further disease outbreaks have occurred. 


\section{Surveillance in 2003-04}

To detect SVC virus, sampling must be done at water temperatures that normally occur in the United States during spring and fall. Therefore, in 2003 APHIS conducted SVC surveillance of farmed goldfish, carp, and koi carp from April to June and from September to December. Testing in the spring was conducted on 3,300 fish in 12 States on 34 sites as part of the official surveillance or as part of a voluntary health-certification program. All results were negative for SVC. Fall sampling was conducted in 8 States, and 3,390 fish from 30 sites were tested. Once more, all results were negative for SVC.

During 2004, surveillance continued on farms around the country. All tests (586) on koi from the North Carolina-Virginia farm were negative for SVC. Other samples from operations in Arkansas, Florida, Indiana, and Missouri $(6,330)$ also tested negative. No fish caught in the wild and sampled by the U.S. Fish and Wildlife Service tested positive for SVC in 2004 .

\section{Current Status of Import Protocols}

APHIS is preparing a general import protocol for all fish imported to the United States that are susceptible to SVC virus to prevent further introductions of the disease and to protect farmed populations of SVC-susceptible fish. 


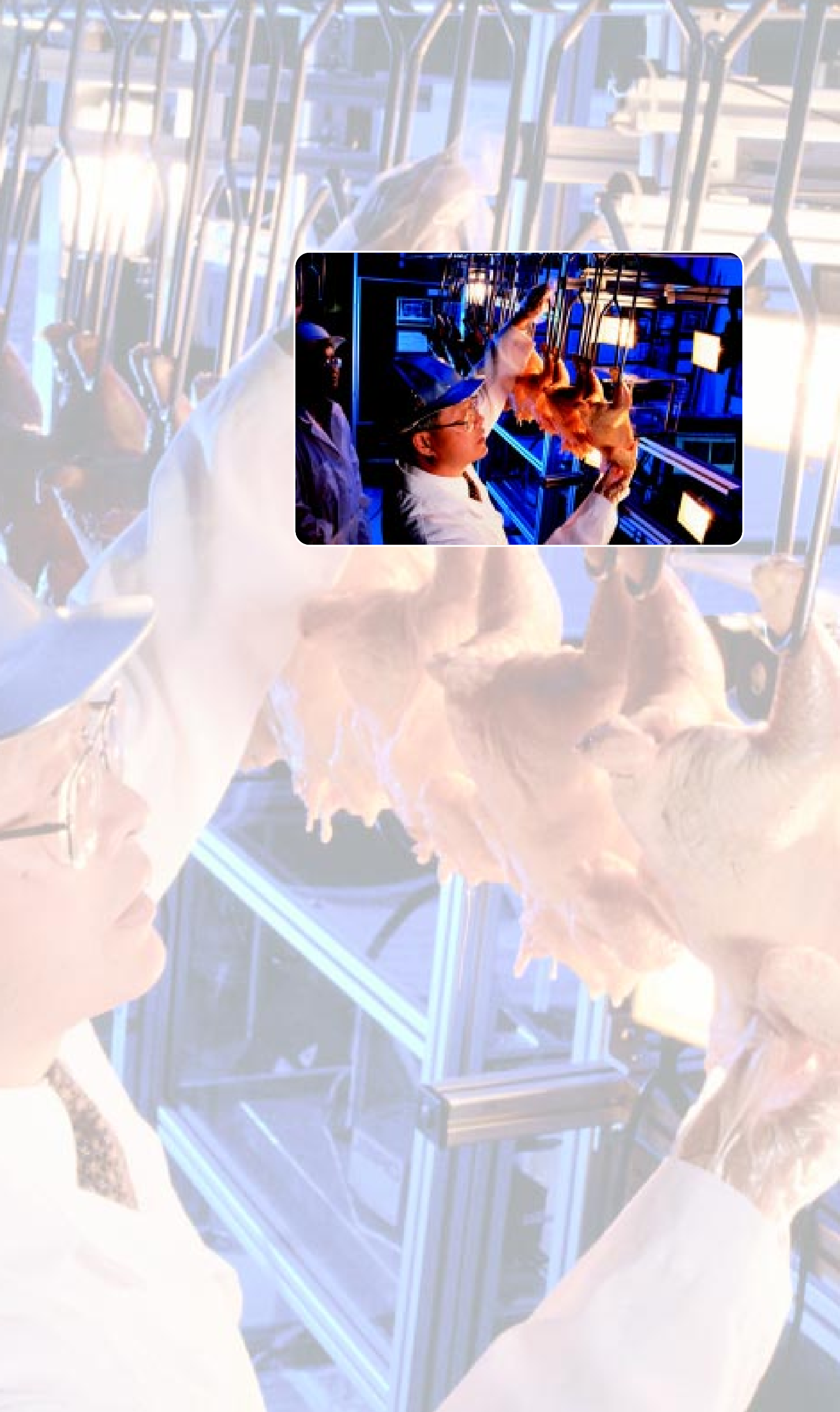




\section{A P PENDIX 1 \\ Commodity Tables}

TABLE A1.1

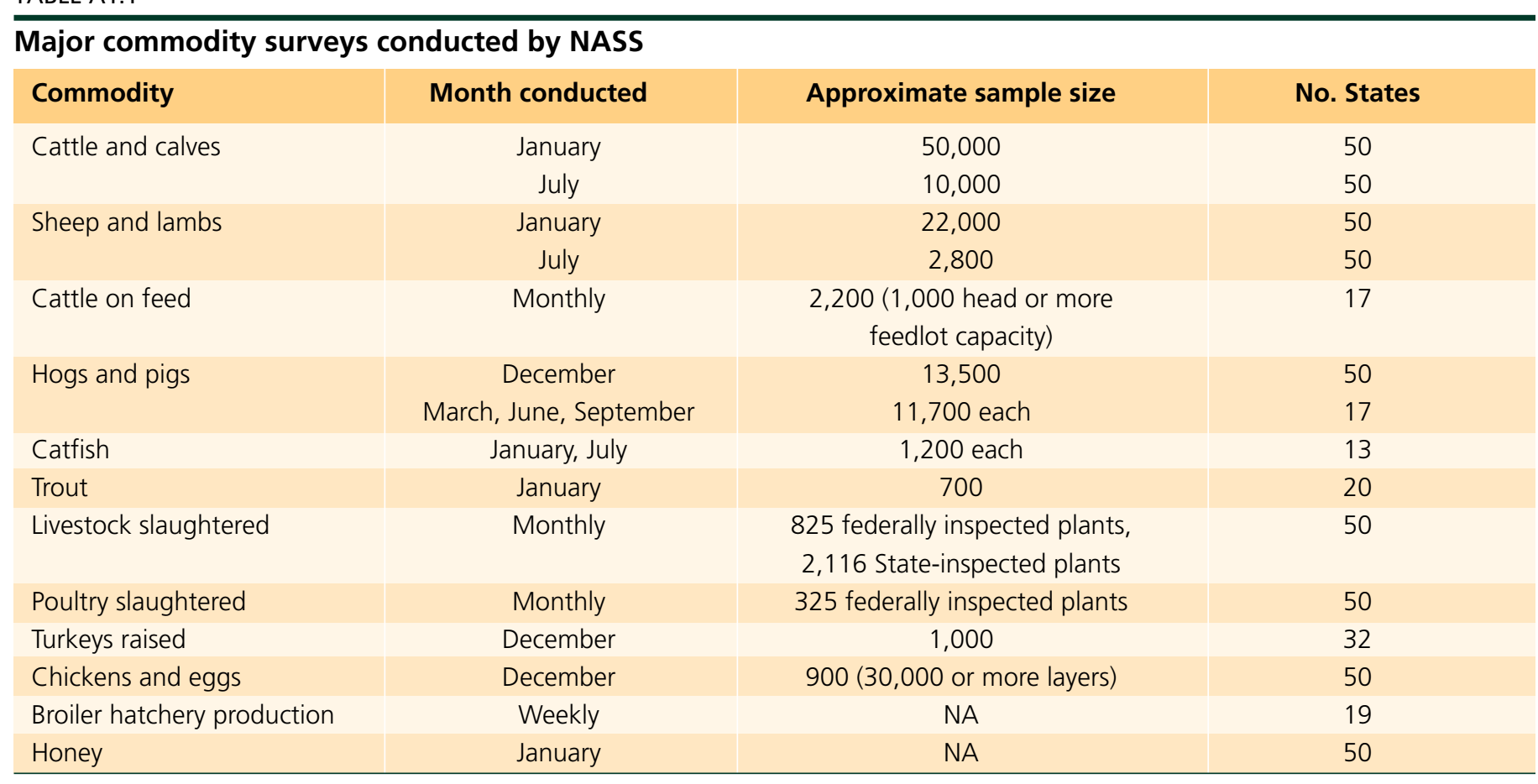

$\mathrm{NA}=$ not available.

TABLE A1.2

Value of production for selected agricultural commodities for 2003 and 2004

\begin{tabular}{|c|c|c|c|c|}
\hline Commodity & $\begin{array}{c}2003 \\
(\$ 1,000)\end{array}$ & $\begin{array}{c}\text { Percent } \\
\text { of } \\
\text { total } \\
\text { value }\end{array}$ & $\begin{array}{c}2004 \\
(\$ 1,000)\end{array}$ & $\begin{array}{c}\text { Percent } \\
\text { of } \\
\text { total } \\
\text { value }\end{array}$ \\
\hline Cattle & $32,112,931$ & 16.5 & $34,887,821$ & 16.7 \\
\hline Milk from milk cows & $21,381,324$ & 11.0 & $27,549,413$ & 13.1 \\
\hline Poultry & $23,295,445$ & 12.0 & $28,872,757$ & 13.8 \\
\hline Swine & $9,663,024$ & 5.0 & $13,071,677$ & 6.2 \\
\hline Catfish and trout & 489,070 & 0.3 & 548,891 & 0.3 \\
\hline Sheep, including wool & 419,891 & 0.2 & 442,264 & 0.2 \\
\hline Honey & 253,106 & 0.1 & 201,790 & 0.1 \\
\hline Total of preceding livestock and products ${ }^{1}$ & $87,614,791$ & 45.1 & $105,574,613$ & 50.4 \\
\hline Field and miscellaneous crops & $82,244,236$ & 42.3 & $78,004,294$ & 37.2 \\
\hline Fruits and nuts & $13,332,082$ & 6.9 & $14,621,703$ & 7.0 \\
\hline Commercial vegetables & $11,140,197$ & 5.7 & $11,207,834$ & 5.4 \\
\hline Total value of preceding crops & $106,716,515$ & 54.9 & $103,833,831$ & 49.6 \\
\hline All commodities above & $194,331,306$ & 100.0 & $209,408,444$ & 100.0 \\
\hline
\end{tabular}

1Production data for equines were not available. 
TABLE A1.3

Cattle and calves production, ${ }^{1} 2003$ and 2004

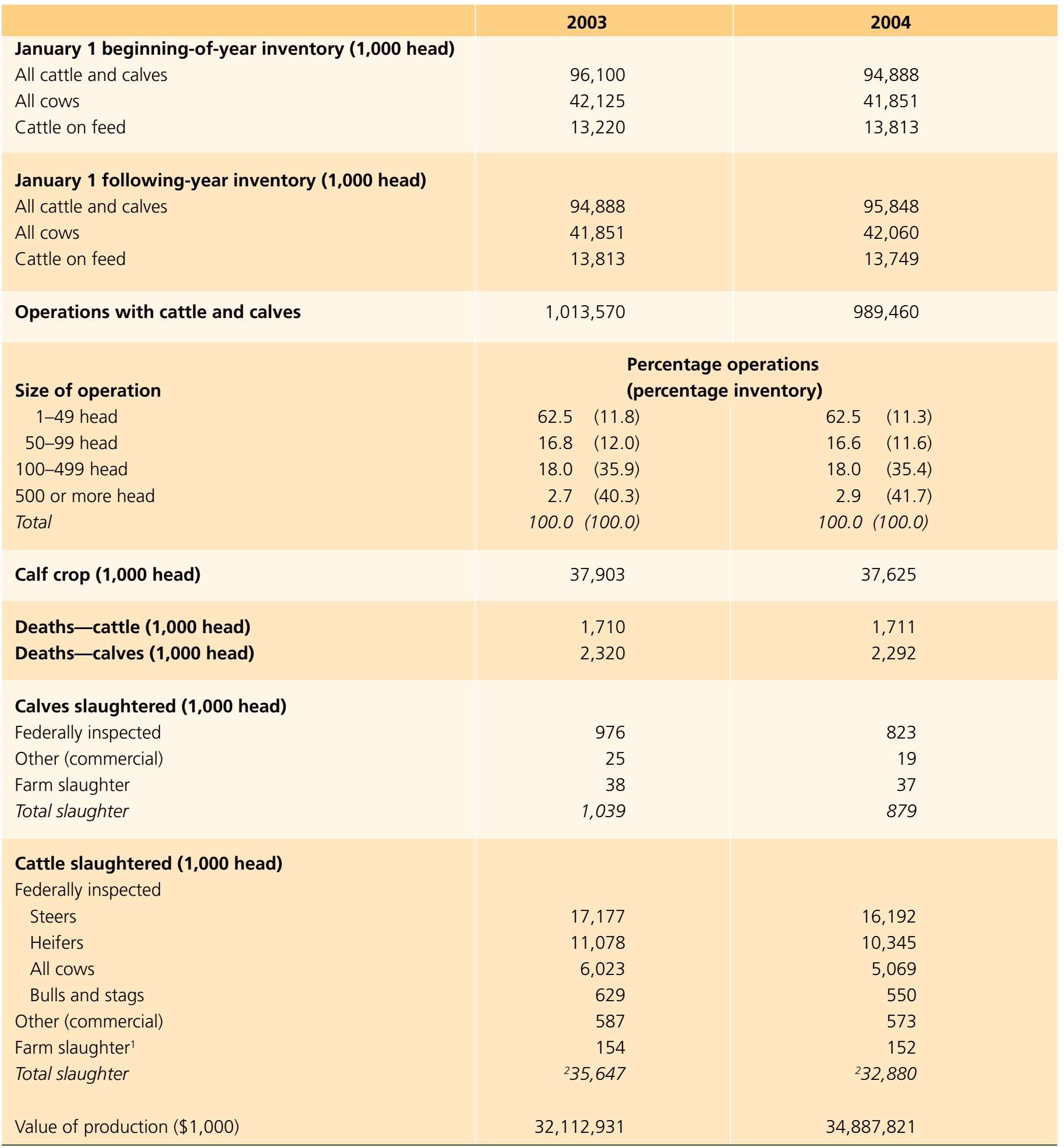

Source: USDA-NASS.

${ }^{1}$ Farm slaughter includes animals slaughtered on farms primarily for home consumption. It excludes custom slaughter for farmers at commercial establishments but includes mobile slaughtering on farms.

${ }^{2}$ May not total due to rounding. 
TABLE A1.4

Milk cow production, 2003 and 2004

\begin{tabular}{|c|c|c|}
\hline & 2003 & 2004 \\
\hline \multicolumn{3}{|l|}{ January 1 beginning-of-year inventory (1,000 head) } \\
\hline Milk cows & 9,142 & 8,990 \\
\hline Milk replacement heifers & 4,114 & 4,020 \\
\hline \multicolumn{3}{|l|}{ January 1 following-year inventory (1,000 head) } \\
\hline Milk cows & 8,990 & 9,005 \\
\hline Milk replacement heifers & 4,020 & 4,133 \\
\hline \multirow[t]{2}{*}{ Operations with milk cows } & 86,360 & 81,440 \\
\hline & \multicolumn{2}{|c|}{$\begin{array}{l}\text { Percentage operations } \\
\text { (percentage inventory) }\end{array}$} \\
\hline 1-29 head & $(2.3)$ & 29.1 \\
\hline 30-49 head & $(6.9)$ & 19.1 \\
\hline 50-99 head & $29.9 \quad(18.8)$ & $29.5 \quad(17.8)$ \\
\hline 100-199 head & $12.7 \quad(15.7)$ & $12.8(15.1)$ \\
\hline 200-499 head & $5.5 \quad(15.4)$ & $5.8 \quad(15.3)$ \\
\hline 500 or more head & $3.4 \quad(40.9)$ & $3.7 \quad(43.1)$ \\
\hline Total & $100.0(100.0)$ & $100.0(100.0)$ \\
\hline \multicolumn{3}{|l|}{ Cows slaughtered (1,000 head), federally inspected } \\
\hline Dairy cows & 2,860 & 2,363 \\
\hline Other cows & 3,163 & 2,706 \\
\hline All cows & 6,023 & 5,069 \\
\hline \multicolumn{3}{|l|}{ Milk production } \\
\hline Average number of milk cows during year ( 1,000 head) & 9,083 & 9,010 \\
\hline Milk production per milk cow (lb) & 18,760 & 18,957 \\
\hline Milk fat per milk cow (lb) & 688 & 696 \\
\hline Percentage of fat & 3.67 & 3.67 \\
\hline Total milk production (million lb) & 170,394 & 170,805 \\
\hline Value of milk produced $(\$ 1,000)$ & $21,381,324$ & $27,549,413$ \\
\hline
\end{tabular}

Source: USDA-NASS. 
TABLE A1.5

Beef cow production, 2003 and 2004

January 1 beginning-of-year inventory (1,000 head)

Beef cows

Beef replacement heifers

\section{January 1 following-year inventory (1,000 head)}

Beef cows

Beef replacement heifers

Operations with beef cows

\section{Size of operation}

$$
\begin{aligned}
& \text { 1-49 head } \\
& \text { 50-99 head }
\end{aligned}
$$

100-499 head

500 or more head

Total

\section{Cows slaughtered (1,000 head) Federally inspected}

Dairy cows

Other cows

All cows

Source: USDA-NASS.
32,983
32,861

5,624

5,518

32,861

33,055

5,518

5,746

792,050

774,630

Percentage operations (percentage inventory)

$78.3(29.1)$

$77.7 \quad(28.1)$

$12.1 \quad(19.0)$

$12.3 \quad(19.1)$

$9.3(38.3)$

$0.7 \quad(14.5)$

$0.7 \quad(14.4)$

$100.0(100.0)$

TABLE A1.6

\section{Cattle-on-feed production, 2003-05}

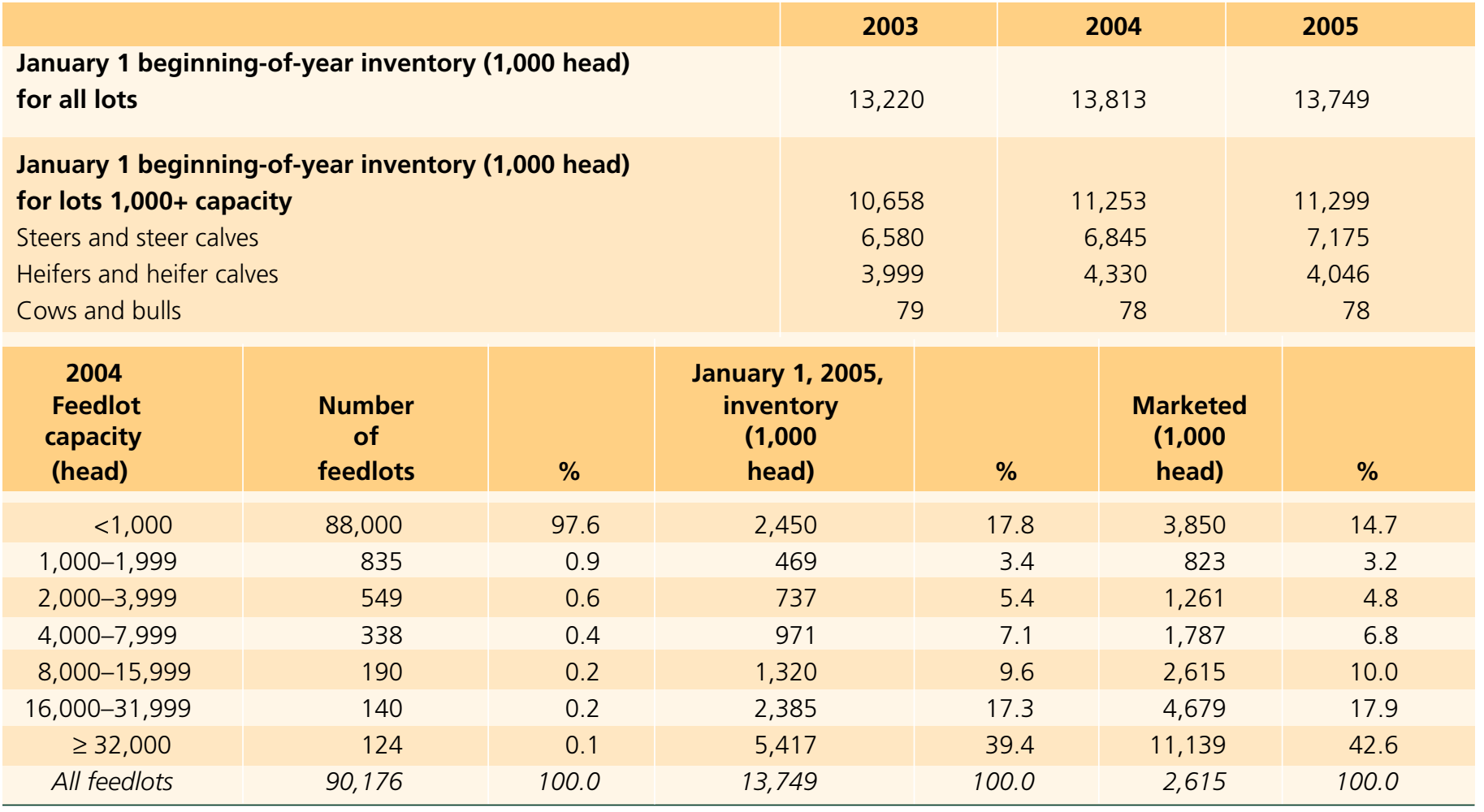

Source: USDA-NASS.

$2,860 \quad 2,363$

$3,163 \quad 2,706$

$6,023 \quad 5,069$ 
Hog and pig production, 2003 and 2004

2003

2004

December $1^{1}$ beginning-of-year inventory (1,000 head)

All hogs and pigs

59,554

260,444

Breeding

6,058

6,009

Market

53,496

54,434

December 1 end-of-year inventory (1,000 head)

All hogs and pigs

260,444

${ }^{2} 60,645$

Breeding

6,009

5,969

Market

54,434

54,675

Operations with hogs and pigs

73,720

69,420

Size of operation

1-99 head

100-499 head

500-999 head

1,000-1,999 head

2,000-4,999 head

$\geq 5,000$ head

Total

\begin{tabular}{rrrr}
\multicolumn{5}{c}{$\begin{array}{c}\text { Percentage operations } \\
\text { (percentage inventory) }\end{array}$} \\
60.4 & $(1.0)$ & 60.5 & $(1.0)$ \\
15.6 & $(4.5)$ & 15.0 & $(4.0)$ \\
7.7 & $(6.5)$ & 7.4 & $(6.0)$ \\
6.6 & $(11.0)$ & 6.4 & $(10.0)$ \\
6.6 & $(24.0)$ & 7.4 & $(26.0)$ \\
3.1 & $(53.0)$ & 3.3 & $(53.0)$ \\
100.0 & $(100.0)$ & 100.0 & $(100.0)$
\end{tabular}

102,457

December-November

Pigs per litter

December-November ${ }^{1}$

8.88

8.94

Deaths (1,000 head)

7,646

7,462

Slaughter (1,000 head), federally inspected

Barrows and gilts

96,242

98,831

Sows

3,215

3,271

241

259

1,233

1,103

112

110

101,043

2103,573

Total slaughter

Value of production $(\$ 1,000)$

$9,663,024$

$13,071,677$

Source: USDA-NASS.

'December of the preceding year.

${ }^{2}$ May not total due to rounding. 
Sheep production in the United States, 2003 and 2004

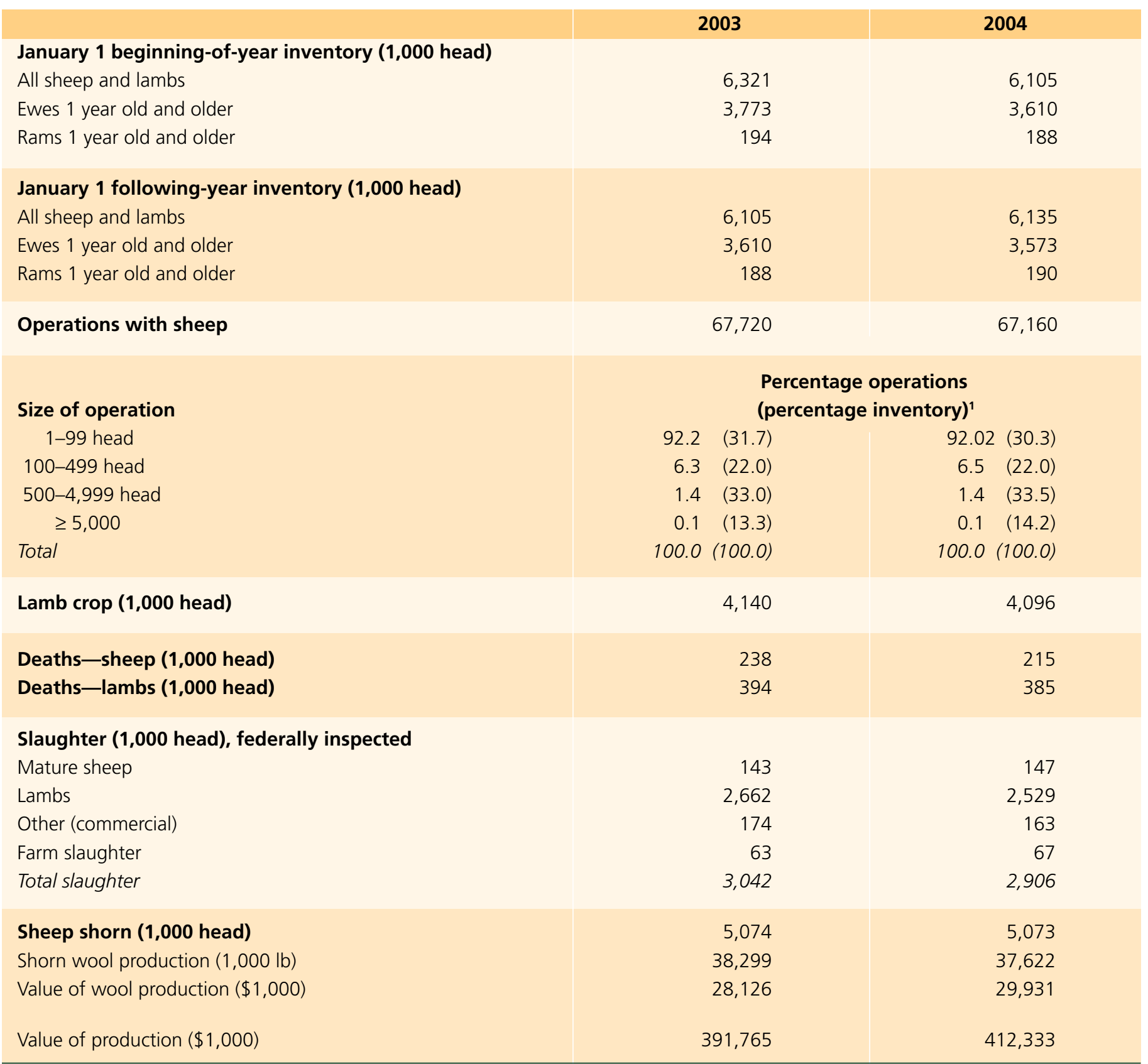

Source: USDA-NASS.

${ }^{1}$ End-of-year survey for breeding sheep (inventory). 
Poultry production in the United States, 2003 and 2004

\begin{tabular}{|c|c|c|}
\hline & 2003 & 2004 \\
\hline December 1 total layers $(1,000$ head $)$ & 340,979 & 344,278 \\
\hline Annual average number of layers $(1,000$ head $)$ & 338,393 & 342,279 \\
\hline Total egg production (million eggs) & 87,473 & 89,131 \\
\hline Number of broilers produced ( 1,000 head) & $8,492,850$ & $8,740,650$ \\
\hline Number of chickens lost (1,000 head) & 86,862 & 101,079 \\
\hline Number of turkeys raised $(1,000$ head) & 274,048 & 264,207 \\
\hline Young turkeys lost as a percentage of total poults placed & 11.2 & 10.4 \\
\hline \multicolumn{3}{|l|}{ Number slaughtered (1,000 head) } \\
\hline Turkeys-young & 264,753 & 251,563 \\
\hline Turkeys—old & 3,028 & 2,745 \\
\hline Turkeys-total & 267,781 & 254,308 \\
\hline Ducks & 24,301 & 25,967 \\
\hline \multicolumn{3}{|l|}{ Value of production $(\$ 1,000)$} \\
\hline Broilers & $15,214,947$ & $20,446,086$ \\
\hline Eggs & $5,333,014$ & $5,303,244$ \\
\hline
\end{tabular}

Source: USDA-NASS.

TABLE A1.10

\section{Equine production in the United States, 1997 and 1998}

\begin{tabular}{l|r|r} 
& $\mathbf{1 9 9 7}$ & $\mathbf{1 9 9 8}$ \\
\hline End-of-year ${ }^{\mathbf{1}}$ inventory (1,000 head) & 5,250 & 5,317 \\
\hline On farms & 3,200 & NA \\
On nonfarms & 2,050 & NA \\
Number sold & 540 & 558 \\
Value of sales $(\$ 1,000)$ & $1,641,196$ & $1,753,996$ \\
\hline
\end{tabular}

Source: USDA-NASS (March 2, 1999).

January 1 of the following year. 
TABLE A1.11

Catfish and trout production in the United States, 2003 and 2004

\begin{tabular}{|c|c|c|}
\hline & 2003 & 2004 \\
\hline \multicolumn{3}{|c|}{$\begin{array}{l}\text { Catfish } \\
\text { Number of fish on January } 1 \text {, following year }(1,000)\end{array}$} \\
\hline $\begin{array}{l}\text { Foodsize } \\
\text { Stockers } \\
\text { Fingerlings } \\
\text { Broodfish }\end{array}$ & $\begin{array}{r}356,839 \\
855,522 \\
727,071 \\
1,098\end{array}$ & $\begin{array}{r}344,085 \\
655,080 \\
704,160 \\
1,034\end{array}$ \\
\hline $\begin{array}{l}\text { Number of operations on } \\
\text { January } 1 \text {, following year }\end{array}$ & 1,147 & 1,158 \\
\hline $\begin{array}{l}\text { Sales }(\$ 1,000) \\
\text { Foodsize } \\
\text { Stockers } \\
\quad \text { Fingerlings } \\
\text { Broodfish } \\
\text { Total sales }\end{array}$ & $\begin{array}{r}397,072 \\
6,304 \\
21,225 \\
423 \\
425,024\end{array}$ & $\begin{array}{r}450,873 \\
6,260 \\
22,175 \\
867 \\
480,175\end{array}$ \\
\hline $\begin{array}{l}\text { Trout } \\
\text { Number of fish sold }(1,000) \\
\quad \geq 12 \text { inches } \\
6-12 \text { inches } \\
1-6 \text { inches }\end{array}$ & $\begin{array}{r}46,056 \\
6,413 \\
7,357\end{array}$ & $\begin{array}{r}47,481 \\
5,528 \\
5,550\end{array}$ \\
\hline $\begin{array}{l}\text { Sales }(\$ 1,000) \\
\quad \geq 12 \text { inches } \\
6-12 \text { inches } \\
1-6 \text { inches } \\
\text { Total sales }\end{array}$ & $\begin{array}{r}52,898 \\
5,732 \\
1,240 \\
59,870\end{array}$ & $\begin{array}{r}57,082 \\
5,838 \\
966 \\
63,886\end{array}$ \\
\hline $\begin{array}{l}\text { Eggs sold } \\
\text { Number of eggs }(1,000) \\
\text { Total value of sales }(\$ 1,000)\end{array}$ & $\begin{array}{r}263,545 \\
4,176\end{array}$ & $\begin{array}{r}289,620 \\
4,830\end{array}$ \\
\hline $\begin{array}{l}\text { Total value of fish sold plus } \\
\text { value of eggs sold }(\$ 1,000)\end{array}$ & 64,046 & 68,716 \\
\hline Number of operations selling trout & 331 & 365 \\
\hline $\begin{array}{l}\text { Number of operations selling } \\
\text { or distributing trout, or both }\end{array}$ & 545 & 601 \\
\hline
\end{tabular}

Source: USDA-NASS.
TABLE A1.12

Honey production ${ }^{1}$ in the United States, 2003 and 2004

\begin{tabular}{l|r|r} 
& $\mathbf{2 0 0 3}$ & $\mathbf{2 0 0 4}$ \\
\hline Honey-producing colonies $(\mathbf{1 , 0 0 0})$ & 2,599 & 2,556 \\
\hline Yield per colony $(\mathrm{lb})$ & 70 & 71.8 \\
\hline Production $(1,000 \mathrm{lb})$ & 181,727 & 183,582 \\
\hline Stocks on December $15(1,000 \mathrm{lb})$ & 40,785 & 61,222 \\
\hline Value of production $(\$ 1,000)$ & 253,106 & 201,790 \\
\hline
\end{tabular}

Source: USDA-NASS.

${ }^{1}$ For producers with five or more colonies.

TABLE A1.13

\section{Production data on miscellaneous livestock, 2002}

\begin{tabular}{l|r|r|r|}
\hline Milk goats & $\begin{array}{c}\text { Number of } \\
\text { farms }\end{array}$ & $\begin{array}{r}\text { Inventory } \\
\text { Number sold }\end{array}$ \\
\hline Angora goats & 22,389 & 290,789 & 113,654 \\
Meat and other & 5,075 & 300,753 & 91,037 \\
\hline \multicolumn{1}{|l}{ goats } & 74,980 & $1,938,924$ & $1,709,619$ \\
\hline Mules, burros, & & & \\
\hline donkeys & 29,936 & 105,358 & 17,385 \\
\hline Mink & 310 & $1,113,941$ & $2,506,819$ \\
\hline Rabbits & 10,073 & 405,241 & 886,841 \\
\hline Ducks & 26,140 & $3,823,629$ & $24,143,066$ \\
\hline Geese & 17,110 & 173,000 & 200,564 \\
\hline Pigeons & 4,405 & 449,255 & $1,160,364$ \\
\hline Pheasants & 4,977 & $2,267,136$ & $7,206,460$ \\
\hline Quail & 3,742 & $4,888,196$ & $19,157,803$ \\
\hline Emus & 5,224 & 48,221 & 15,682 \\
\hline Ostriches & 1,643 & 20,560 & 16,038 \\
\hline Bison & 4,132 & 231,950 & 57,210 \\
\hline Deer & 4,901 & 286,863 & 43,526 \\
\hline Elk & 2,371 & 97,901 & 16,058 \\
\hline Llamas & 16,887 & 144,782 & 18,653 \\
\hline Source: & & & \\
\hline
\end{tabular}

Source: USDA-NASS 2002 Census of Agriculture.

TABLE A1.14

\section{Slaughter statistics, CY 2004}

\begin{tabular}{|c|c|c|c|}
\hline Commodity & $\begin{array}{c}\text { Federally inspected } \\
\text { plants (no.) }\end{array}$ & $\begin{array}{l}\text { Slaughter in federally } \\
\text { inspected plants } \\
(1,000 \text { head })^{1}\end{array}$ & $\begin{array}{l}\text { Slaughter in State or } \\
\text { custom plants } \\
(1,000 \text { head })\end{array}$ \\
\hline Calves & 234 & 819.3 & 19.5 \\
\hline Hogs & 664 & $101,706.3$ & $1,102.6$ \\
\hline Sheep and lambs & 500 & $2,666.6$ & 163.1 \\
\hline
\end{tabular}

Source: USDA-NASS Livestock Slaughter 2004 Summary, March 2004.

IIncludes data from week ending January 10, 2004, through January 1, 2005. 


\section{APPENDIX 2 \\ Tables on FAD Investigations}

TABLE A2.1

\section{FAD Investigations by State, 2004}

\begin{tabular}{|c|c|c|c|c|c|}
\hline AK & Alaska & 1 & NC & North Carolina & 13 \\
\hline$A L$ & Alabama & 2 & ND & North Dakota & 0 \\
\hline AR & Arkansas & 9 & NE & Nebraska & 13 \\
\hline AZ & Arizona & 28 & $\mathrm{NH}$ & New Hampshire & 4 \\
\hline CA & California & 62 & NJ & New Jersey & 7 \\
\hline $\mathrm{CO}$ & Colorado & 300 & NM & New Mexico & 102 \\
\hline $\mathrm{CT}$ & Connecticut & 7 & NV & Nevada & 10 \\
\hline DE & Delaware & 1 & NY & New York & 4 \\
\hline $\mathrm{FL}$ & Florida & 9 & $\mathrm{OH}$ & Ohio & 7 \\
\hline GA & Georgia & 26 & OK & Oklahoma & 10 \\
\hline $\mathrm{HI}$ & Hawaii & 3 & OR & Oregon & 8 \\
\hline IA & lowa & 11 & PA & Pennsylvania & 9 \\
\hline ID & Idaho & 22 & PR & Puerto Rico & 5 \\
\hline IL & Illinois & 11 & $\mathrm{RI}$ & Rhode Island & 0 \\
\hline IN & Indiana & 9 & SC & South Carolina & 2 \\
\hline KS & Kansas & 9 & SD & South Dakota & 2 \\
\hline KY & Kentucky & 10 & TN & Tennessee & 23 \\
\hline LA & Louisiana & 11 & TX & Texas & 142 \\
\hline MA & Massachusetts & 7 & UT & Utah & 4 \\
\hline MD & Maryland & 1 & VA & Virginia & 12 \\
\hline ME & Maine & 0 & VT & Vermont & 7 \\
\hline Ml & Michigan & 6 & WA & Washington & 14 \\
\hline MN & Minnesota & 9 & WI & Wisconsin & 34 \\
\hline MO & Missouri & 6 & WV & West Virginia & 6 \\
\hline MS & Mississippi & 3 & WY & Wyoming & 6 \\
\hline MT & Montana & 6 & Total & & 1,013 \\
\hline
\end{tabular}


Complaints, by species disclosed in FAD investigations, 2004

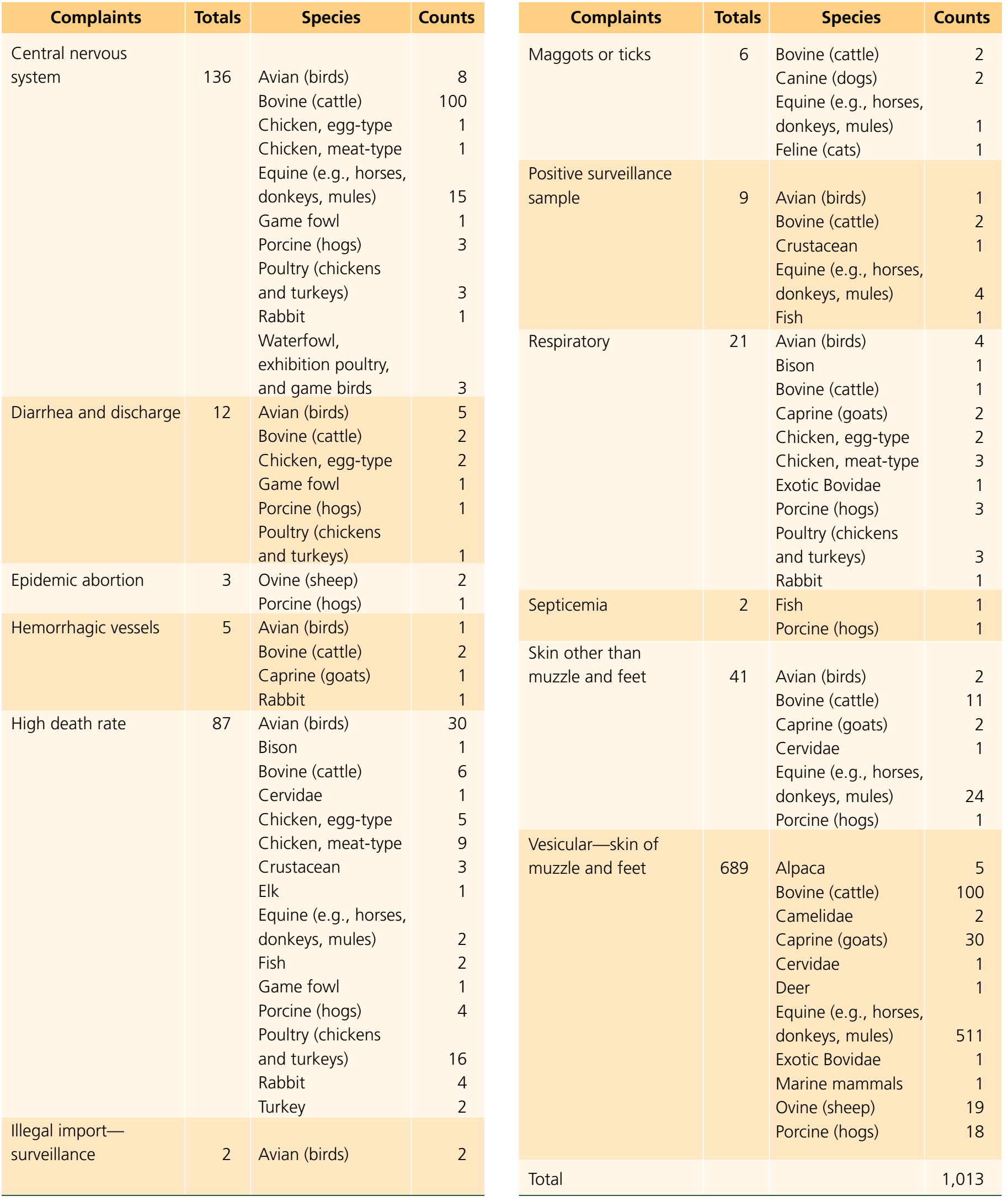




\section{A P PENDIX 3 \\ Animal Health Contacts in the United States}

\section{USDA National Animal Health Policy and Programs}

Dr. Jere Dick, Associate Deputy Administrator 4700 River Rd., Unit 33

Riverdale, MD 20737-1231

Phone: (301) 734-5034

Fax: (301) 734-8818

\section{OIE Delegate}

Dr. Peter Fernandez

Minister, Regional Director

Europe, Middle East, Africa

United States Mission to the European Union

Boulevard du Regent, 27

1000 Brussels, Belgium

Phone: (32-2)508-2762

Fax: (32-2)511-0918

\section{International Standards Team}

Dr. Michael David, Director

4700 River Rd., Unit 33

Riverdale, MD 20737-1231

Phone: (301) 734-5324

Fax: (301) 734-8818

National Veterinary Services Laboratory

Dr. Randall Levings, Director

1800 Dayton Rd.

P.O. Box 844

Ames, IA 50010

Phone: (515) 663-7301

Fax: (515) 663-7397

Center for Veterinary Biologics

Dr. Richard Hill, Director

510 South $17^{\text {th }}$ St., Suite 104

Ames, IA 50010

Phone: (515) 232-5785

Fax: (515) 232-7120
Centers for Epidemiology and Animal Health

Dr. Thomas Walton, Director

2150 Centre Ave., Bldg. B, MS 2W3

Fort Collins, CO 80526-8117

Phone: (970) 494-7200

Fax: (970) 472-2668

\section{United States Animal Health Association}

Dr. Rick Willer

Arizona Dept. of Agriculture

1688 W. Adams

Phoenix, AZ 85007

Phone: (602) 542-4293

Fax: (602) 542-4290

\section{USDA-APHIS Eastern Region}

Dr. Jack Shere, Regional Director

Venture II Building, Centennial Campus

North Carolina State University

920 Main Campus Dr., Suite 200

Raleigh, NC 27606

Phone: (919) 855-7250

Fax: (919) 855-7295

\section{USDA-APHIS Western Region}

Dr. Jose Diez, Regional Director 2150 Centre Ave., Bldg. B, MS 3E13

Fort Collins, CO 80526-8117

Phone: (970) 494-7400

Fax: (970) 494-7355 


\section{USDA Area Veterinarians-in-Charge}

\section{Alabama}

Dr. O. W. Hester

Phone: (334) 223-7141

Alaska

Dr. Gary L. Bricker

Phone: (360) 753-9430

Arizona

Dr. Hortentia Harris

Phone: (480) 491-1002

Arkansas

Dr. Ronnie Blair

Phone: (501) 224-9515

California

Dr. Paul Ugstad

Phone: (916) 857-6170

Colorado

Dr. Roger Perkins

Phone: (303) 231-5385

Connecticut

Dr. William G. Smith

Phone: (508) 865-1421

Delaware and

District of Columbia

Dr. Steven N. Finch

Phone: (410) 349-9708

Florida

Dr. Robert E. Southall

Phone: (352) 333-3120

Georgia

Dr. Edgardo Arza

Phone: (770) 922-7860

Hawaii

Dr. Gary L. Bricker

Phone: (360) 753-9430

Idaho

Dr. Cynthia Gaborick

Phone: (208) 378-5631

Illinois

Dr. Lennis Knight

Phone: (217) 241-6689

Indiana

Dr. Francisco Collazo-Mattei

Phone: (317) 290-3300
Iowa

Dr. Kevin L. Petersburg

Phone: (515) 284-4140

Kansas

Dr. Kevin P. Varner

Phone: (785) 235-2365

Kentucky

Dr. Barbara A. Bischoff

Phone: (502) 227-9651

Louisiana

Dr. Joel Goldman

Phone: (225) 389-0436

Maine

Dr. William G. Smith

Phone: (508) 865-1421

Maryland

Dr. Steven N. Finch

Phone: (410) 349-9708

Massachusetts

Dr. William G. Smith

Phone: (508) 865-1421

Michigan

Dr. Reed Macarty

Phone: (517) 324-5290

Minnesota

Dr. Michael L. Stine

Phone: (651) 290-3691

\section{Mississippi}

Dr. Charles P. Nettles

Phone: (601) 965-4307

Missouri

Dr. Dave Hopson

Phone: (573) 636-3116

Montana

Dr. Paul Sciglibaglio

Phone: (406) 449-2220

Nebraska

Dr. Kathleen Akin

Phone: (402) 434-2300

Nevada

Dr. Paul Ugstad

Phone: (916) 857-6170
New Hampshire

Dr. William G. Smith

Phone: (508) 865-1421

New Jersey

Dr. Jonathan T. Zack

Phone: (609) 259-8387

New Mexico

Dr. Michael T. Greenlee

Phone: (505) 761-3160

New York

Dr. Roxanne Mullaney

Phone: (518) 869-9007

North Carolina

Dr. Eric Coleman

Phone: (919) 855-7700

North Dakota

Dr. Larry Schuler

Phone: (701) 250-4210

Obio

Dr. Susan Skorupski

Phone: (614) 469-5602

\section{Oklaboma}

Dr. Burke Healey

Phone: (405) 427-9413

Oregon

Dr. Don Herriott

Phone: (503) 399-5871

\section{Pennsylvania}

Vacant

Phone: (717) 782-3442

\section{Puerto Rico}

Dr. Miguel A. Borri-Diaz Phone: (787) 766-6050

\section{Rbode Island}

Dr. William G. Smith

Phone: (508) 865-1421

\section{South Carolina}

Dr. Delorias Lenard

Phone: (803) 788-1919

South Dakota

Dr. Lynn A. Tesar

Phone: (605) 224-6186

\section{Tennessee}

Dr. Allen M. Knowles

Phone: (615) 781-5310

Texas

Dr. Jerry Diemer

Phone: (512) 916-5551

Utah

Dr. Robert DeCarolis

Phone: (801) 524-5010

Vermont

Dr. William G. Smith

Phone: (508) 865-1421

Virginia

Dr. Terry L. Taylor

Phone: (804) 771-2774

Washington

Dr. Gary L. Brickler

Phone: (360) 753-9430

West Virginia

Dr. Susan Skorupski

Phone: (614) 469-5602

\section{Wisconsin}

Dr. Linn Wilbur

Phone: (608) 270-4000

\section{Wyoming}

Dr. Bret A. Combs

Phone: (307) 432-7960 


\section{A P PENDIX 4 Key U.S. Animal Health Web Sites}

Agricultural Marketing Service

http://www.ams.usda.gov

Agricultural Research Service

http://www.ars.usda.gov

American Association of Bovine Practitioners http://www.aabp.org

American Association of Equine Practitioners http://www.aaep.org

American Association of Swine Veterinarians http://www.aasp.org

American Sheep Industry Association

http://www.sheepusa.org

American Veterinary Medical Association

http://www.avma.org

Animal and Plant Health Inspection Service http://www.aphis.usda.gov

Centers for Disease Control and Prevention http://www.cdc.gov

Centers for Epidemiology and Animal Health http://www.aphis.usda.gov/vs/ceah

Center for Veterinary Biologics

http://www.aphis.usda.gov/vs/cvb

Code of Federal Regulations

http://www.gpoaccess.gov/nara

Commodity Credit Corporation

http://www.fsa.usda.gov/ccc

Economic Research Service

http://www.ers.usda.gov

Environmental Protection Agency

http://www.epa.gov

Exotic Wildlife Association

http://www.exoticwildlifeassociation.com
Federal Emergency Management Agency

http://www.fema.gov

Federal Register

http://www.archives.gov/federal_register

Food Animal Residue Avoidance Databank http://www.farad.org

Food Safety and Inspection Service

http://www.fsis.usda.gov

Foreign Agricultural Service

http://www.fas.usda.gov

Grain Inspection, Packers, and Stockyards

Administration

http://www.usda.gov/gipsa

Holstein Association USA, Inc.

http://www.holsteinusa.com

International Organization for Standardization

http://www.iso.ch/iso/en/ISOOnline.openerpage

National Agricultural Statistics Service

http://www.usda.gov/nass

National Animal Health Emergency Management System

http://www.usaha.org/NAHEMS

National Cattlemen's Beef Association

http://www.beef.org

National Center for Animal Health Surveillance

http://www.aphis.usda.gov/vs/ceah/ncahs

National Center for Import and Export

http://www.aphis.usda.gov/vs/ncie

National Marine Fisheries Service

http://www.nmfs.noaa.gov

National Pork Producers Council

http://www.nppc.org 
National Poultry Improvement Plan http://www.aphis.usda.gov/vs/npip

National Veterinary Services Laboratories http://www.aphis.usda.gov/vs/nvsl

North American Deer Farmers Association http://www.nadefa.org

North American Elk Breeders Association http://www.naelk.org

Office International des Epizooties http://www.oie.int

Plant Protection and Quarantine http://www.aphis.usda.gov/ppq

United States Animal Health Association http://www.usaha.org

U.S. Department of Agriculture http://www.usda.gov
U.S. Department of Defense http://www.defenselink.mil

U.S. Department of Health and Human Services http://www.hhs.gov

U.S. Department of Homeland Security http://www.dhs.gov/dhspublic

U.S. Fish and Wildlife Service http://www.fws.gov

U.S. Food and Drug Administration http://www.fda.gov

Veterinary Services http://www.aphis.usda.gov/vs

World Trade Organization http://www.wto.org 


\section{A P PENDIX 5 \\ Acronyms and Abbreviations}

\begin{tabular}{|c|c|c|c|}
\hline AAVLD & $\begin{array}{l}\text { American Association of Veterinary } \\
\text { Laboratory Diagnosticians }\end{array}$ & $\begin{array}{l}\text { EP } \\
\text { ESF }\end{array}$ & $\begin{array}{l}\text { Emergency Programs } \\
\text { Emergency support functions }\end{array}$ \\
\hline AHP & Animal Health Program & FAD & Foreign animal disease \\
\hline AI & Avian influenza & FADDL & Foreign Animal Disease Diagnostic \\
\hline AIN & Animal Identification Number & & Laboratory \\
\hline AMS & Agricultural Marketing Service & FAS & Foreign Agricultural Service \\
\hline APHIS & Animal and Plant Health Inspection & FDA & Food and Drug Administration \\
\hline & Service & FMD & Foot-and-mouth disease \\
\hline ARS & Agricultural Research Service & FR & Federal Register \\
\hline ASEPHP & $\begin{array}{l}\text { Aquaculture, Swine, Equine, and } \\
\text { Poultry Health Programs }\end{array}$ & FSIS & Food Safety and Inspection Service \\
\hline AVIC & Area Veterinarian-in-Charge & HPAI & High-pathogenicity avian influenza \\
\hline AVMA & $\begin{array}{l}\text { American Veterinary Medical } \\
\text { Association }\end{array}$ & HSPD & $\begin{array}{l}\text { Homeland Security Presidential } \\
\text { Directive }\end{array}$ \\
\hline BRT & Brucellosis ring test & ICS & Incident Command System \\
\hline BSE & Bovine spongiform encephalopathy & IPPC & $\begin{array}{l}\text { International Plant Protection } \\
\text { Convention }\end{array}$ \\
\hline BTS & Border and Transport Security & IREGS & International Regulation Retrieval \\
\hline CADIA & Center for Animal Disease Information & & System \\
\hline & & IS & International Services \\
\hline CEAH & $\begin{array}{l}\text { Centers for Epidemiology and Animal } \\
\text { Health }\end{array}$ & ISA & Infectious salmon anemia \\
\hline CEI & Center for Emerging Issues & LPAI & Low-pathogenicity avian influenza \\
\hline CFIA & Canadian Food Inspection Agency & MAP & Mycobacterium avium paratuberculosis \\
\hline CFR & U.S. Code of Federal Regulations & MCI & Market Cattle Identification \\
\hline CNS & Central nervous system & NAHEMS & $\begin{array}{l}\text { National Animal Health Emergency } \\
\text { Management System }\end{array}$ \\
\hline $\mathrm{CSF}$ & Classical swine fever & NAHLN & National Animal Health Laboratory \\
\hline CSREES & Cooperative State Research, Education, & & Network \\
\hline CVB & $\begin{array}{l}\text { and Extension Service } \\
\text { Center for Veterinary Biologics }\end{array}$ & NAHMS & $\begin{array}{l}\text { National Animal Health Monitoring } \\
\text { System }\end{array}$ \\
\hline CWD & Chronic wasting disease & NAHRS & National Animal Health Reporting \\
\hline DHS & U.S. Department of Homeland & & System \\
\hline & Security & NAHSS & $\begin{array}{l}\text { National Animal Health Surveillance } \\
\text { Sustem }\end{array}$ \\
\hline ELISA & Enzyme-linked immunosorbent assay & & \\
\hline END & Exotic Newcastle disease & NAIS & National Animal Identificatic \\
\hline
\end{tabular}




\begin{tabular}{|c|c|c|c|}
\hline NASS & National Agricultural Statistics Service & SIP & Surveillance and Identification \\
\hline NCAHP & $\begin{array}{l}\text { National Center for Animal Health } \\
\text { Programs }\end{array}$ & SPRS & $\begin{array}{l}\text { Programs } \\
\text { Standardized Premises Registration }\end{array}$ \\
\hline NCAHS & $\begin{array}{l}\text { National Center for Animal Health } \\
\text { Surveillance }\end{array}$ & SPS & $\begin{array}{l}\text { System } \\
\text { Sanitary and Phytosanitary }\end{array}$ \\
\hline NCIE & National Center for Import and Export & SVC & Spring viremia of carp \\
\hline NIMS & National Incident Management System & TAHC & Texas Animal Health Commission \\
\hline NMFS & National Marine Fisheries Service & $\mathrm{TB}$ & Tuberculosis \\
\hline NPIP & National Poultry Improvement Plan & TBT & Tropical bont tick \\
\hline NRP & National Response Plan & TSE & Transmissible spongiform \\
\hline NSU & National Surveillance Unit & & \\
\hline NVS & National Veterinary Stockpile & UM\&R & Uniform methods and rules \\
\hline NVSL & $\begin{array}{l}\text { National Veterinary Services } \\
\text { Laboratories }\end{array}$ & USAHA & $\begin{array}{l}\text { United States Animal Health } \\
\text { Association }\end{array}$ \\
\hline OIE & World Organisation for Animal Health & USDA & U.S. Department of Agriculture \\
\hline PIN & Premises Identification Number & USTCP & U.S. Trichinae Certification Program \\
\hline PPQ & Plant Protection and Quarantine & USTR & U.S. Trade Representative \\
\hline PRV & Pseudorabies virus & VBJDCP & $\begin{array}{l}\text { Voluntary Bovine Johne's Disease } \\
\text { Control Program }\end{array}$ \\
\hline RHP & Ruminant Health Programs & VS & Veterinary Services \\
\hline RSSS & $\begin{array}{l}\text { Regulatory Scrapie Slaughter } \\
\text { Surveillance }\end{array}$ & WS & Wildlife Services \\
\hline SFCP & Scrapie Flock Certification Program & WTO & World Trade Organization \\
\hline
\end{tabular}

